\title{
I. John Maynard Keynes’ „The Economic Consequences of the Peace“ und das lange Ende der Pax Britannica Oeconomica
}

\section{Keynes' Kritik an der Versailler Friedensordnung}

Zwei Jahre nach dem Tod von John Maynard Keynes und das ganze Ausmaß der Zerstörung Europas vor Augen, notierte der südafrikanische Premierminister Jan Christian Smuts im Rückblick auf seine Zeit als Delegierter bei der Versailler Friedenskonferenz: „The paramount task [...] was to bring Germany back into the fold. It was impossible to cut her out. One should think of it in physical terms. Here was a great mass of people in the centre of Europe, with outstanding qualities of industry, scientific ability and discipline. One could not just ignore them or ostracise them. Some means must be found for assimilating them. In 1919 the central problem was the reintegration of Germany and [...] that is the problem to-day. People should go back to Keynes. "1 Smuts fühlte sich in dieser schwierigen Nachkriegsphase geradezu gedrängt, hinsichtlich der Deutschlandpolitik an die drei Jahrzehnte zurïckliegenden Ereignisse zu erinnern. Er verwies auf die Kontinuität und den ökonomischen Grundcharakter des Deutschlandproblems. Ein erfolgreicher Wiederaufbau Europas ließ sich seiner Meinung nach auf die Frage nach der Integration des Potentials der wirtschaftlich bedeutendsten Macht Kontinentaleuropas reduzieren. Das Besondere an Smuts' Aussage war freilich der Hinweis auf Keynes. Welches Interesse hatte ausgerechnet der bedeutendste Nationalökonom seiner Zeit an der deutschen Frage? In welcher Verbindung stand er zur Deutschlandpolitik seiner Zeit? Was verbirgt sich hinter dem Rat, man solle sich zur Schaffung von Sicherheit und Stabilität in Europa auf Keynes besinnen?

Bereits zu einem sehr frühen Zeitpunkt während des Zweiten Weltkrieges kam es innerhalb der britischen Regierung zu Diskussionen hinsichtlich der wirtschaftlichen Behandlung Deutschlands nach der Zerschlagung der Achsenmächte und der damit verbundenen sicherheitspolitischen Implikationen. Keynes wurde zu einer wichtigen treibenden Kraft dieses Teils der Deutschlandplanungen. Sein Einfluß ergibt sich schon aus der Tatsache, daß er als einer der Teilnehmer und eindringlichen Kritiker der Versailler Friedensvertragsverhandlungen seine Erfahrungen und die in einer Reihe von Publikationen vorgelegten theoretischen Überlegungen zum Reparations- und Transferproblem einbringen konnte. Darüber hinaus versuchte er als Mitglied des 1930 gegründeten Economic Advisory Council auf der Grundlage seiner mit der im gleichen Jahr veröffentlichten Schrift "A Treatise on Money“ begonnenen und 1936 in der "General Theory of Employment, Interest and Money "ausgeformten Theorie Einfluß zu nehmen auf den wirtschaftspolitischen Entscheidungsprozeß der Regierung. Außerdem hatte er als späterer Leiter der britischen Delegation in den Verhandlungen mit den USA über eine Neuordnung des Weltwirtschaftssystems ein besonderes Interesse an allen die Entwicklung und den Wiederaufbau der kriegsgeschädigten Nationalökonomien mitbestimmen-

1 Jan Christian Smuts, 8.6.1948, zit. nach: Harrod, Keynes, S. 266. 
den Faktoren. Hier war neben der künftigen Gestaltung der anglo-amerikanischen Wirtschaftsbeziehungen die Frage nach der künftigen wirtschaftlichen Rolle Deutschlands von besonderer Wichtigkeit. Dies war der Kern seiner Erfahrungen von 1919.

Um Keynes' Bedeutung für die Nachkriegsplanungen der britischen Regierung und besonders die Zielrichtung seines Beitrags zu den deutschlandpolitischen Diskussionen genauer ermitteln zu können, ist es notwendig, zunächst auf die Hintergründe seiner Doppelrolle als herausragender Wissenschaftler und einflußreicher „Politiker“ einzugehen ${ }^{2}$. Dies erscheint um so notwendiger, als sein wirtschaftstheoretischer Ansatz über den Zusammenhang von Währungspolitik, Vollbeschäftigung und Außenhandel im Laufe des Zweiten Weltkrieges innerhalb der Beamtenschaft in Whitehall für heftige Diskussionen sorgte und die Beamten des Schatzamts in ihrer Traditionsverbundenheit herausforderte; darüber hinaus entwickelten sich seine Theorien zu einem wichtigen Instrument für die Formulierung der Wirtschaftspolitik der Labour-Regierung der Nachkriegszeit. Es muß gleichfalls betont werden, daß die Grundlagen dieser „Keynesschen Revolution" zwar in den zwanziger und dreißiger Jahren gelegt worden waren, jedoch erst in der praktischen Auseinandersetzung mit Fragen der Nachkriegsordnung jenen "Schliff“ erhielten, der ihnen politische Durchsetzungskraft verlieh"

Als Nationalökonom in Cambridge lehrend und als politisch Liberaler der Bloomsbury Group um Virginia und Leonard Woolf angehörend ${ }^{4}$, stand Keynes der britischen Friedensbewegung nahe ${ }^{5}$. In diesem Kontext muß auch seine Arbeit als Berater im Schatzamt in beiden Weltkriegen gesehen werden, das er als zentrale Stelle zur Einflußnahme ansah' ${ }^{6}$. Eine prägende Kraft ging von seiner Tätigkeit als Delegierter bei den Friedensvertragsverhandlungen in Versailles aus; die Erfahrungen in Paris bildeten die Basis für seine Arbeit als Berater in Whitehall und prädestinierten ihn zu einem der besten Kenner der ökonomischen Dimension des Deutschlandproblems. Keynes beurteilte den Versailler Vertrag vor allem aus einer ökonomischen Perspektive, und seine Vorstellung von einer gerechten und funktionsfähigen Friedensordnung wurzelte in der Art und Weise der wirtschaftlichen Beziehungen der Staaten untereinander. Machtpolitische Erwägungen blieben demgegenüber weitgehend untergeordnet. Kriege schädigten seiner Meinung nach nur den wirtschaftlichen Prosperitätsprozeß, und selbst ein

\footnotetext{
2 Vgl. Johnson; Moggridge, Keynes, S. 113-146; Biven, S. 12-18. Obwohl Keynes seine Verbindung zur Universität Cambridge nie völlig aufgab, nahm er nach seinem Ausscheiden aus den Diensten des Schatzamts 1919 und in der Folge der Niederschrift der „Economic Consequences of the Peace" seine Lehrtätigkeit am King's College nicht wieder auf und wandte sich verstärkt journalistischen Aufgaben sowie Arbeiten für die Londoner City zu - ein Schritt, der ihn näher an die monetären und politischen Schalthebel der britischen Wirtschaft bringen sollte.

${ }^{3}$ Auf die Debatte um die "Keynessche Revolution“ in der britischen Wirtschaftspolitik kann in diesem Zusammenhang nicht eingegangen werden. Vgl. zusammenfassend Peden, Keynes, the Treasury and British Economic Policy, sowie die in Anm. 62 der Einleitung angegebene Literatur.

4 King's College, Cambridge, Keynes Papers (im folgenden KCKP), PS/7/22, Keynes an Viscount Samuel; PS/7/24, Keynes an Sir Percy Harris, 24.6.1942; „Am I a Liberal“ [1925], in: JMK IX, S. 295-306; "Liberalism and Labour", in: ebenda, S. 307-311; Levy; Crabtree/Thirlwall (Hrsg.); Edel; Harrod, Keynes, S. 172-194, 331-334, 362-364; Bivan, S. 8-12; Clarke, Keynesian Revolution, S. 10-12; Moggridge, Maynard Keynes, S. 213-232; kritisch zu Harrod Skidelsky, Keynes, Bd. I, S. 242-251.

5 JMK XVI, S. 157-162, 178-184; Moggridge, Maynard Keynes, S. 254-261.

6 Skidelsky, Keynes, Bd. I, S. 401; Peden, Keynes, the Treasury and British Economic Policy, S. 13. Vgl. allgemein auch Chester.
} 
nichtkriegerisches außenpolitisches Konfliktverhalten erschien ihm nur als Ablenkung von den allgemeinen Anstrengungen zur Wiederherstellung von dauerhaften, soliden und sozial gerechten Wirtschaftsverhältnissen. Unter Ausblendung politischer und militärischer Gesichtspunkte, deren Tragweite er andererseits aber auch nicht in Frage stellte, erkannte er in der Versailler Reparationsregelung ökonomische Fesseln, die einen Wiederaufbau Deutschlands schwer behindern mußten; infolgedessen lag in ihr ein Sprengsatz für weitere soziale Unruhen und damit womöglich erneuter, potentiell globaler Konflikte verborgen. Zugleich sah er darin eine Gefahr für die internationalen Wirtschaftsbeziehungen. Ein Land mit stabilen sozio-ökonomischen Verhältnissen war für Keynes gleichbedeutend mit einem friedlichen Land, ein funktionierendes Netz auBenwirtschaftlicher Beziehungen Garant einer internationalen Friedensordnung. Eine durch den Krieg verursachte, anhaltende ökonomische Destabilisierung und Verarmung würde in seinen Augen dagegen unweigerlich zu Chaos, Revolution und vor allem zur Zerstörung sozialer und moralischer Strukturen führen ${ }^{7}$. Keynes' Werk ist profunder Ausdruck der Krise von Liberalismus und Rationalismus seit dem ausgehenden 19. Jahrhundert. Seine Weltsicht, so charakterisierte es eine seiner Schülerinnen, war eher ästhetisch denn politisch: „He hated unemployment because it was stupid and poverty because it was ugly. He was disgusted by the commercialisation of modern life. [...] He indulged in an agreeable vision of a world where economics has ceased to be important and our grandchildren can begin to lead a civilised life. But in that vision there is room for a rich man to enjoy his wealth in a civilised manner." 8

Der Erste Weltkrieg brachte ungeachtet des Wahlsieges von Lloyd George im Dezember 1918 den Niedergang des politischen Liberalismus in Großbritannien und hatte auch die wirtschaftliche Basis des viktorianischen Optimismus gebrochen. Zugleich wirkten diese Tendenzen und insbesondere die Ereignisse im Verlaufe der Konferenz von Versailles als Katalysator für Keynes' Denken und drängten ihn in eine neue Richtung, die, auf der Erkenntnis der Fragilität der Wirtschaftsbeziehungen vor 1914 aufbauend, die Hoffnung weckte, den Traum einer Anpassung der Grundlagen des englischen Liberalismus des 19. Jahrhunderts an die veränderten Bedingungen des neuen Zeitalters vielleicht doch noch zu retten. Der "Alte Liberalismus“ Gladstonescher Provenienz war durch einen „Neuen Liberalismus“ mit sozialdemokratischer Prägung zu ersetzen. Allein, wie eng die Allianz zwischen Liberalismus und Sozialismus wirtschafts- und sozialpolitisch zu knüpfen war, blieb eine auch für Keynes offene Frage ${ }^{9}$. „Fear for the future of the established order had been growing during the war; Paris confirmed it. The task of building the future would start, not end, with the Allied victory. For all its faults the bourgeois civilization of the late nineteenth century had seemed the stepping stone to a

\footnotetext{
7 Vgl. Skidelsky, Keynes, Bd I, S. 400-402; Moggridge, Keynes, S. 11-24. Keynes stand damit in der Tradition der klassisch-liberalen Interpretation des Krieges und des daraus abgeleiteten Friedensmodells, die sich im 18. Jahrhundert durchzusetzen begann und jede kriegerische Auseinandersetzung von Staaten untereinander als wirtschaftlich schädigend und den ökonomischen Entwicklungsprozeß hemmend begriff. Vgl. Milward, S. 9-15; Niedhart, Internationale Beziehungen, S. $13 \mathrm{f}$.

8 Robinson, What Has Become of the Keynesian Revolution?, S. 128; vgl. John Maynard Keynes, „My Early Beliefs“, in: JMK IX, S. 436f.; Skidelsky, Keynes, Bd. II, S. XVIII-XXV.

` Vgl. Clarke, Keynesian Revolution, S. 13.
} 
higher life. That promise had to be recreated out of the debris of the war." 10 Der Krieg hatte daher mit seiner Zerstörung der alten Ordnung nach Keynes' Meinung den Grad der Verflechtung der internationalen Wirtschaftsbeziehungen deutlich gemacht. Und das Versailler Vertragswerk trug seiner Meinung nach den Keim erneuter wirtschaftlicher Destabilisierung und sozialer Krisen bereits in sich.

Der Kern der in seinem 1919 publizierten Buch "The Economic Consequences of the Peace“ zusammengefaßten Kritik bestand denn auch in dem Vorwurf an die "Großen Drei“" sie hätten politischen Erwägungen den Vorzug gegeben vor wirtschaftlicher Vernunft. Die Staatsmänner hätten nicht zur Kenntnis genommen, daß das Hauptproblem nicht politischer oder territorialer, sondern finanzieller und wirtschaftlicher Natur sei ${ }^{11}$. Demgegenüber wolle er zeigen, "that the Carthaginian peace is not practically right or possible". Die Befürworter eines harten Friedens seien sich nicht nur der ökonomischen Voraussetzungen des Friedensvertrages nicht bewußt, sie übersähen auch die veränderten wirtschaftlichen Grundbedingungen, die die Zukunft Europas fortan bestimmen würden. „The clock cannot be set back. You cannot restore Central Europe to 1870 without setting up such strains in the European structure letting loose such human and spiritual forces as, pushing beyond frontiers and races, will overwhelm not only you and your ,guarantees' but your instructions, and the existing order of society. "12 Keynes begründete seine Skepsis hinsichtlich der Tragfähigkeit der alten wirtschaftlichen Ordnung mit dem Hinweis auf den bereits vor dem Weltkrieg prekären, durch ihn schließlich aber vollends zerstörten Zustand dieses "wirtschaftlichen Utopia"13. Das Ziel allen Wirtschaftens, die Balance zwischen wachsender Bevölkerung und den Mitteln zu ihrer Versorgung, schien zerbrochen, der „Malthusische Teufel“ entfesselt.

Das Gleichgewicht ging nach Keynes auf vier Entwicklungen zurück. Erstens wurde der enorme Bevölkerungszuwachs nach 1870 besonders im Kaiserreich, aber auch in Österreich-Ungarn und Rußland ermöglicht durch die im Zuge der industriellen Revolution sich vollziehende Umwandlung von einem weitgehend autarken Agrarstaat zu einer riesigen, international arbeitsteiligen Industrienation. Umgekehrt war der Zustrom an Arbeitskräften eine wesentliche Voraussetzung dafür, daß die industriellen Zentren mit voller Kraft arbeiten und eine Ausweitung der Exportproduktion garantieren konnten, die wiederum für die Einfuhr notwendiger Rohstoffe und Nahrungsmittel unverzichtbar war, um die Bedürfnisse einer wachsenden Bevölkerung zu befriedigen. Zweitens konnten in Zentraleuropa Behinderungen durch Grenzen und Zölle auf ein Minimum reduziert werden, während gleichzeitig die Anbindung der verschiedenen Währungen an den Goldstandard den Fluß von Kapital und Handel erleichterte. Die dadurch entstandene „nahezu absolute Sicherheit von Besitz und Person“ mündete schließlich in die Entstehung eines europäischen Wirtschaftssystems mit dem Deutschen Reich als Zentrum, das mit seinem industriellen Wachstum auch den Wohlstand seiner Nachbarstaaten förderte. In einigen Fällen, vor allem in den südosteuropäischen Staaten, führte die Ausdifferenzierung der wirtschaftlichen Interdependenz durch die deutschen Vorkriegsinvestitionen darüber hinaus zu einer "friedlichen Penetration", die die Entwick-

\footnotetext{
${ }^{10}$ Skidelsky, Keynes, Bd. I, S. 401.

${ }_{11}$ JMK II, S. 92, 143; zum Hintergrund insgesamt Carr.

12 JMK II, S. 23.

${ }^{13}$ Ebenda, S. 5. Zum Folgenden ebenda, S. 5-16; vgl. Moggridge, Keynes, S. 59.
} 
lung dieser Länder auch organisatorisch entscheidend vorantrieb. Drittens waren ihrerseits die Umwandlung der wirtschaftlichen Struktur Kontinentaleuropas und die Herausbildung ökonomischer Interdependenzen, welche die Schwelle zu Abhängigkeitsbeziehungen noch nicht überschritten, durch die allgemein akzeptierte Vorstellung der Klassischen Ökonomie von der Selbstregulierungskraft des Marktes abgesichert; man ging unausgesprochen davon aus, daß die Folgen der Kapitalakkumulation, d. h. die Ungleichheit bei der Verteilung von Wohlstand, aufgewogen werden durch ein „kapitalistisches Ethos", die Gewinne mit dem Ziel des Ausbaus der Gesamtwirtschaft zu reinvestieren und nicht zu konsumieren. Als vierten Aspekt betonte Keynes schließlich die bevorzugten Bedingungen, die das Handelsverhältnis mit den Rohstoffe und Nahrungsmittel produzierenden Ländern außerhalb Europas vor 1914 geprägt hatten. Der Krieg, so resümierte er, habe die latente Instabilität dieses Systems bloßgelegt, und es wäre Aufgabe der Friedenskonferenz gewesen, eine Grundlage für den europäischen Wiederaufbau zu legen, die dieser Instabilität und den durch den Krieg veränderten Bedingungen, im besonderen aber auch der Rolle des deutschen Wirtschaftspotentials, Rechnung getragen hätte.

Die scharfe Kritik von Keynes an den Reparationsklauseln des Versailler Vertrags beruhte daher nicht nur auf der Einsicht, daß die Alliierten die deutsche Zahlungsfähigkeit in grober Weise überschätzt hatten, was seiner Meinung nach zu gewaltigen Störungen der deutschen Wirtschaft wie letztlich des internationalen Wirtschaftsgefüges insgesamt führen werde. Sie gründete vielmehr in der Erkenntnis, daß das Vertragswerk in der Tradition der Siegfrieden des 19. Jahrhunderts stand und die Wiederherstellung gerade jenes Wirtschaftsgefüges implizierte, deren Instabilität der Erste Weltkrieg seiner Meinung nach bloßgelegt hatte: Die Durchsetzung einer „harten“ Reparationslösung entsprach der Rückkehr zum wirtschaftspolitischen Status quo ante; umgekehrt erforderte eine den veränderten Rahmenbedingungen angepaßte Reorganisation der internationalen Wirtschafts- und Finanzbeziehungen eine konstruktive, d. h. "milde" Wiedergutmachungspolitik, welche die Realität globaler währungs- und handelspolitischer Vernetzungen anerkannte. Die erste dieser alternativ zu verstehenden Optionen der Friedenspolitik hatte sich also vor allem deshalb diskreditiert, weil sie sich den veränderten sozio-ökonomischen Bedingungen nach dem Großen Krieg verweigerte. Wollte man Deutschland reparationswirtschaftlich ,aussaugen“, so folgte daraus der Zwang, zu den ökonomischen und wirtschaftspolitischen Grundsätzen der Vorkriegszeit zurückzukehren. Und das bedeutete auch die Wiederbelebung des unzulänglichen Kriseninstrumentariums und die Verschärfung der sozialen Spannungen im Inneren. Keynes knüpfte damit an Ideen aus dem Umkreis der britischen Friedensbewegung insbesondere von John A. Hobson und Norman Angell an. Namentlich Angell hatte schon 1910 in seinem Buch "The Great Illusion“ Hobsons Imperialismuskritik aufgenommen und mit seinen eigenen Veröffentlichungen Keynes direkt beeinflußt. Angell vertrat die These, daß Kriege im allgemeinen und Reparationen im besonderen wegen der wachsenden internationalen Verflechtung von Handel und Finanzen auch für die Sieger von Nachteil seien; in diesem Zusammenhang hatte er auch die Frage nach der wirtschaftlichen Integration Deutschlands als Kern jeder stabilen Friedensordnung betont ${ }^{14}$.

${ }^{14}$ Mayer, S. 25-27; Moggridge, Maynard Keynes, S. 289; Gebele, S. 93 f.; zu Hobson vgl. unten Kap. I.2. 
Nichts demonstrierte für Keynes diesen Strukturwandel und die gegenseitige Abhängigkeit von Siegern und Besiegten deutlicher als das Schuldenproblem, das beide Seiten ungeachtet des traditionellen machtpolitischen Kalküls unter rekonstruktionspolitischen Vorzeichen zur Kooperation geradezu zwang. Zum besseren Verständnis von Keynes' eigentlichem Anliegen wie vor allem auch seiner während des Zweiten Weltkrieges formulierten deutschland- und reparationspolitischen Überlegungen bietet deshalb ein Blick auf das "Grand Scheme“, das die Thesen der „Economic Consequences“ brennpunktartig zusammenfaßte, eine wichtige Orientierungshilfe. Diese Denkschrift hatte er im Mai 1919 in einem letzten Versuch, die Konferenz in seinem Sinne zu beeinflussen, den britischen und amerikanischen Delegationen unterbreitet. Der Grundgedanke von Keynes' Vorlage bestand in der Streichung aller oder doch des größten Teils der Kriegsschulden, vor allem durch das Hauptgläubigerland USA. Von einer solchen Lösung würde auch Großbritannien selbst profitieren, dessen von Keynes auf nahezu eine Milliarde Pfund geschätzte Schuldenlast gegenüber dem amerikanischen Finanzministerium den Haushalt mit jährlich etwa $£ 100$ Millionen belasten würde. „Such a burden“, warnte er, "will cripple our foreign development in other parts of the world, and will lay us open to future pressure by the United States of the most objectionable description. ${ }^{15}$ Keynes versuchte aber in erster Linie darzulegen, daß ein geringerer wirtschaftlicher Druck auf die Siegerstaaten auch eine weniger exzessive Reparationsregelung ermöglichen würde: „For this reason the question of inter-allied indebtedness is clearly bound up with the intense popular feeling amongst European allies on the question of indemnities - a feeling which is based not on any reasonable calculation of what Germany can, in fact, pay, but on a well-founded appreciation of the intolerable financial situation in which these countries will find themselves unless she pays." 16

Zu diesem Zweck erarbeitete er im April 1919 einen komplizierten Entwurf, in dessen Mittelpunkt die Ersetzung der interalliierten Kriegsschulden durch öffentliche Schuldverschreibungen der Feindstaaten stand. Ziel war es, den Kreditkreislauf anzukurbeln, die europäischen Staaten mit dem nötigen Kapital zur Finanzierung dringend benötigter Importe zu versehen und gleichzeitig die Schuldenlast zu reduzieren ${ }^{17}$. In einem aufschlußreichen Begleitschreiben erläuterte der Ökonom mit besonderer Eindringlichkeit und Klarheit sein Anliegen. Die angeschlagenen Wirtschaftsbeziehungen, so erklärte er, würden gegenwärtig allein durch amerikanische Hilfslieferungen vor dem völligen $\mathrm{Zu}$ sammenbruch bewahrt, während Großbritannien nur in geringfügigem Maß ergänzende Unterstützung zur Verfügung stellen konnte. Dagegen gebe es keine langfristigen Wiederaufbaupläne, die auch die ehemaligen Feindstaaten einschlössen, in denen jedes wirtschaftliche Leben zum Erliegen gekommen sei. Auch in Großbritannien, das im Vergleich zu den kontinentaleuropäischen Staaten unter weitaus günstigeren Bedingungen

15 "Memorandum on the Treatment of Inter-Allied Debt Arising Out of the War" [April 1919], in: JMK XVI, S. 418 f., hier S. 418.

16 "The Treatment of Inter-Ally Debt Arising Out of the War" [März 1919], in: ebenda, S. 420-428, hier S. 421; Hervorhebung im Original. Diese und andere Passagen wurden später wörtlich in die „Economic Consequences“ übernommen; vgl. JMK II, S. 176.

${ }^{17} \mathrm{KCKP}, \mathrm{RT} / 16 / 29-31$, „Scheme for the Rehabilitation of European Credit and for Financing Relief and Reconstruction" [April 1919]; JMK XVI, S. 429-431. Vgl. JMK II, S. 152-157. Vgl. zum Hintergrund Harrod, Keynes, S. 246-248; Skidelsky, Keynes, Bd. I, S. 367-375; Moggridge, Maynard Keynes, S. 308-310. 
den Frieden beginne, werde der Ankurbelungsprozeß der Produktion durch die Frage nach der Schuldenabwicklung mit dem amerikanischen Finanzministerium entscheidend gelähmt: „In short, the economic mechanism of Europe is jammed. Before the war, as Mr. Hoover has said, 400 million Europeans by working their hardest just managed to feed, clothe and house themselves, and perhaps amass six months' capital on which to live. That capital has vanished; the complicated machinery of internal and external production is more or less smashed; production has to a great extent ceased. The largely increasing population of Europe has only been maintained by the increasing development and inter-connection of world industry and finance. If this is not only checked, but for the time being destroyed, it is difficult to see how the population can be maintained, at any rate during the very painful period of drastic readjustment. "18

Nach dieser Warnung vor den Folgen eines Fehlens umfassender Langzeitpläne und im Bewußtsein, daß eine Rückkehr zu den Verhältnissen von vor 1914 nicht mehr möglich war, entwickelte Keynes im weiteren eine Kritik der Möglichkeiten des freien Unternehmertums, die gegenwärtige Krise zu überwinden. Dies erfolgte freilich nicht mit prononciert antikapitalistischer Attitüde. Vielmehr ließ sich Keynes dabei von der Einsicht in die Grenzen des freien Marktes leiten und suchte angesichts der bedrohlichen Sogwirkung der russischen Revolution und der schleichenden Erosion der ökonomischen Grundlagen westlicher Zivilisation nach Wegen zur Stabilisierung des kapitalistischen Wirtschaftssystems: „In some quarters the hope is entertained that with the early removal of obstacles in the form of the blockade and similar measures to free international intercourse, private enterprise may be safely entrusted with the task of finding the solution. I am in accord with the view that an early removal of such obstacles is an essential measure, and that in the long run we must mainly look for our salvation to the renewed life of private enterprise and of private initiative. Indeed, so far as trading and manufacture is concerned, as distinct from finance, no other measures should be necessary from the outset. Nevertheless, in the financial sphere, the problem of restoring Europe is almost certainly too great for private enterprise alone, and every delay puts this solution further out of court. There are two main obstacles: (a) the risks are too great; (b) the amounts are too big and the credit required too long. The more prostrate a country is and the nearer to Bolshevism the more presumably it requires assistance. But the less likely is private enterprise to give it. " ${ }^{19}$ Keynes schlug daher ein kurz- und ein langfristiges Mittel zur Bekämpfung der Krise vor: erstens eine direkte Wirtschaftshilfe in noch größerem Rahmen als bisher, die nach Lage der Dinge nur von den USA kommen könne, und zweitens die Wiederherstellung eines funktionierenden Kreditsystems auf internationaler Basis. Keynes ließ keinen Zweifel an der größeren Anziehungskraft der letzteren Maßnahme, da in ihr die Interessen der Siegerstaaten und Neutralen an Reparationen und Wiedergutmachung mit denen der Besiegten an einem vernünftigen Verhältnis von Zahlungsverpflichtungen und Sicherung ihrer wirtschaftlichen Existenz zum

18 "Draft for an Explanatory Letter to Be Addressed by the Prime Minister to the President, M. Clemenceau, and Signor Orlando“, in: JMK XVI, S. 431-436, hier S. 433.

${ }^{19}$ Ebenda, S. $433 \mathrm{f}$. Wie Keynes später in einem Interview formulierte, habe er schon früh bemerkt, daß die wirtschaftspolitische Diskussion von den beiden Extremen der uneingeschränkten Befürworter des Kapitalismus und jener Gruppe, die für seine völlige Überwindung eintrete, beherrscht werde. Demgegenüber gebe es zuwenig Sympathie für Versuche, „to make the private property system work better". JMK XXI, S. $492 \mathrm{f}$. (Hervorhebung im Original). 
Vorteil des allgemeinen Wiederaufbaus Europas verschmolzen. Keynes dachte in diesem Zusammenhang direkt an die seiner Meinung nach kaum zu überschätzende sicherheitspolitische Funktion der Wiederherstellung eines europäischen Wirtschaftsgleichgewichts: "A proposal“, so schloß er, „which unfolds future prospects and shows the peoples of Europe a road by which food and employment and orderly existence can once again come their way, will be a more powerful weapon than any other for the preservation from the dangers of Bolshevism of that order of human society which we believe to be the best starting-point for future improvement and greater well-being. " 20

Doch alle noch so gut plazierten Argumente fruchteten wenig. Auch diesem letzten Versuch, den Verhandlungsstillstand in Versailles zu durchbrechen, war kein Erfolg beschieden. Zwar vermochte er das britische Schatzamt auf seine Seite zu ziehen. Schatzkanzler Chamberlain notierte, der Keynes-Plan würde Siegerstaaten wie Besiegten gleichermaßen die nötigen Mittel für den Wiederaufbau bereitstellen und die Friedensbedingungen damit für alle Seiten annehmbarer machen; auch die USA würden, durch die Aussicht auf verbesserte Sicherheiten sowie größere Geschäfte an Europa gebunden und die Friedensordnung dadurch insgesamt stabiler ${ }^{21}$. Premierminister Lloyd George betrachtete das Junktim, die Reparationsforderungen zu reduzieren, wenn im Gegenzug Washington die Kriegsschulden erließ, als äußerst präsentabel für das Parlament und konnte ebenfalls für den Plan gewonnen werden. Doch die Amerikaner reagierten zurückhaltend und wiesen auf zu erwartenden Widerstand des Kongresses hin, der kaum zur Streichung der Kriegsschulden der europäischen Länder bereit sein werde. Wie Präsident Wilson Lloyd George zu erkennen gab, befürchteten die USA, für die de facto als Reparationen fungierenden Obligationen der deutschen Regierung und ihrer ehemaligen Alliierten an die Siegerstaaten zahlen zu müssen. Statt dessen empfahl er, daß die Regierungen sich so rasch wie möglich aus dem „banking business“ zurückziehen und die Kreditgeschäfte privaten Kanälen überlassen sollten ${ }^{22}$. Diese bereits wesentliche Aspekte der US-Reparationspolitik nach dem Zweiten Weltkrieg antizipierende Haltung ließ Keynes' Entwurf zur Reform des internationalen Finanzwesens keine Chance zur Durchsetzung. Aus seiner Enttäuschung machte er keinen Hehl. Das amerikanische Finanzministerium, so schrieb er an seinen Bloomsbury-Freund und Maler Duncan Grant, "turned it down firmly as a most immoral proposal which might cost them something and which Senators from Illinois wouldn't look at. They had a chance of taking a large or at least a humane view of the world but unhesitatingly refused to sign it. Wilson [...] is the greatest fraud on earth. " 23

Seine Kritik am Versailler Friedenssystem und die für die Kriegszielplanungen Großbritanniens im Zweiten Weltkrieg aufschlußreichen Schlußfolgerungen aus seiner Tätigkeit als Treasury-Berater können vor diesem Hintergrund in sieben Punkten zusammengefaßt werden:

${ }^{20}$ JMK XVI, S. 436. Vgl. auch das vorausgehende, das Schuldenproblem besonders eindrucksvoll darstellende „Indemnitäts-Memorandum“ Keynes' vom März 1919, das teilweise wörtlich in die „Economic Consequences" übernommen wurde; JMK II, S. 170-179.

${ }^{21}$ KCKP, RT/16/13-16, Chamberlain an Lloyd George, 17.4.1919; Auszug in: JMK XVI, S. 428.

22 KCKP, RT/16/33 f., Wilson an Lloyd George, 3.5.1919; Auszug in: JMK XVI, S. 440f.; vgl. Skidelsky, Keynes, Bd. I, S. 368-370; Moggridge, Maynard Keynes, S. $308 \mathrm{f}$.

${ }^{23}$ Keynes an Duncan Grant, 14.5.1919, zitiert nach: Skidelsky, Keynes, Bd. I, S. 371; vgl. KCKP, RT/16/39-41, Keynes an Philip Kerr, 10.5.1919; JMK XVI, S. $441 \mathrm{f}$. 
1. Eine Rückkehr zu den ordnungspolitischen Rahmenbedingungen des Status quo ante war ausgeschlossen. Die Gefahr einer Entfesselung des „Malthusischen Teufels“ im ausgehenden 19. Jahrhundert konnte abgewendet werden durch die Herausbildung multilateraler Wirtschaftsstrukturen in Kontinentaleuropa mit dem Deutschen Reich als Motor und Kern der Industrialisierung; gleichzeitig hatten aber daraus resultierende Hegemonialbestrebungen des Kaiserreichs, zunächst ökonomischer, schließlich auch machtpolitischer Art, zur Erosion dieser Strukturen geführt, die durch den Weltkrieg dann völlig zerstört wurden. Das Dilemma bestand also bereits vor 1914 aus der Sicht von Keynes in der Befriedung bzw. Einbindung des ökonomischen Potentials Deutschlands.

2. Die Integration der deutschen Industrie mußte nach Keynes' Ansicht auch den Schlüssel für eine jeder Friedensordnung zugrunde liegende Reorganisation der internationalen Wirtschaftsbeziehungen darstellen. Ohne eine die ehemaligen Feindstaaten ebenfalls einbeziehende langfristige Konzeption, etwa zur Lösung des Schuldenproblems, mußte ein stabiler europäischer Wiederaufbau Stückwerk bleiben. Das Schuldenproblem war umgekehrt eng verbunden mit der Reparationsfrage, und erst die Lösung beider, sich gegenseitig beeinflussender Problemkomplexe bot die Voraussetzungen für eine kurzfristige Sicherung der Kreditbasis und damit für einen geordneten Wiederaufbauprozeß Westeuropas. Doch unabhängig von der Schaffung einer gesunden Finanzbasis, die an Deutschland vorbei kaum zu realisieren war, zeigte eine genaue und vorurteilslose Analyse der ökonomischen Strukturen vor dem Krieg für Keynes, daß das deutsche Potential in seine frühere Rolle im Zentrum der freilich modifizierungsbedürftigen europäischen Wirtschaftsbeziehungen wieder eingesetzt werden mußte.

3. Die Frage, wie diese Reorganisation genau aussehen sollte, ließ Keynes zunächst offen. Neben dem Gedanken, das deutsche Wirtschaftspotential als Initialzündung für den europäischen Wiederaufbau zu mobilisieren, hatte er in den „Economic Consequences“ immerhin bereits angedeutet, daß er eine Rückkehr zu einer Politik des Laissez-faire im allgemeinen und zum Goldstandard im besonderen für ausgeschlossen, ja gefährlich hielt ${ }^{24}$. Diese Ansicht begründete er mit zwei Entwicklungen, die seiner Ansicht nach für den Gleichgewichtsverlust im ökonomischen System der Vorkriegszeit verantwortlich waren: erstens die Zerstörung der sozialen und psychologischen Bedingungen, die für den Zusammenhalt gesorgt hatten, und zweitens die Verschlechterung der Investitionsmöglichkeiten mit dem Ende der Übersee-Expansion, die den Rahmen für das bildete, was Keynes als Kern des „kapitalistischen Ethos“ ansah: die Umwandlung von Sparkapital in Investitionskapital. Vor dem philosophischen Hintergrund seines „Treatise on Probability" war dies gleichbedeutend mit dem Verfall geltender Werte: Die auf der Basis allgemein akzeptierter Werte eine große Wahrscheinlichkeit besitzenden Erwartungen des Homo oeconomicus regelten auch das Wirtschaftsleben und verliehen dem System des Laissez-faire ein hohes Maß an Berechenbarkeit und Stabilität; erst der Werteverfall und der damit verknüpfte, von persönlichem wie nationalem Egoismus geprägte Verhaltenswandel entzogen diesem Funktionsmechanismus die Grundlage ${ }^{25}$. Mit Bezug auf die Vorstellungen des Klassischen Liberalismus ließe sich auch sagen, daß mit

\footnotetext{
${ }^{24}$ Vgl. auch die pointierte Darstellung des amerikanischen Keynesianers Harris, Keynes, S. 62-72, 164-173.

${ }^{25}$ Skidelsky, Keynes's Philosophy of Practice, S. $120 \mathrm{f}$.
} 
der Unterminierung des Funktionszusammenhangs von Kapitalbildung und allgemeinem Wohlstand die Raison d'être von Adam Smiths „System der natürlichen Freiheit“ zerstört war. Die Wechselwirkung beider Faktoren, auf die Keynes im Zusammenhang mit dem Ringen um die Versailler Friedensregelung hinwies, beschrieb Joseph Schumpeter in seinem Nachruf auf den Nationalökonomen treffend: „Laissez-faire capitalism, that ,extraordinary episode‘, had come to an end in August, 1914. The conditions were rapidly passing in which entrepreneural leadership was able to secure success after success, propelled as it had been by rapid growth of populations and by abundant opportunities to invest that were incessantly recreated by technological improvements and by a series of conquests of new sources of food and raw materials. Under these conditions, there had been no difficulty about absorbing the savings of a bourgeoisie that kept on baking cakes, in order not to eat them'. But now (1920) those impulses were giving out, the spirit of private enterprise was flagging, investment opportunities were vanishing, and bourgeois saving habits had, therefore, lost their social function, their persistance actually made things worse. "26 Damit sei aber erstens eine wesentliche Säule im Gebäude des (britischen) Wirtschaftsliberalismus zerbröckelt, zweitens habe ein zentrales Mittel britischer Friedenspolitik nicht mehr zur Verfügung gestanden, und schließlich müsse drittens, um die Tradition beider als Kernelemente des politischen Zielrahmens von Großbritannien zu retten, angesichts zunehmender internationaler Marktkonkurrenz nach Ersatzmechanismen gesucht werden. Keynes spürte, daß Lord Salisburys Maxime, Großbritannien strebe nur nach Gebietserweiterungen, weil es gleichzeitig den handelspolitischen Frieden wünsche ${ }^{27}$, bereits vor dem Großen Krieg zur Unwirksamkeit verurteilt worden war. Seine Erfahrungen in Versailles mit dem Problem der künftigen wirtschaftlichen und politischen Rolle Deutschlands waren daher auch die Initialzünder für seine Überlegungen zu einer Kritik an dem vorherrschenden Laissez-faire-Dogma.

4. Kurzfristig dachte Keynes dabei an eine Rehabilitation des Kreditsystems durch gegenseitige Tilgung der Kriegsschulden. Ob ergänzt durch eine von ihm vorübergehend vertretene Umwandlung von Reparationen in ein System von Schuldverschreibungen oder, wie in den "Economic Consequences“ vorgeschlagen ${ }^{28}$, durch eine umfangreiche Anleihe, dies würde mit einem Streich sowohl das schwierigste Problem für die britische Wirtschaft beseitigen als auch den europäischen Ländern insgesamt jenes Kapital bereitstellen, das sie bis zur Gesundung ihrer Exportindustrien für die Finanzierung der Importe benötigten. Dem Schulden- und Reparationsproblem kam dabei für Keynes geradezu paradigmatische Bedeutung zu: „The existence of the great war debts is a menace to financial stability everywhere. [...] Entangling alliances or entangling leagues are nothing to the entanglements of cash owing." ${ }^{29}$ Gerade an diesem Punkt zeigt sich besonders deutlich der von Keynes diagnostizierte und gegenüber den alliierten Regierungsvertretern behauptete Grundlagenwandel in der Außen- und Sicherheitspolitik: Im Gegensatz zum herrschenden Politikverständnis, das in Versailles noch einmal die Ober-

${ }^{26}$ Schumpeter, S. 500 f. (Hervorhebungen im Original). Zu Keynes' Analyse der Krise der „großen kapitalistischen Klassen“ vgl. JMK II, S. $149 \mathrm{f}$. Für eine allgemeine Einordnung aus Keynes' Feder vgl. John Maynard Keynes, The End of Laissez-Faire, in: JMK IX, S. 272-294; im Kontext der "General Theory“ vgl. JMK VII, S. 333-371.

${ }^{27} \mathrm{Vgl}$. Porter, S. 145. Vgl. auch Cain, Economic Foundations.

${ }^{28}$ JMK II, S. 179-183.

29 JMK XVI, S. 423; JMK II, S. 177. 
hand behielt, maß Keynes im Hinblick auf die Antriebsmomente der internationalen Beziehungen der Verschuldungsfrage einen weitaus größeren Wert bei als traditionellen vertragspolitischen Bindungen. Der Schlüssel für einen dauerhaften und stabilen Frieden lag also angesichts der wirtschaftlichen Probleme und der Tatsache, daß Sieger wie Besiegte trotz aller Unterschiede im gleichen Boot saßen, nicht in einer notdürftig verschleierten Revitalisierung der alten Bündnispolitik gegen Deutschland und einer entsprechenden kompromißlosen Reparationspolitik alten Stils, sondern umgekehrt in der gemeinsamen Überwindung der wirtschaftlichen Kriegsfolgen durch eine grundlegende Neuordnung des weltwirtschaftlichen Geflechts und unter Einbeziehung Deutschlands ${ }^{30}$.

5. Kennzeichnend für Keynes' Überlegungen ist eine Vermischung von ökonomischen Aspekten mit dem Gedanken der sozialen Sicherheit. Die Kritik an den wirtschaftspolitischen Grundsätzen einer Laissez-faire-Politik überzeugte ihn davon, daß nur die Reorganisation der internationalen Finanzbeziehungen die Schaffung stabiler sozialer Verhältnisse in Großbritannien, aber auch in den übrigen Ländern Europas, garantieren konnte. Die Unfähigkeit der „Profiteure“, d. h. der von den steigenden Preisen profitierenden „unternehmerischen Klasse von Kapitalisten“, führte seiner Ansicht nach dazu, daß die europäischen Regierungen in ihren Bemühungen, ihre Wirtschaftspolitik weiterhin an traditionellen Grundsätzen zu orientieren, den $\mathrm{Haß}$ des verarmten Teils des Bürgertums wie des Proletariats auf sich lenkten und sozialen Unruhen und kommunistischen Gruppierungen den Weg ebneten: „By combining a popular hatred of the class of entrepreneurs with the blow already given to social security by the violent equilibrium of wealth which is the inevitable result of inflation, these governments are fast rendering impossible a continuance of the social and economic order of the nineteenth century. But they have no plan for replacing it. " ${ }^{31}$ Keynes' Analyse der Versailler Friedensregelung lenkte seine Aufmerksamkeit mithin auf den Zusammenhang von sozialer Sicherheit nach innen und wirtschaftlicher Sicherheit nach außen, die beide nur durch eine neue Grundlegung der internationalen Wirtschaftsbeziehungen und zugleich durch die radikale Kritik an einer starren und traditionsverhafteten Volkswirtschaftslehre verwirklicht werden konnten: „From the notion that national security cannot be entrusted to the free market, arises naturally the idea that national welfare may also be too valuable to be entrusted to it." 32 Der Kern dieser Einsicht in die Wechselwirkung von binnenund außenwirtschaftspolitischen Prozessen bestand in dem von Keynes gegen die wirtschaftspolitische Orthodoxie vertretenen Primat der ersteren gegenüber den letzteren. Dies bedeutete freilich nicht eine Unterbewertung des wirtschaftlichen Internationalismus, sondern lediglich dessen Unterordnung unter das Ziel der Schaffung einer ausrei-

\footnotetext{
${ }^{30}$ Auch im Bereich der Diplomatie kam es zu analogen Bemühungen um eine Neuordnung des Instrumentariums. Parallel zur Entwicklung von Autarkic- und Protektionismustendenzen in der ökonomischen Sphäre - d. h. einer wirtschaftlichen Blockbildung - traten z. B. der traditionellen Bündnispolitik als „diplomatische Ersatzinstrumente“ zur Regulierung der Instabilität des internationalen Staatensystems in der Zwischenkriegszeit vermehrt Nichtangriffspakte an die Seite. Wie in der Wirtschaftspolitik mutierte dieses Mittel bilateraler Diplomatie in den Händen der Diktatoren freilich bald zu Instrumenten der Kriegsvorbereitung. Vgl. dazu Ahmann; Watt, 1939 Revisited, S. $685 \mathrm{ff}$.

${ }^{31}$ JMK II, S. 150.

${ }^{32}$ Skidelsky, Reception, S. 104.
} 
chenden inneren sozialen Sicherheit; d. h., der Aufbau eines funktionierenden und ausgeglichenen multilateralen Wirtschaftssystems war nicht mehr wie bisher Zweck an sich, sondern gewann seine Bedeutung zuallererst aus seiner Funktionalisierung mit Blick auf die Vermeidung von Arbeitslosigkeit und die ausreichende Versorgung im Inneren. In diesem Sinne stellt Keynes' Tätigkeit im Rahmen der Versailler Friedenskonferenz auch den Startpunkt seiner Bemühungen um eine Theoretisierung und Operationalisierung seiner gewonnenen Erfahrungen dar. Darauf hat bereits Schumpeter nachdrücklich hingewiesen: "In those pages of the Economic Consequences of the Peace we find nothing of the theoretical apparatus of the General Theory. But we find the whole of the vision of things social and economic of which that apparatus is the technical complement. The General Theory is the final result of a long struggle to make that vision of our age analytically operative." 33

6. Keynes ließ keinen Zweifel daran - und hier führte er eine weitere entscheidende gedankliche Neuerung ein, mit der er weit über traditionelle Friedensvorstellungen hinausging -, daß der besondere Stellenwert, den er Deutschland innerhalb seiner Konzeption zuerkannte, nicht nur aus dessen zentraler wirtschaftlicher Bedeutung resultierte. Hinzu kam eine wichtige sicherheitspolitische Relevanz. In den „Economic Consequences" findet sich bereits eine Unterscheidung angelegt, die auf den Kern der deutschlandpolitischen Diskussion während des Zweiten Weltkrieges vorausweist. Keynes schlug die Gründung einer Freihandelszone in Europa unter den Auspizien des Völkerbundes vor, in der die Mitgliedstaaten jede protektionistische Zollpolitik aufgeben würden und der neben den Ländern Zentral-, Ost- und Südosteuropas schließlich auch Großbritannien angehören sollte. Seinen Kritikern hielt er den Integrationsgedanken entgegen: „It would be objected, I suppose, by some critics that such an arrangement might go some way in effect towards realising the former German dream of Mittel-Europa. If other countries were so foolish as to remain outside the union and to leave to Germany all its advantages, there might be some truth in this. But an economic system, to which everyone had the opportunity of belonging and which gave special privilege to none, is surely absolutely free from the objections of a privileged and avowedly imperialistic scheme of exclusion and discrimination. " 34 Die wirtschaftliche Integration des Reichs erschien Keynes daher nicht nur als die notwendige Bedingung für den Wiederaufbau Europas, sie war zugleich Mittel für eine anhaltende Sicherheit vor einem möglichen Wiederaufleben deutscher Hegemonialbestrebungen. Hier war aus struktureller Perspektive ein Ansatz skizziert, der erst nach 1945 von Schuman und Adenauer aufgenommen wurde. Soweit Keynes ausdrücklich die Mitwirkung Großbritanniens forderte und damit auch einen möglichen Ausweg aus den britischen Wirtschafts- und Sicherheitsproblemen wies, ist es eine bittere Ironie der Geschichte, daß das Inselreich sich dem Gedanken der europäischen Kooperation auch noch nach dem Ende des Zweiten Weltkrieges dauerhaft verweigerte. Gleichzeitig erkannte Keynes aber, daß das deutsche Potential zur Stabilisierung der Wirtschaftsbeziehungen in Europa und damit auch zum Schutz vor den „dunklen Mächten“ beitragen würde, als die er unmißverständlich die Wirkungen der russischen Revolution identifizierte. Er unterstrich Lenins Ansicht, wonach es keinen besseren Weg zur Vernichtung des kapitalistischen Systems gebe als den,

${ }^{33}$ Schumpeter, S. 501 (Hervorhebungen im Original). Vgl. ferner Opie, S. 78.

${ }^{34}$ JMK II, S. 168-170, Zitat S. 169. 
eine Währung durch Inflation, die viele verarme und wenige reich mache, verkommen zu lassen. Die „Profiteure“ aber, bar jenes kapitalistischen Ethos, welches das Funktionieren des Wirtschaftskreislaufs vor 1914 gewährleistet hatte, spielten in die Hände der Revolutionäre. Um so größere Bedeutung kam also der Konsolidierung Westeuropas $\mathrm{zu}^{35}$. Auf die Rolle Deutschlands eingehend, formulierte Keynes dazu drei Jahre später: „European civilisation requires support from every quarter, to escape decline. The young republic of Germany may still prove one of its good friends. Western Europe has need of the German republic, of reconciliation with her, and of joint defence against the dark forces. "36 Auch wenn diese Überlegung noch sehr allgemein gehalten war, im Kontext seiner Bemerkungen in den „Economic Consequences" wird doch deutlich, daß es nicht nur um ein Konzept wirtschaftlicher Sicherheit vor Deutschland ging, sondern im gleichen Atemzug um die Erlangung von Sicherheit mit Deutschland vor einem Übergreifen des kommunistischen Einflusses auf Europa.

7. Schließlich sei noch auf die von Keynes implizit vorgenommene Trennung von wirtschaftlicher und militärischer Sicherheit hingewiesen. Zwar wird dieser Aspekt an keiner Stelle direkt angesprochen, doch unterliegt es keinem Zweifel, daß Keynes eine Entmilitarisierung Deutschlands für wünschenswert hielt. Freilich ermöglichte gerade eine Unterscheidung zwischen beiden Begriffen die konstruktive Erweiterung des Sicherheitskonzepts: Das Argument, daß eine Verarmung Zentraleuropas unweigerlich den "final civil war between the forces of reaction and the despairing convulsions of revolution " ${ }^{37}$ einläute, also genau jenes $\mathrm{Maß}$ an Sicherheit vernichtet, das eine angeblich die wirtschaftliche Genesung der Siegermächte vorantreibende harte Friedensregelung zuallererst schaffen sollte, wurde von ihm umgekehrt. Seine Gegenthese erhielt gerade dadurch ihre argumentative Wirkungskraft: Die wirtschaftliche Rekonstruktion Deutschlands garantierte seiner Meinung nach nicht geringere, sondern größere Sicherheit vor Deutschland und mit Deutschland gegen den Bolschewismus. Keynes' Kritiker warfen ihm später wiederholt eine zu starke Konzentration auf die Ökonomie vor, die dem politischen und militärischen Spielraum der Entscheidungsträger jener Tage nicht die gebührende Beachtung schenke ${ }^{38}$. Die Frage der militärischen Sicherheit, etwa in Form einer Besatzung oder durch umfassende Abrüstungsmaßnahmen unter Aufsicht des Völkerbunds, lag freilich außerhalb von Keynes' Hauptinteresse und hätte seine Argumentationslinie beträchtlich verwässert; dennoch blieb er für eine kohärente Argumentation offen, sofern sie die von ihm postulierte Basis wirtschaftlicher Vernunft nicht verließ ${ }^{39}$.

Keynes selbst gab dem Versailler Friedenssystem keine lange Lebensdauer. „I doubt", so schrieb er im April 1920, „if the Treaty will last in its present form for two years from now, - that is the extreme limit of its life. But more and more I feel that it will be killed

\footnotetext{
35 Ebenda, S. 148 f.

36 "Is a Settlement of the Reparation Question Possible Now?" [Manchester Guardian Commercial, 28.9.1922], in: JMK XVIII, S. 32-44, hier S. 43.

37 Besonders eindrucksvoll vorgebracht in: JMK II, S. 169 f., Zitat S. 170.

${ }^{38}$ Vgl. z. B. JMK VII, S. 3-109 passim; Kritik Eyre Crowes in: Harrod, Keynes, S. 239f.; Churchill, The World Crisis, S. 155f. (vgl. dazu die aufschlußreiche Besprechung dieses Bandes durch Keynes in: JMK X, S. 52-57); zur Kritik in Frankreich Mantoux. Eine inhaltliche Auseinandersetzung mit den Vorwürfen findet sich in Harrod, Keynes, S. 269-275.

${ }^{39}$ Vgl. zur Besatzungsfrage etwa JMK XVII, S. 134-136, 246f.; zur Abrüstungsfrage ebenda, S. $241 \mathrm{f}$., $271,450-454$.
} 
not by the formal act of Governments, but by the mere march of events. It will just become absurd, irrelevant, inapplicable, and a time will soon arrive when no one will pay the least attention to it. For practical reasons Europe will have to find for itself some new solution, if it is to survive at all." 40 Das Keynessche „Netzwerk" der Kritik, das die Strukturkrise der europäischen sowie implizit der britischen Wirtschaft vor dem Großen Krieg in ihrem Kern freilegte, dabei für Europa ein Integrationsproblem identifizierte und für Großbritannien eine „Anpassungs- und Modernisierungskrise“ diagnostizierte ${ }^{41}$; eine Kritik, die das Ende des Wirtschaftsliberalismus um seiner eigenen Rettung willen wünschte und die Zukunft des ökonomischen Internationalismus durch dessen Unterordnung unter die Priorität binnenwirtschaftlicher Ziele zu sichern versuchte; eine Kritik schließlich, die die Inflexibilität einer überkommenen volkswirtschaftlichen Orthodoxie vehement attackierte und ihr die wirtschaftspolitische Kraft der Regierungen als Regulativ zur gezielten Förderung eines Programms sozialer Sicherheit im Inneren bei gleichzeitiger wirtschaftlicher Sicherheit im Äußeren entgegenstellte - diese Kritik antizipierte brennpunktartig alle jene Diskussionen, die den wirtschaftspolitischen Entscheidungsfindungsprozeß der folgenden 25 Jahre bestimmen sollten. Sie lieferte zugleich einen Begründungszusammenhang für das außenpolitische Konfliktverhalten Londons und die wirtschaftlichen Krisen der Zwischenkriegszeit in Großbritannien. In gleicher Weise mag man in Keynes' Bemerkungen die Probleme jenes Wandels gespiegelt sehen, dem das internationale wirtschaftliche Beziehungsgeflecht seit dem letzten Drittel des 19. Jahrhunderts ausgesetzt war und dem erst mit den Institutionen des BrettonWoods-Systems und des Schumanplans nach dem Zweiten Weltkrieg Rechnung getragen wurde. Keynes sah sich zu Recht an einer Epochenschwelle. „My Christmas thoughts are", schrieb er am Heiligen Abend 1917 an seine Mutter, "that a further prolongation of the war [...] probably means the disappearance of the social order we have known hitherto. With some regrets I think I am on the whole not sorry. The abolition of the rich will be rather a comfort and serve them right anyhow. What frightens me more is the prospect of general impoverishment. In another year's time we shall have forfeited the claim we had staked out in the New World and in exchange this country will be mortgaged to America.“ Aus allem zog er den Schluß, „that, because our rulers are as incompetent as they are mad and wicked, one particular era of a particular kind of civilisation is very nearly over" ${ }^{42}$. Diese Zäsur empfand er schließlich auch in bezug auf seine eigenen politischen und wissenschaftlichen Arbeiten. Die „Economic Consequences of the Peace" markieren daher auch einen persönlichen Wendepunkt: „The difference really is that my mind has crossed a Rubicon. I have struck my tents and am on the march." 43

Die kritischen Bemerkungen von Keynes zur Versailler Friedensordnung und seine deutschlandpolitischen Überlegungen waren vor allem das Ergebnis einer eingehenden Auseinandersetzung mit Wirtschaft, Politik und Nationalökonomie vor dem Ausbruch des Ersten Weltkrieges. Im Hinblick auf den weiteren Gang der Arbeit sind daher an dieser Stelle einige klärende Hinweise notwendig, die nicht nur Keynes' Thesen in ihren

${ }^{40} \mathrm{KCKP}, \mathrm{EC} / 2 / 3 / 13-16$, Keynes an Norman H. Davis, US-Treasury, 18.4.1920.

${ }^{41}$ Meyers, Die vierte Teilstreitkraft, S. $195 \mathrm{f}$.

42 JMK XVI, S. $265 \mathrm{f}$.

${ }^{43} \mathrm{KCKP}, \mathrm{EC} / 2 / 3 / 13-16$, Keynes an Norman H. Davis, US-Treasury, 18.4.1920. Vgl. ähnlich KCKP, EC/2/4/69-72, Minute Keynes, 22.5.1919. 
Kontext stellen, sondern wesentliche Kontinuitätslinien deutlich werden lassen und Strukturvorgaben für die britische Deutschlandpolitik nach 1945 schlaglichtartig erhellen.

\section{Die Krise der weltwirtschaftlichen Ordnung vor dem Ersten Weltkrieg und die Zerstörung der Pax Britannica Oeconomica}

Mit Blick auf die hier erörterten Zusammenhänge bleibt festzuhalten, daß die Geschichte Großbritanniens in der zweiten Hälfte des 19. Jahrhunderts bis zum Ausbruch des Ersten Weltkrieges primär die Geschichte innerer und äußerer wirtschaftlicher Veränderung ist. Vordergründig betrachtet, könnten Keynes' berechtigte Kritik an den Grundsätzen der Versailler Konferenz und seine Hinweise auf die Unzulänglichkeit der Wirtschaftsmechanismen der Vorkriegszeit zu dem Schluß verleiten, daß der Erste Weltkrieg, ebenso wie dreißig Jahre später der Zweite Weltkrieg, einen in seinen Auswirkungen primär negativ zu kennzeichnenden Wendepunkt in der wirtschaftlichen Entwicklung der internationalen Staatengemeinschaft markierte. Diese Sichtweise verkürzt jedoch den Sachverhalt um einen zentralen Aspekt. Sowohl der ungewollte Modernisierungsschub, den der Krieg auslöste, als auch die Tatsache, daß er sich, rückschauend und aus makrökonomischer Perspektive betrachtet, als zyklische Abwärtsbewegung darstellt, der in den Jahren 1919/20 ein Boom folgte, stellen ihn in den Kontext längerfristiger Tendenzen ${ }^{44}$. Seine Hauptwirkung bestand in der Beschleunigung von Trends, die für den aufmerksamen Beobachter in der Vorkriegsentwicklung bereits zu erkennen und Teil eines umfassenderen weltwirtschaftlichen Wandels waren. Mit Blick auf die Entwicklung in Großbritannien steht es außer Frage, daß der Große Krieg den Anpassungsund Modernisierungsdruck der Zeit vor 1914 verstärkte.

\section{Die Ausbildung der außenpolitischen Grundinteressen Großbritanniens}

Die charakteristischen Merkmale der mittelviktorianischen Periode hat ein britischer Wirtschaftshistoriker treffend wie folgt zusammengefaßt: „To save abundantly and invest prudently; to develop foreign markets and to be ready to supply them with the kind of goods they could most plentifully absorb; to concentrate productive resources on the enlargement of capital equipment, on providing the basic necessities of existence while paying little attention to luxuries, and on the development of those business services which the whole trading world required; to improve productive techniques in the main occupations where practicable and, having done so, to specialize on those where the greatest comparative advantage was attained - these were the tasks which the mid-Victorians attempted. They were not essentially different from the tasks confronting the two or three preceding generations but some of them, especially the active promotion of foreign markets and enterprise, the development of business services and the extension of industrial specialization, were carried a good deal further; and, in a setting where institutions, policies and foreign political and economic conditions were generally more fa-

${ }^{44}$ Zum Modernisierungseffekt und zur zyklischen Einordnung vgl. Milward, passim. 
vourable than before, all of them were tackled with greater success. " ${ }^{45}$ Hinter dieser Auflistung verbirgt sich freilich ein klar zu umreißendes Muster eines den „Großen Viktorianischen Boom " ${ }^{46}$ tragenden Wirtschaftsinternationalismus ${ }^{47}$. Er beruhte im wesentlichen auf zwei Säulen: dem ständigen Ausbau der Ressourcenbasis, militärisch abgesichert durch die unangefochtene maritime Überlegenheit des Landes, sowie einem politisch-institutionellen Rahmen, der den reibungslosen Ablauf des internationalen Handelsverkehrs garantierte. Mit der langsamen Auflösung der Handelsblöcke Frankreichs, Spaniens, der Niederlande und Großbritanniens im zeitlichen Umfeld der napoleonischen Kriege begann die Entwicklung Großbritanniens zur ökonomischen Führungsmacht. Die größere Bedeutung des Exports von Manufakturwaren als Ausgleich für den steigenden Bedarf an außereuropäischen Konsumgütern wirkte als Antriebsmoment für die Handelsausweitung nach Übersee, ohne allerdings den Hang der europäischen Mächte zu größtmöglicher wirtschaftlicher Selbstversorgung entscheidend bedrohen zu können. Obwohl die Auslandsmärkte, die in zunehmendem Maße den Handel vor allem mit dem für Großbritannien wenig zugänglichen französischen Block kompensierten, weiter ausgebaut wurden und Englands maritime Vormachtstellung im Zuge der Expansionsbewegung nach Südamerika und Asien etabliert werden konnte, versetzte erst der Aufstieg der Baumwollindustrie nach der Jahrhundertwende die britische Wirtschaft in jene Position eines relativen Wettbewerbsvorteils, die den pluralistischen Charakter des internationalen Wirtschaftssystems zu durchbrechen vermochte.

Der in der Forschung immer wieder als der zentrale Begründungszusammenhang dieser Entwicklung hervorgehobene „Frühstart“ des Landes in der Industrialisierung resultierte dabei in der Ausdifferenzierung einer imperialen bzw. hegemonialen Wirtschaftsstruktur, die sowohl die britische Vorrangstellung begünstigte als auch einen Modernisierungsschub bei seinen Handelspartnern durch die drastische Nachfragesteigerung nach britischem Kapital und britischen Fertigwaren auslöste ${ }^{48}$. Gleichzeitig bestand ein fast kontinuierlich wachsender Importüberschuß, der der britischen Industrie die für ihre Expansion notwendigen Rohstoffe und Nahrungsmittel zuführte; die daraus entstehende negative Handelsbilanz konnte durch die sogenannten „unsichtbaren“ Einkünfte aus Serviceleistungen wie Schiffstransporte, Versicherungen und Auslandsinvestitionen ausgeglichen werden - ein Effekt, der durch das gesamte 19. Jahrhundert Bestand haben und in seiner Bedeutung stetig zunehmen sollte ${ }^{49}$. Dabei lag der Schwerpunkt des Produktionsprozesses auf wenigen, vor allem Basisgüter wie Textilien herstellenden Sektoren der britischen Industrie, die langfristig nicht nur die internationale Nachfrage dominierten, sondern zugleich durch den Transfer von Kapital und Arbeitskräften in diese Zweige die strukturelle Entwicklung der britischen Industrie auf lange Sicht entschei-

\footnotetext{
${ }^{45}$ Ashworth, S. $21 \mathrm{f}$.

${ }^{46}$ Zusammenfassend Church.

${ }^{47}$ Richardson, S. 130; Skidelsky, Reception, S. 96-98.

48 Einen glänzenden, den Forschungsstand zusammenfassenden Überblick bieten Cain/Hopkins, Political Economy, besonders S. 466-474. Vgl. auch Hobsbawm, S. 56-78; Mathias, S. 31-59, 76-97, 110-159. Bei der Unterscheidung zwischen pluralistischer und imperialer bzw. hegemonialer Wirtschaftsstruktur lehne ich mich an Konzepte an, die in den Publikationen von Krasner und Rowland (Hrsg.) entwickelt wurden.

49 Vgl. Imlah, S. 37 f., 70-75; Mathias, S. 277-299.
} 
dend prägten ${ }^{50}$. Die Konzentration eines Großteils der nationalen Ressourcen auf die Herstellung exportorientierter Fertigwaren, die technische und organisatorische Innovationsfähigkeit der hierfür relevanten Sektoren sowie die Ausweitung bzw. Schaffung von Exportmärkten können daher als die tragenden Elemente der viktorianischen Wirtschaft betrachtet werden ${ }^{51}$. Die Gesamtperiode zeichnete sich zudem dadurch aus, daß hohen Wachstumsraten in den fünfziger Jahren stagnierende und in den sechziger Jahren nur mäßig steigende Löhne gegenüberstanden, so daß das ,viktorianische Wirtschaftswunder" keinesfalls als eine Zeit steigender Prosperität gelten kann. Die für die Zeit hohen Investitionsraten lassen darauf schließen, daß akkumuliertes Kapital nahezu ausnahmslos der weiteren industriellen Expansion diente: im Jahrzehnt bis 1860 vornehmlich zum Ausbau der Infrastruktur in Großbritannien; danach floß in fast gleichem Ausmaß britisches Kapital ins Ausland 52 . Auch wenn über die genaue Gewichtung äußerer und innerer Faktoren bei der Begründung des Wachstums der britischen Wirtschaft im 19. Jahrhundert kein endgültiges Urteil gefällt werden kann, so läßt sich doch feststellen, $\mathrm{daß}$ die Interdependenz beider für das steigende Volumen des Welthandels insgesamt verantwortlich war und dabei dessen weitere Ausdifferenzierung um Großbritannien als Kern vorantrieb.

Parallel hierzu entwickelte sich ein politisch-institutioneller Rahmen, der nicht nur die wirtschaftliche Expansion Großbritanniens weiter förderte, sondern auch den Durchbruch zur Schaffung einer hegemonialen Wirtschaftsstruktur ermöglichte. Von den drei für die Argumentation dieser Studie wichtigen konstitutiven Elementen dieses Rahmens sei zunächst die besondere Bedeutung des Prinzips des Freihandels hervorgehoben. In der ersten Hälfte des 19. Jahrhunderts setzte sich bei Industriellen wie Politikern angesichts des Bevölkerungszuwachses die Einsicht durch, daß eine Ausweitung der industriellen Tätigkeit des Landes mit dem doppelten Ziel der Schaffung von Arbeitsplätzen und der Deckung dringend erforderlicher Nahrungsmittelimporte die Überwindung des auf Selbstversorgung zielenden Kolonialsystems notwendig machte. Die Beseitigung etwa von Zöllen für Agrarprodukte ermöglichte zudem den Erzeugerländern den Erwerb von Sterling zum Kauf britischer Waren und sollte insgesamt die Penetration der Auslandsmärkte erleichtern. Die Öffnung des britischen Marktes durch die einseitige Verpflichtung auf das Freihandelsprinzip versprach zum einen eine Lösung des Versorgungproblems in Großbritannien. Zum anderen schien die damit verknüpfte Aussicht auf lukrative Agrarexporte der Handelspartner Großbritanniens dem internationalen Wirtschaftsgefüge einen überzogenen Wettbewerbscharakter zu nehmen und den Weg zur Schaffung eines komplementären Systems zu ebnen, das de facto freilich den industriellen Vorsprung Großbritanniens sicherte ${ }^{53}$.

\footnotetext{
50 Der Anteil der Fertigwaren an den britischen Güterexporten zwischen 1850 und 1870 wird auf zeitweise $80 \%$ geschätzt, von denen wiederum $70 \%$ Textilien waren; schätzungsweise die Hälfte aller Ressourcen wurden in den ersten 60 Jahren des 19. Jahrhunderts den drei wichtigen Industriesektoren Fertigwarenproduktion, Bergbau und Bauindustrie zugeleitet; ca. die Hälfte aller Erwerbstätigen war in diesen drei Sektoren (30\%) und in der Landwirtschaft $(20 \%)$ beschäftigt. Vgl. Church, S. 57; McCloskey, S. 109; Ashworth, S. 19; Imlah, S. 104-107.

51 Ashworth, S. 10.

52 Church, S. 26-28, 71-75; Feinstein, Capital Accumulation.

53 Vgl. Cain/Hopkins, Political Economy, S. 476-478; Mathias, S. 266-277.
} 
Die vielleicht wichtigste Folge dieser mit Gladstones Wirtschaftspolitik zu Beginn der 1860er Jahre ihren Abschluß findenden Hinwendung zum Freihandel war der Aufstieg Londons zum finanziellen und kommerziellen Zentrum des entstehenden multilateralen Wirtschaftssystems. Das sich vergrößernde internationale Handelsvolumen bewirkte eine sogar die Fertigwarenindustrie übertreffende Wachstumsrate des „unsichtbaren Einkommens " 54 , dessen finanzielle Abwicklung die britische Metropole verstärkt in den Mittelpunkt rücken ließ. Darüber hinaus konnten nur Londons Banken die immer gröBer werdende Nachfrage nach Kapital befriedigen.

Als wichtigstes Instrument wirkte sich dabei das reibungslose Funktionieren des Goldstandards, dem zweiten hier zu erwähnenden Element des politisch-institutionellen Rahmens, fördernd auf den Fluß des Kapitalexports und die Schaffung einer stabilen monetären Ordnung aus ${ }^{55}$. Die bankenwirksame Anbindung der britischen Währung an Gold erfolgte nach den napoleonischen Kriegen, nachdem bereits ein Jahrhundert zuvor durch Isaac Newton der Goldpreis in Sterling festgelegt worden war. Dieser Schritt garantierte die Stabilität des Pfundes und erleichterte dadurch den Kapitalfluß - ein Vorteil, dessen Tragweite erst im Zusammenhang mit der oben skizzierten Ausweitung des industriellen Sektors voll sichtbar wurde: In den Jahren nach 1870, als auch die wichtigsten anderen europäischen Währungen sowie der US-Dollar die Sicherheit von festen Wechselkursen suchten, wie sie der Goldstandard bot, etablierte sich die englische Hauptstadt fest als finanzielles Zentrum und Clearinghaus des Welthandels. Von besonderer Bedeutung ist dabei das "Symbioseverhältnis“, das zwischen Goldstandard und Freihandelsprinzip bestand. Der einseitige Verzicht auf protektionistische Maßnahmen mußte zwangsläufig für Großbritanniens Wirtschaft einen erheblichen Importüberschuß bewirken, der nur durch Steigerungen des „unsichtbaren Einkommens“ aufgewogen werden konnte; ein funktionierender Goldstandard erleichterte zahlungstechnisch nicht nur die Ausweitung des Handelsverkehrs insgesamt und besonders das Wachstum des „tertiären Sektors“, sondern sorgte zusätzlich auch für hohe Einnahmen aus dem Kapitalexport ${ }^{56}$. Die Hinwendung zu Freihandel und Goldstandard sowie deren komplementärer Charakter waren zwei zentrale Voraussetzungen für die Ausdifferenzierung bislang existierender Handelsblöcke zu einem multilateralen ökonomischen System unter britischer Führung.

Das Festhalten an beiden Prinzipien und der damit verbundene Aufstieg der britischen Wirtschaft begründeten drittens eine wirtschaftsliberale Tradition, deren Laissez-faireCharakter sich zu einer politisch nahezu unangreifbaren "Apriori-Doktrin" 57 entwikkelte. Der freien Hand, die die Regierungen den Unternehmern handelspolitisch ließen, entsprach der „Automatismus“ des Goldstandards, der die Selbstregulierung des internationalen Währungsverkehrs zu gewährleisten schien. ${ }^{58}$ Positiv gewendet, sollte für jede vom Schatzamt eingeschlagene Politik der Grundsatz gelten, mögliche Eingriffe in den Wirtschaftsprozeß zu minimieren und einen ausgeglichenen Haushalt anzustreben.

${ }^{54}$ Mathias, S. 222 (Tab. VId), 225; Imlah, S. 72.

55 Vgl. zum Folgenden insgesamt Hawtrey, The Gold Standard; Ashworth, S. 163-185; Mathias, S. 321-330; Skidelsky Retreat Frem Leadership, S. 158-163; Drummond, The Gold Standard.

57 Hobsbawm, S. 230.

58 Tomlinson, Problems, S. 43. 
Staatsausgaben, so die Auffassung, besäßen weniger wirtschaftliche Dynamik als Privatausgaben, sei es in Form von Konsumgütern, sei es in Form von Privatinvestitionen, und ohne sie verlören auch Zolltarife ihre Bedeutung. Überdies war man der festen Meinung, daß das Konkurrenzverhältnis, in das eine Regierung in der Absicht, eine aktive Ausgabenpolitik zu verfolgen, mit der Industrie im Kampf um Investitionskapital unweigerlich trat, insgesamt schädigend auf das Wirtschaftsleben wirken mußte. In den Worten Gladstones: „[...] money should be left to fructify in the pocket of the tax-payer." 59

Die hier in idealtypischer Weise skizzierte ressourcenmäßige und politisch-industrielle Absicherung einer die Beziehungen der Mächte im 19. Jahrhundert prägenden Pax Britannica Oeconomica weist mithin auf zwei Charaktermerkmale hin: Die hegemoniale Stellung, die Großbritannien in wirtschaftlicher Hinsicht einnahm und deren Herausbildung im Zuge des Ausgreifens auf überseeische Märkte die militärische Überlegenheit des Landes zur See entscheidend vorantrieb, sich gleichzeitig aber auch unter dem Schirm militärischer Sicherheit vollzog, durchbrach ein bislang bestehendes System des Wirtschaftspluralismus auf der Basis einer dauerhaften Wachstums- und Expansionsdynamik. Die hegemoniale Rolle Großbritanniens bedeutete jedoch darüber hinaus, daß London zugleich Verantwortung für das Funktionieren eines jetzt komplementär ausgerichteten Wirtschaftsgefüges und innerhalb dieses Systems eine Schiedsrichterrolle übernahm ${ }^{60}$. Dieser „spätviktorianische Ausgleich“61 zwischen der britischen und der Weltwirtschaft, so die allgemeine Erwartung, werde jeden kriegerischen Konflikt aufgrund der durch die wirtschaftliche, institutionelle und militärische Vormachtstellung eines Landes abgesicherten engen Verflechtung von Staaten überflüssig machen, die sich in ihrer wirtschaftlichen Aktivität ergänzten. Umgekehrt mußte eine an Friedenserhaltung orientierte und Bündnisse daher ausschließende Außenpolitik, wie sie schließ lich in dem Schlagwort der "splendid isolation“ ihren Ausdruck fand, dieses primär auf wirtschaftlicher Sicherheit beruhende System auf diplomatischer Ebene ergänzen. Eine außenpolitische Pax Britannica war daher eine logische Folge jenes auch in Keynes noch tief verwurzelten wirtschaftsliberalen Denkens, das kriegerische Konflikte als Eingriffe in den ökonomischen Wachstumsprozeß auffaßte. Mit Hobsbawm kann man aus dieser Perspektive betrachtet für die mittelviktorianische Zeit feststellen: „All that British industry needed was peace: and there was peace." ${ }^{\text {62 }}$

\section{Weltwirtschaftlicher Strukturwandel und die Entstehung des deutsch-britischen Gegensatzes}

Die prekäre Balance eines Systems, das wirtschaftlich im wesentlichen durch Großbritanniens Doppelrolle als Importeur von Primärprodukten und Exporteur von Kapital sowie Gütern eines eng umgrenzten Industriesektors auf der einen Seite und als Bankenzentrum für die Abwicklung des Finanzverkehrs auf der anderen gewährleistet wurde,

${ }^{59}$ Zitiert nach: Bridges, S. 7. Die grundlegende Studie über den Entstehungsprozeß dieser haushaltstechnischen Orthodoxie innerhalb des Schatzamts bietet immer noch Rosevaere, besonders S. 138-151, 186-234. Zum Kontinuitätsproblem in diesem Zusammenhang vgl. Middleton, besonders S. 50-52, 62-65. Vgl. auch Hennessy.

60 Vgl. Mathias, S. 230.

${ }^{61}$ Ashworth, S. 305.

62 Hobsbawm, S. 232; ähnlich auch Rostow, S. 204. 
mußte jedoch im Falle einer Veränderung des äußeren ökonomischen Operationsfeldes in Gefahr geraten. Gerade die starke Spezialisierung auf wenige Sektoren der exportorientierten Industrie und die daraus resultierende Abhängigkeit vom Verkauf von Textilien, Kohle und Maschinen sowie von den Einkünften der britischen Handelsflotte bedingte eine besondere Anfälligkeit der britischen Wirtschaft und ließ nicht nur Pessimisten befürchten, daß die erfolgreichen Industrien des 19. Jahrhunderts „the gasping dinosaurs of the twentieth “63 werden könnten. Überdies mußte sich dann auch das für die Pax Britannica Oeconomica charakteristische Merkmal der Trennung von Industrie und Finanzen als nachteilig erweisen, insofern notwendige Maßnahmen zur Modernisierung im Inneren durch die weiter steigende Nachfrage nach britischem Investitionskapital im Ausland erheblich gebremst wurden ${ }^{64}$. Was aber, so mußte man mit Blick auf Großbritanniens Rolle als Gleichgewichtshalter im europäischen Mächtesystem fragen, würde passieren, wenn das defensive Moment der britischen Politik der Friedenssicherung sich in der Folge der zweiten industriellen Revolution zu einem retardierenden Moment entwickelte? Würde dieser neuerliche Industrialisierungsschub nicht insbesondere bei Großbritanniens wichtigsten Wirtschaftskonkurrenten erheblich größere wirtschaftliche Beschleunigungskräfte freisetzen? Und würde die daraus resultierende Zunahme des Außendrucks nicht genau jene wirtschaftliche und politische Vormachtstellung des Königreichs gefährden, die zuallererst Motor und Garant der Industrialisierungsmöglichkeit dieser aufstrebenden Staaten war? Stellte schließlich eine Veränderung des wirtschaftlichen Umfeldes nicht auch die bestehenden außenpolitischen (Bündnisfreiheit, Nicht-Intervention) und außenwirtschaftspolitischen (Freihandel, Goldstandard) Grundsätze in Frage, so daß eine offensive Rolle Großbritanniens im Mächtekonzert erforderlich würde?

Tatsächlich vollzog sich in den letzten 40 Jahren vor Ausbruch des Ersten Weltkrieges ein gewaltiger ökonomischer Wandlungsprozeß, in dessen Verlauf der Vorsprung der britischen Wirtschaft von den aufstrebenden Wirtschaftsmächten nicht nur wettgemacht werden konnte; in bestimmten Sektoren gelang es ihnen sogar, eine Führungsposition zu erlangen. Der Vorsprung Großbritanniens begann sich langsam in eine strukturelle Unterlegenheit gegenüber den wichtigsten Marktkonkurrenten zu verwandeln. Die angesprochene Konzentration auf die „alten“ Industrien, ergänzt durch die steigende Bedeutung von „invisible earnings“ und Kapitalexporten, führte zu einem Industrialisierungsschub anderer Länder in jenen Sektoren, die binnen kurzem die internationale Nachfrage dominieren sollten. Auch das Schwergewicht industrieller Innovation, etwa im Transportwesen, in der Elektrotechnik und der Chemie, verlagerte sich mehr und mehr zugunsten der aufsteigenden Mächte USA und Deutschland.

Doch war es nicht nur die sich wandelnde Nachfragestruktur im internationalen Handel, die die britische Exportindustrie auf lange Sicht weniger wettbewerbsfähig machte. Auch eine schärfere Konkurrenz in den traditionellen Produktionszweigen, oftmals flankiert von umfassenden protektionistischen Maßnahmen, die die Wirtschaftsbeziehungen der Länder untereinander zu beherrschen begannen, während Großbritannien sich zur Beibehaltung des Freihandelsprinzips gezwungen sah, verschlechterten die britischen Exportchancen drastisch. Zum gleichen Zeitpunkt wurde die Abhängigkeit von

${ }^{63}$ Mathias, S. 231.

${ }^{64}$ Vgl. Cain/Hopkins, Political Economy, S. 481-484. 
Importen immer offensichtlicher ${ }^{65}$, und die steigende Nachfrage nach Auslandswaren ließ die Schere in der Außenhandelsbilanz immer weiter auseinandergehen. Hinzu kam, $\mathrm{da} ß$ in Großbritannien die Entwicklung der neuen Industrien nicht schnell genug voranschritt, um den Positionsverlust der alten auszugleichen, es den alten Industrien aber wiederum an ausreichender Innovationskraft mangelte, um notwendige Modernisierungen durchzuführen oder doch wenigstens genügend Investitionskapital anzuziehen ${ }^{66}$. Im Rückblick stellte das Committee on Commercial and Industrial Policy after the War unter Lord Alexander H. B. Balfour während des Ersten Weltkrieges zum Schrecken der Schutzzollbefürworter fest, daß die britische Industrie es nicht verstanden hatte, rechtzeitig und ausreichend insbesondere in die neuen Industriezweige zu investieren ${ }^{67}$.

Die Folgen dieser strukturellen Veränderungen werden jedoch erst vor dem Hintergrund der enormen Ausdehnung des Welthandels ermeßbar, die sich vor dem Ersten Weltkrieg vollzog und zu völlig neuen und weiter ausdifferenzierten Wirtschaftsverflechtungen führte: Allein zwischen 1900 und 1913 verdreifachte sich das internationale Handelsvolumen. Angesichts der erwähnten Handicaps der britischen Industrie mußte diese Ausweitung zu erheblichen Verschiebungen in der Rangfolge der europäischen Volkswirtschaften führen, die den weitaus größten Teil des Welthandels auf sich vereinigten $^{68}$. Innerhalb eines allgemeinen zyklischen Aufwärtstrends seit den neunziger Jahren des ausgehenden 19. Jahrhunderts konnte vor allem das Kaiserreich außerordentliche Wachstumsraten verzeichnen. Die deutsche Wirtschaft holte nicht nur im Bereich der Auslandsinvestitionen auf. Vor allem die im Vergleich zu Großbritannien größeren Steigerungsraten, etwa in der Industrieproduktion und der Exportwirtschaft, sowie der wachsende Anteil der deutschen Handelsflotte am internationalen Frachtaufkommen, das bis dahin eine feste britische Domäne gewesen war, hatten zur Folge, daß das Deutsche Reich in den wichtigen Märkten West- und Südosteuropas sowie Südamerikas eine dominante Position aufbauen konnte ${ }^{69}$. Dabei lag das Schwergewicht der Exporte deutlich auf den expandierenden Industrien (Elektro- und chemische Industrie, Maschinen, Fahrzeuge), während die niedrigeren britischen Zuwachsraten weitgehend auf den Exporten der weiterhin kontrahierenden Sektoren (Textilindustrie) basierten. Ein besonders wichtiges Merkmal dieser Entwicklung ist die Tatsache, daß trotz der bereits erwähnten Trennung von Industrie und Finanz in Großbritannien die Harmonisierung von Waren- und Kapitalexporten der deutschen Wirtschaft im Hinblick auf die handelspolitische Penetration der genannten Regionen weitaus besser gelang und dadurch stärkere Abhängigkeiten aufgebaut werden konnten, als dies London möglich war.

${ }^{65}$ So stieg der Anteil der Fertigwaren an den Importen zwischen 1870 und 1914 von $15 \%$ auf $20 \%$ (1850: 7\%); daneben gewannen Nahrungsmittelimporte eine besondere Bedeutung: 1913 wurden 40\% des Fleisch- und $55 \%$ des Getreidebedarfs importiert. Im Vergleich hierzu fiel die Steigerungsrate für Exporte insgesamt in der zweiten Hälfte des 19. Jahrhunderts von 5,7\% (1859) auf 0,4\% (1900); erst im Jahrzehnt vor Ausbruch des Ersten Weltkrieges konnte nach und nach wieder eine Wachstumsrate von 5,4\% erreicht werden. Vgl. Mathias, S. 223 (Tab. VIg), 232, 292 (Tab. X).

${ }^{66} \mathrm{Vgl}$. ebenda, S. 234.

${ }^{67}$ Gebele, S. $179 f$.

${ }^{68} \mathrm{Vgl}$. zur Rolle Europas in der Weltwirtschaft zusammenfassend Schmidt, Der europäische Imperialismus, S. 31-44. Vgl. dort auch das Folgende.

${ }^{69} \mathrm{Vgl}$. dazu und zum Folgenden die Angaben in: ebenda, S. 37-43. 
Der Impetus, den die Weltwirtschaft insgesamt durch den überwiegend mit britischem Kapital finanzierten zweiten Industrialisierungsschub im letzten Drittel des 19. Jahrhunderts sowie durch die sich daran anschließende Explosion des Welthandels in den beiden Jahrzehnten vor Ausbruch des Ersten Weltkrieges erhielt, mußte den internationalen Wirtschaftsbeziehungen zwangsläufig wieder ein stärkeres pluralistisches Gepräge verleihen. Diese Entwicklung ließ schließlich auch den Wettbewerbsaspekt im Gegensatz zum bisher vorherrschenden komplementären Charakter erneut in den Vordergrund rücken. Der Prozeß der Industrialisierung ist kein Nullsummenspiel ${ }^{70}$. Vielmehr zeigte sich, "that no country could permanently maintain a current account surplus and that economic hegemony, through the burdens it assumed, would ultimately become self-destructive“ ${ }^{\text {"71. }}$. Unter dieser Bedingung ließe sich nicht zuletzt mit Blick auf die weitere Entwicklung in der Zwischenkriegszeit und nach Beendigung des Zweiten Weltkrieges formulieren, daß die jeweils führende Wirtschaftsmacht die Spielregeln zwar bestimmen und im Falle Großbritanniens auch als ihr Schiedsrichter fungieren kann. Relative Verschiebungen im wirtschaftlichen Machtgefüge können jedoch dazu führen, daß aufsteigende Länder eine Angleichung des Wirtschaftssystems an ihre Interessen anstreben. Dies kann etwa dann eintreten, wenn sich eine solche Macht durch das bestehende Regelwerk in seinem Drang behindert fühlt und eine "gerechtere" Ordnung verlangt. Sie kann sich aber auch aufgrund ihrer Wirtschaftskraft aus dem System zurückziehen und versuchen, andere Länder in ihrer Abhängigkeit in einem Akt permanenter Regelverletzung an sich zu binden. In beiden Fällen entstünde eine neue Wirtschaftsordnung, entweder auf der Basis der neuen Machtverhältnisse oder als geschlossene Wirtschaftsräume ${ }^{72}$. In diesem Sinne unterschied sich auch der „neue “ Pluralismus vom Wirtschaftssystem der Zeit vor den napoleonischen Kriegen radikal durch den Einfluß, den das 19. Jahrhundert als das Jahrhundert des Bürgertums und des damit verbundenen Aufstiegs des Nationalstaats auf das Wirtschaftsleben ausübte. Ökonomische Aktivitäten wurden mehr und mehr von politischen Untertönen durchsetzt; ihr konkurrenzwirtschaftlicher Charakter stellte eine fundamentale Bedrohung der britischen Ressourcenbasis dar, während die aufkommenden Nationalwirtschaften den politisch-institutionellen Rahmen der Pax Britannica Oeconomica zu demontieren begannen.

Diese Entwicklung hatte eine Reihe von Auswirkungen auf die Wirtschaftsbeziehungen der Staaten im 20. Jahrhundert. So ist es kein Zufall, daß seit den 1890er Jahren die Zahlungsbilanz Großbritanniens mehr und mehr die Aufmerksamkeit der britischen Ökonomen erregte. Wie bereits hervorgehoben wurde, begünstigte ein stabiler Währungskurs im wirtschaftspolitischen Verständnis der Zeit den Fluß des Kapitals und stellte daher in Zeiten einer festen Anbindung der Währung an Gold ein politisches Anathema dar. In diesem Sinne sahen die Experten in der Londoner City genausowenig wie die Entscheidungsträger im Schatzamt in der negativen Handelsbilanz, mit der das Land über weite Strecken vor dem Ersten Weltkrieg konfrontiert wurde, ein politisches Problem, da es vornehmlich darauf ankam, die Goldreserven auszubauen. Die wachsende Bedeutung der Zahlungsbilanz steht in direktem Verhältnis zum Aufstieg des National-

\footnotetext{
70 Mathias, S. 234.

${ }^{71}$ Skidelsky, Retreat From Leadership, S. 164.

72 Vgl. dazu ausführlich Block, S. 4.
} 
staats $^{73}$. Die nachlassende Konkurrenzfähigkeit der britischen Industrie mußte daher zwangsläufig den unsichtbaren Einkünften als dem Garanten einer positiven Zahlungsbilanz noch stärkeres Gewicht verleihen. Der stabilisierenden Wirkung dieses Mechanismus wirkte jedoch entgegen, daß ein Großteil der britischen Kredite zum Ausbau der Exportindustrien in den Konkurrenzländern diente. Konnte am Ende, so fragten sich immer wieder besorgte Zeitgenossen, eine mit britischem Kapital finanzierte Industrialisierung potentieller Wirtschaftsrivalen gar ein gefährliches Maß an relativer Deindustrialisierung bewirken ${ }^{74}$ ? Es war daher nur eine Frage der Zeit, bis auch das Freihandelsprinzip verstärkt Gegenstand politischer Kontroversen wurde. Denn auch wenn, wie die Free Traders betonten, die kaum bedrohte Vorrangstellung des Dienstleistungssektors und vor allem der Banken in Großbritannien den Goldfluß weiterhin sicherstellen würde, so verbarg sich aus der Sicht der Fair Traders doch hinter der positiven Zahlungsbilanz eine für die britische Industrie wenig schmeichelhafte Handelsbilanz, deren defizitäre Struktur - zwischen 1870 und 1905 verdreifachte sich die Lücke zwischen Imund Exporten ${ }^{75}$ - eine nachlassende Wettbewerbsfähigkeit vor allem gegenüber dem Deutschen Reich verriet. Aus der historischen Rückschau ist klar, daß hier eine Hypothek entstand, die fortan auch den außenpolitischen und außenwirtschaftspolitischen Entscheidungsprozeß in London belasten sollte.

Eine weitere Reaktion in Großbritannien auf die Herausbildung nationaler Volkswirtschaften ist die Gewichtung der Arbeitslosenfrage als Problem des politischen Entscheidungsprozesses. Die Herausforderung durch den internationalen Wettbewerb, der sich die britische Industrie zunehmend ausgesetzt sah, verstärkte den Schock vermeintlicher militärischer Inkompetenz im Burenkrieg und mündete in eine „Quest for National Efficiency"76. Wollte das Land seine wirtschaftliche Stellung behaupten, so mußte ein noch größerer Teil des Arbeitskräftepotentials für die Verbrauchsgüterproduktion und/ oder den tertiären Sektor mobilisiert werden. Ein großes Heer Arbeitsloser stellte zudem angesichts des anhaltenden Bevölkerungswachstums wie auch des Wohlstands, den der Wirtschaftsboom seit der Mitte der neunziger Jahre für weite Kreise brachte und der Unzufriedenheit in den sozial schwachen Gruppen wecken mußte, eine Bedrohung des sozialen Friedens im Inneren dar. Entscheidend war freilich, daß die Arbeitslosigkeit als Anliegen politischer Gruppen zwar an Bedeutung gewann, jedoch in für die Zeit typischer Laissez-faire-Manier weitgehend als soziales und weniger als wirtschaftliches Problem betrachtet wurde. Die Reform der „Poor Laws“ und die Reorganisation des Arbeitsmarktes nach der Jahrhundertwende etwa deuten auf den Vorrang sozial-administrativer Maßnahmen hin, die eine direkte Form staatlicher Intervention in den Wirtschaftsprozeß bewußt umgingen 77 . Beide Aspekte, das Verhältnis von Freihandel und Währungspolitik wie auch die Arbeitslosenfrage, sollten in der Zwischenkriegszeit zentrale Bedeutung gewinnen und einer radikalen Kritik durch Keynes unterzogen werden.

\footnotetext{
${ }^{73}$ Tomlinson, Problems, S. 33.

${ }^{74} \mathrm{Vgl}$. zusammenfassend Saul, Industrialisation and De-Industrialisation.

75 Vgl. Imlah, S. 70-75.

${ }_{76}$ Searle, besonders S. 1-53, 207-216, 235-256. Vgl. auch Ashworth, S. 250, sowie zur Bedeutung des Burenkrieges für die Entfaltung des deutsch-britischen Gegensatzes Rosenbach.

${ }_{77}$ Vgl. Tomlinson, Problems, S. 13-25, 50 f., 53 f.; Ashworth, S. 216-238, besonders S. 223-229; Rose.
} 
Als besonderes Kennzeichen der Epoche vor Kriegsausbruch, das zugleich auf den Grundwiderspruch der Pax Britannica Oeconomica hinweist, kann vor dem bisher gezeichneten Hintergrund das potentiell explosive Spannungsverhältnis gelten, das sich aus dem zeitlichen Nebeneinander von aufsteigenden Nationalwirtschaften und der stärkeren Verflechtung der internationalen Wirtschaftsbeziehungen ergibt. Mit anderen Worten: Erst die nationalistische Ausrichtung verlieh dem im Entstehen begriffenen wirtschaftspluralistischen System seine Sprengkraft. Beispielsweise war die Ablösung des sächsischen Industriezentrums durch die Ruhr nicht etwa einfach ein isolierter Vorgang, der den wirtschaftlichen Aufstieg Deutschlands markierte. Dieser Prozeß war vielmehr Teil eines Wachstumsprozesses, der auch die Reviere Belgiens, Luxemburgs und Nordostfrankreichs umfaßte und innerhalb dessen sich Abhängigkeitsverhältnisse herausbildeten, die in einer Zeit des wachsenden Nationalismus schließlich auch eine politische Bedeutung gewannen ${ }^{78}$. Nationalwirtschaftliche Orientierung und politischer Nationalismus bewirkten tektonische Verschiebungen im machtpolitischen Gefüge zugunsten des Deutschen Reichs, die den defensiven Charakter der Führungsrolle Großbritanniens durch eine offensive und dem Nationalstaatsprinzip verpflichtete Pax Germanica zu ersetzen drohten. Einem überhöhten Nationalismus kam dabei nach innen ${ }^{79}$ wie auch nach außen eine große kompensatorische Bedeutung $\mathrm{zu}^{80}$. In Großbritannien wiederum traf diese Herausforderung auf ein durch die langanhaltende zyklische $\mathrm{Ab}$ wärtsbewegung von der Mitte der siebziger bis zur Mitte der neunziger Jahre stark ausgeprägtes Krisenbewußtsein in der Bevölkerung, wie es sich besonders prononciert in der offiziellen Untersuchung der Royal Commission on the Depression of Trade and Industry widerspiegelte ${ }^{81}$. Diese Wirtschaftskrise erscheint manchem Betrachter als „Mythos"82. So zutreffend dieser Befund aus der wirtschaftshistorischen Rückschau auch ist, die Zeitgenossen empfanden jene Krise doch als „Große Depression“ und entwickelten ihrerseits Bedrohungsgefühle, die sich - durch die Dominanz deutscher Verbrauchsgüter auf dem britischen Markt bestätigt - zunehmend auf die deutsch-britische Handelsrivalität richteten ${ }^{83}$.

Auf den Gegensatz von pluralistischem und hegemonialem Wirtschaftssystem bezogen, bestanden zumindest theoretisch zwei Möglichkeiten, diesen Grundwiderspruch aufzulösen und einen Konflikt zu vermeiden. Unter Anerkennung der komplexeren Wirtschaftsverflechtung hätte London versuchen können, den Grad der internationalen Zusammenarbeit und die Rolle der Führungsmacht auf den Stand der neuen ökonomischen Interdependenz anzuheben - dies hätte vor allem die Schaffung neuer internationaler Institutionen sowie eine grundlegende Modifikation der britischen Wirtschaftspolitik insbesondere im Hinblick auf deren drei „Säulen“ Freihandel, Goldstandard und der Doktrin des ausgeglichenen Haushalts bedeutet. Umgekehrt hätte der Grad wirtschaftlicher Verflechtung auf ein Maß der internationalen Zusammenarbeit reduziert werden können, deren Steuerung noch innerhalb der Kapazität der Führungsmacht lag;

${ }_{78}$ Vgl. auch Saul, Industrialisation and De-Industrialisation, S. 6.

${ }^{79} \mathrm{Vgl}$. Wehler.

${ }^{80}$ Vgl. Mommsen, Zeitalter, passim; Skidelsky, Retreat From Leadership, S. 163 f.

81 Vgl. die Materialien und Berichte der Royal Commission on the Depression of Trade and Industry. Parliamentary Papers 1886, Bde. XXI-XXIII.

${ }^{82}$ Zusammenfassend Saul, Myth.

${ }^{83}$ Williams, Made in Germany; vgl. Gall, S. 70, 107; Hoffman; Kennedy, Rise; Buchheim. 
als Folge hiervon wäre die wirtschaftliche Entwicklung mindestens verlangsamt und wären die Erfolge der Industrialisierung in Frage gestellt worden ${ }^{84}$. Freilich: Eine wirtschaftsintegrative Lösung, die den Verschiebungen innerhalb der Wirtschaftsbeziehungen Rechnung getragen, zugleich das Nationalstaatsprinzip aber transzendiert hätte, mochte einem keynesianischen Beobachter des 20. Jahrhunderts rückschauend als ein verpaßter Ausweg erscheinen. Der Zeitgenosse erkannte darin jedoch genausowenig eine realistische Alternative wie in einer Rückkehr zum ökonomischen Status quo ante.

In der Praxis konkurrierten drei Bewegungen miteinander ${ }^{85}$. Eine erste Gruppe ging von der Unterscheidung zwischen industriellem und finanziellem Kapitalismus aus, die der Geopolitiker Halford Mackinder um die Jahrhundertwende erstmals in die Diskussion eingebracht hatte. Sie argumentierte, daß zwar die britische Exportindustrie gegenüber ihren Konkurrenten schlechter abschneide, die Nachfrage nach britischem Kapital aber immer größer werde und der Ausweg aus einer drohenden Krise daher in einer Spezialisierung des Landes auf die Finanzierung des Welthandels liege. Demgegenüber warnten etwa Kolonialminister Joseph Chamberlain und seine Tariff Reform Campaign davor, daß gerade eine Beschränkung auf die Rolle des Bankiers nur die Industrialisierung der Marktkonkurrenten vorantreibe, die überdies einen rigorosen Protektionismus verfolgten und Großbritannien langfristig vom internationalen Markt zu verdrängen drohten. Sie befürworteten die Schaffung eines autarken und in sich geschlossenen Empire-Marktes, eines nach außen geschützten „Imperial Zollverein"86. Diese Gruppe spiegelte deutlich das Eindringen nationalegoistischer Ziele auch in die öffentliche Auseinandersetzung Großbritanniens wider, und sie kann als direkte Reaktion auf die wirtschaftliche Herausforderung durch das Deutsche Reich verstanden werden ${ }^{87}$. Eine Chamberlains Intentionen völlig entgegengesetzte, nämlich „kleinenglische“ Lösung propagierte dagegen der Ökonom J. A. Hobson in seiner klassischen, 1902 erstmals erschienenen Schrift über "Imperialismus“. In diesem einflußreichen Buch bestritt der Autor die Notwendigkeit der Entwicklung überseeischer Märkte und propagierte dagegen ein Programm nationaler Selbstversorgung ${ }^{88}$. Dem Hinweis auf den Primat der innenpolitischen Entwicklung entsprach dabei seine Ablehnung des Protektionismus. Diese zunächst am Beispiel der USA entwickelte Kritik ${ }^{89}$ entfaltete er im Laufe des Ersten Weltkrieges im Kontext einer antideutschen Debatte über wirtschaftliche Kriegsziele und warnte eindringlich vor einer Politik der wirtschaftlichen Ausgrenzung

${ }^{84}$ Vgl. Skidelsky, Retreat From Leadership, S. 164. Eine weitere Möglichkeit hätte natürlich, wie skizziert, auch die Anwendung ökonomischer Macht zur bewußten Verletzung der Systemmechanismen sein können. Wie weiter unten noch zu zeigen sein wird, war die Pax Britannica Oeconomica allerdings gerade nicht durch Großbritanniens wirtschaftliche Stärke gekennzeichnet, sondern durch die Bereitschaft der übrigen Systemmitglieder, das Pfund Sterling als Leitwährung anzuerkennen. In der Zwischenkriegszeit wird erst die deutsche Wirtschaftspolitik diesen Weg einschlagen.

${ }^{85} \mathrm{Vgl}$. zum Folgenden ebenda, S. 166-168.

${ }^{86}$ So die treffende Kennzeichnung durch Hobson. Vgl. Hobson, S. 111 (dt. Ausgabe).

${ }^{87}$ Die direkte Rückführung der Zollreforminitiative auf die deutsch-britische Wirtschaftsrivalität ist die durchgängige These von Cain, Political Economy in Edwardian England.

${ }^{88}$ Hobson; vgl. dazu Schröder, Hobsons Imperialismustheorie; Cain/Hopkins, British Imperialism 1688-1914, S. $16 \mathrm{f}$. Vgl. auch Baumgart, S. 65-70, 75-78 und passim; Hampe, S. 17-25 passim, 126-129, 234-237; Mommsen, Imperialismustheorien, S. 12-19; Reifeld, S. 44f.; Rosenbach, S. $139 \mathrm{f}$.

${ }^{89}$ Mock, S. 200. 
Deutschlands. Demgegenüber trat Hobson für ein internationalistisches und kooperatives Wirtschaftssystem ein, das die Kontinentalmacht ausdrücklich einschloß und auf die Möglichkeit eines auf dem Gedanken wirtschaftlicher Sicherheit gegenüber Deutschland beruhenden Friedensmodells verwies ${ }^{90}$. Es ist anzunehmen, daß Keynes mit Hobsons Ideen über dessen publizistische Arbeit für die Union of Democratic Control und die New Republic, für die auch Keynes gelegentlich Beiträge lieferte, kannte ${ }^{91}$.

Alle drei Positionen bedeuten einen Bruch mit Großbritanniens außenwirtschaftspolitischer Tradition. Sie waren Versuche, den genauen Stellenwert des Landes angesichts des sich verändernden internationalen Mächtegefüges neu zu orten. Lediglich Hobsons dezidiert antiimperialistische Position ging dabei von der Annahme aus, daß ein - wie stark auch immer modifiziertes - Festhalten am imperialen Status des Königreichs, d. h. ein Einlassen auf ein Tauziehen um Macht und Märkte, einen weiteren Positionsverlust kaum verhindern werde, während die beiden anderen Gruppen durch die Aufrechterhaltung mindestens einer Traditionslinie - der finanztechnischen oder der imperialen auf der Kontinuität des Großmachtstatus beharrten. Im Gegensatz zu Hobsons kaum durchsetzbaren Ideen besaßen letztere damit einen Berührungspunkt, der schließlich den Ausschlag gab für die Herausbildung eines außenpolitischen Konsenses und der die Aufmerksamkeit Großbritanniens verstärkt auf eine ökonomische Expansionsbewegung nach Übersee lenkte.

Die Austauschbeziehungen zwischen Großbritannien und den übrigen führenden Industrienationen, die sich aus konkurrenzwirtschaftlichen und protektionistischen Gründen immer schwieriger gestalteten, ließen ein Ausweichen auf überseeische Märkte dringend erforderlich erscheinen. Dabei kam nicht nur der Konsolidierung der Absatzgebiete des bestehenden formellen wie informellen Empire eine überragende Bedeutung zu. Die Aussicht auf eine koloniale Expansion nach Afrika sowie die Erweiterung des Einflußbereiches in Asien weckten darüber hinaus die Erwartung, jenes Wirtschaftswachstum - und damit die ressourcenmäßige Basis des britischen Führungsanspruchs zu sichern, das im Wettbewerb mit den aufstrebenden Industriestaaten nicht mehr länger zu erreichen war. Innenpolitisch stieß diese Lösung auf ein starkes Krisen- und Bedrohungsbewußtsein in breiten Schichten der Bevölkerung. Daß sie sich zu einem außenpolitischen Konsens innerhalb der Führungseliten entwickeln konnte, lag freilich daran, daß sie paradoxerweise den Interessen sowohl der Anhänger einer Vision von Großbritannien als unangefochtenem Bankier der Weltwirtschaft als auch der Fair Trade-Bewegung entsprach.

Für die erste Gruppe besaß die Idee eines „formellen Imperialismus“, die im Gegensatz zur rein handelspolitischen Penetration auch auf die Durchsetzung politischer Herrschaft in den überseeischen Regionen abzielte, ohne Frage insofern eine gewisse Attraktivität, als sie andernfalls unabwendbare und kapitalintensive Modernisierungsmaßnahmen der britischen Industrie ersetzte durch die Aussicht auf neue Absatzmöglichkeiten. Der Stellenwert der alten Industrien, und damit die strukturelle Dominanz des Dienstleistungssektors, blieb erhalten ${ }^{92}$. Zugleich entsprach eine Übersee-Expansion auch den Vorstellungen jener Gruppe, die nach einer Antwort auf die nationalwirt-

\footnotetext{
${ }^{\circ}$ Vgl. Gebele, S. 187f.; Gardner, Safe for Democracy, S. 11-14.

${ }^{91}$ Gebele, S. 93 f.; Mayer, S. 337 f.

92 Vgl. Cain/Hopkins, Political Economy, S. 485-489; Reynolds, Britannia Overruled, S. $15 \mathrm{f}$.
} 
schaftliche Herausforderung durch Berlin suchte. Die Erschließung neuer Märkte befriedigte einerseits das Bedürfnis nach „imperial consolidation“; andererseits erschien sie als notwendige Maßnahme, einem deutschen, aus macht- wie aus konkurrenzwirtschaftlichen Gründen sich speisenden Kolonialismus Paroli zu bieten. Der Widerspruch, den das Balfour-of-Burleigh-Komitee 1917 konstatierte, daß unternehmerisches Fehlverhalten nicht zuletzt gerade der Industriellen unter den Zollreformern erst jene Situation geschaffen habe, die sie nun nach Handelsschranken rufen lasse, blieb dabei unbeachtet ${ }^{93}$.

Ohne die Bedeutung eines potentiell offensiven Elements in der britischen Außenbzw. Außenwirtschaftspolitik vor dem Ersten Weltkrieg, wie er etwa in der zuletzt genannten Position durchscheint, zu minimieren, bestätigt die hier bewußt erfolgte Betonung der ökonomischen und innenpolitischen Determinanten daher die These vom primär defensiven Kalkül Londons in der letzten Expansionsphase „im Sinne einer antizyklischen Wiederherstellung wirtschaftlicher Prosperität ${ }^{“ 94}$. Mit anderen Worten ließe sich ebenso die These aufstellen, daß der skizzierte „Übergang vom wirtschaftlichen Internationalismus zum Wirtschaftsimperialismus"95 Kern einer innen- und außenpolitischen Krisenstrategie Londons war. Sie war logische Konsequenz aus Überlegungen, wonach ein Positionsverlust Großbritanniens aufgehalten werden könne durch den Vorrang des Dienstleistungssektors vor einer fälligen Restrukturierung der britischen Industrie, während gleichzeitig die Schaffung neuer Märkte garantiert werden sollte. Schließlich diente sie vor dem Hintergrund eines zunehmenden Wirtschaftsnationalismus in den Mächtebeziehungen und drohender sozialer Konflikte im Inneren als notwendige Politik zur Eindämmung der zwei Gefahren, die Lloyd George als die größten für die weitere Entwicklung des Landes erkannte: „An industrial war at home - a disturbance abroad." 96

Dieser Befund wird nicht zuletzt durch die von der Forschung immer wieder hervorgehobene Zurückhaltung der britischen Regierung hinsichtlich der ökonomischen Expansionsbewegung bestätigt ${ }^{97}$. Auch wenn Whitehall wiederholt auf ökonomische Mittel zur Verfolgung außen- und sicherheitspolitischer Ziele zurückgriff - angeführt sei hier nur die Anglo-Persian Oil Company, für die man sich die Aktienmehrheit sichern konnte und deren unrühmliches Ende eine außenpolitische und wirtschaftliche Belastungsprobe in der Mitte des zwanzigsten Jahrhunderts bedeuten sollte -, so wurde dies in Geschäftskreisen eher argwöhnisch beobachtet denn begrüßt ${ }^{98}$. Insgesamt hielt der Staat an seinem nicht-interventionistischen Anspruch sowohl in innen- wie in außenpolitischen Fragen fest. Allerdings gilt auch, daß dieser Anspruch, zumindest in finanzieller Hinsicht, aufgeweicht wurde: Sowohl die Maßnahmen zur sozialen Befriedung im Inneren als auch militärische Aufrüstung und Übersee-Expansion ließen seit den 1890er Jahren die Staatsausgaben sprunghaft ansteigen und spiegelten die stärkere Rolle wider, die dem Staat im Kontext des weltwirtschaftlichen Wandels unter schrittweiser Aufgabe seiner Laissez-faire-Prinzipien zufiel ${ }^{99}$.

\footnotetext{
${ }_{93}$ Gebele, S. 180.

$94 \mathrm{Vgl}$. Meyers, Die vierte Teilstreitkraft, S. $193 \mathrm{f}$.

${ }_{95}$ Richardson, S. 130.

${ }_{96}$ Zitiert nach: Boyle, S. 433.

97 Vgl. vor allem Platt, passim.

${ }^{98}$ Schmidt, Der europäische Imperialismus, S. $61 \mathrm{f}$.

${ }_{99}$ Peacock/Wiseman, S. 35; Feinstein, Statistical Tables, Tab. 2 und 5.
} 
Diese Krisenstrategie hatte weitreichende Konsequenzen. Der wirtschaftliche Positionsverlust Großbritanniens (die sinkenden Exporte, die langsamere Wachstumsrate und mangelnde Investitionen im Land selbst) war ein wesentliches Antriebsmoment jener geographischen Expansion, die zu einer strategischen Überdehnung führte. Die relative Verschlechterung der ökonomischen Entwicklung des Landes gegenüber seinen wichtigsten Konkurrenten bei gleichzeitiger territorialer Ausdehnung führte also nicht nur zu einer immer größer werdenden Kluft zwischen militärischer Kapazität und wirtschaftlichen Ressourcen. Sie ist zuallererst auch Grund für jene koloniale Politik, die aus sicherheitspolitischer Perspektive zu einer Überdehnung führte - ein Prozeß, der schließlich das Primärziel der Friedenswahrung, jetzt allerdings nicht mehr von der Position des dominanten Gleichgewichtshalters aus, verstärkt in den Vordergrund rücken ließ. Es ist eine Ironie der Geschichte, daß jenes außen- bzw. wirtschaftspolitische Vorgehen, das unter der Perspektive der Sicherung ökonomischen Wachstums der Erhaltung des Friedens dienen sollte, eine „Überdehnung“ bzw. „Unterversorgung“ 100 begründete, die den außenpolitischen Entscheidungsprozeß in Whitehall bis weit nach dem Zweiten Weltkrieg bestimmen sollte. Die Anfänge der Dienstleistungsgesellschaft, die hinter dieser Entwicklung sichtbar werden und retrospektiv als beeindruckende Innovationsleistung erscheinen, erweisen sich bei genauerem Hinsehen hinsichtlich ihres tatsächlichen Einflusses auf den außenpolitischen Handlungsspielraum Londons vor dem Ersten Weltkrieg als Belastung. Der strukturelle Vorteil entpuppt sich als ressourcenmäßiger Nachteil, der die Optionen Großbritanniens im diplomatischen Poker unter den gegebenen Umständen de facto einschränkte und im Prozeß der Desintegration der Pax Britannica Oeconomica als Beschleunigungsfaktor wirkte. Das außenpolitische Konfliktverhalten Großbritanniens vor wie nach dem Ersten Weltkrieg ist deshalb mit dem Hinweis auf einen zweiten „Frühstart“ in Richtung Dienstleistungsgesellschaft nur bedingt zu erklären ${ }^{101}$. Vielmehr muß betont werden, daß der britische Imperialismus als ein nach außen gerichteter Konsens zwischen den beiden Elitegruppen der "Finanziers“ und der Zollreformer verstanden werden muß. Der Hinweis, daß die überseeische Expansion de facto wirtschaftlich wenig profitabel gewesen sei und als Antriebsmoment deshalb nur eine geringe Rolle gespielt habe, kann deshalb vernachlässigt werden. Nicht die tatsächlich erzielten Gewinne waren ausschlaggebend; die wirtschaftliche Bedeutung der neuen Märkte lag vielmehr „first, in the promise of relatively protected investment opportunities and second, in the promised relief for social and economic pressures at home“ ${ }^{102}$. Gerade das Ausbleiben einer ausreichenden Gewinnmarge war schließlich dafür verantwortlich, daß es in der britischen Außen- und Sicherheitspolitik zu jener Kluft zwischen den militärischen Verpflichtungen und den zu deren Erfüllung zur Verfügung stehenden wirtschaftlichen Rohstoffen kam.

\footnotetext{
100 Walker, S. 221.

${ }^{101}$ So Mommsen, Entwicklung; ders., Two Centuries; ders., Britain and Germany; Saul, Industrialisation and De-Industrialisation.

${ }^{102}$ Pollard, S. 12. (Hervorhebungen M. P.)
} 


\section{Exekutionsaufschub: Appeasement}

Angesichts dieser Auflösungstendenzen im politischen und wirtschaftlichen Mächtesystem war das Hauptproblem nach dem Ersten Weltkrieg denn auch weniger, die zyklischen Abwärtsbewegungen umzukehren und den wirtschaftlichen Produktionsprozeß unter Friedensbedingungen wieder anzukurbeln. Grundlegender war die Frage, ob die notwendige Neuordnung des Mächtesystems gelingen würde, zumal der Krieg jene Instabilität der internationalen monetären und handelspolitischen Wirtschaftsbeziehungen noch verschärfte, die bereits für die Zeit vor 1914 kennzeichnend gewesen war. Dieser Grundkonflikt lag schließlich auch der Versailler Friedenkonferenz zugrunde: Von der hier zu treffenden Friedensregelung, d. h. letztlich von der Frage der Behandlung Deutschlands, mußte das Gelingen oder Scheitern eines Nachkriegssystems abhängen. Gleichzeitig war die Entscheidung zu treffen, ob die Friedensregelung von einer Rückkehr zum ökonomischen und machtpolitischen Status quo ante oder aber von einer Anpassung des internationalen Mächtesystems an den neuen Grad monetärer und handelspolitischer Interdependenzen flankiert werden sollte.

\section{Finanz- und wirtschaftspolitische Anpassungsprobleme nach 1918}

Insgesamt verstärkte der Erste Weltkrieg den Strukturwandel sowohl des Arbeitsmarktes als auch in Industrie und Handel. Auch der Staat spielte seine im Krieg ausgebaute Rolle als wirtschaftspolitischer Akteur weiter. Zwar hatte das Schatzamt noch in den ersten Monaten nach Ausbruch der Kriegshandlungen geglaubt, daß man die Sicherstellung wichtiger Kriegsmaterialien dem Kräftespiel des freien Marktes und den Gesetzen von Angebot und Nachfrage überlassen könne ${ }^{103}$; die Erfordernisse eines Weltkrieges in bisher noch nie dagewesenem Ausmaß führten jedoch zur Erlassung umfassender Gesetze $^{104}$, die der britischen Regierung weitreichende Vollmachten zur Kontrolle der Produktion an die Hand gaben und die mit dem steten Anstieg der Staatsausgaben in den Jahrzehnten vor 1914 bereits angedeutete Ausweitung der Rolle Whitehalls konsequent vorantrieben. In gleicher Weise rückten die Veränderungen auf dem Arbeitsmarkt die Aspekte des inneren sozialen Friedens weiter in den Vordergrund. Die starke Berufstätigkeit der Frauen und das steigende Interesse der Öffentlichkeit an den Arbeitsbedingungen vor Ort (Arbeitszeiten, Verpflegung, Arbeitsplatzsicherheit etc.), das sich etwa in einer dramatischen Ausweitung der Gewerkschaftsbewegung äußerte, führten schließlich mit dem Jahreswechsel 1916/17 zur Schaffung der Arbeits- und Ernährungsministerien durch die neue Regierung unter Lloyd George, der dann 1919 u. a. die Einrichtung des Gesundheitsministeriums sowie des „Medical Research Council“ folgte ${ }^{105}$. Darüber hinaus beschleunigte der Krieg die technologische Ausdifferenzierung des Produktionsprozesses und intensivierte damit die Modernisierungstendenzen, welche bereits die Industrie der Vorkriegsjahre bestimmt hatten. Als Folge dieser Entwicklung

${ }^{103}$ Lloyd, S. 6-65, 206f., 259-269. Diese Haltung wurde knapp und präzise durch das von Churchill geprägte Schlagwort vom "business as usual“ beschrieben. Vgl. Hurwitz, S.62f.; Mai, S. 34-38; French. Vgl. zusammenfassend Pollard, S. 19-30.

${ }^{104}$ Lloyd, S. 50-65.

${ }^{105}$ Pollard, S. 38-47; Milward, S. 16 ff., 38-40. 
stieg die Nachfrage vor allem nach ungelernten Arbeitern, die sowohl für die neuen Industrien Bedeutung erlangen sollten als auch zur Bedienung effizienterer Maschinen in den alten Industrien ihren gelernten Kollegen vorgezogen wurden („dilution“) ${ }^{106}$. Es konnte nicht ausbleiben, daß diese Veränderung des inneren Sozialgefüges in Großbritannien zu weitverbreiteten Streiks vor allem in den letzten 2 bis 2 1/2 Jahren des Krieges führte und eine Stimmung schuf, in der sich die Aussicht auf einen militärischen Sieg mit der Hoffnung auf verbesserte soziale Lebensbedingungen verband.

Das Handelsministerium trug dieser Entwicklung schon sehr früh Rechnung, indem es bereits fünf Monate nach Kriegsausbruch in einem Memorandum auf Diskussionen über ein mögliches Arbeitslosenproblem bei der Anpassung des Arbeitsmarktes an die Erfordernisse einer Friedenswirtschaft hinzuarbeiten begann ${ }^{107}$. Mehr schien allerdings gefordert, als mit der russischen Oktoberrevolution die Gefahr sozialer Unruhen auch in Großbritannien wuchs. Die sich wandelnde Rolle der Regierung und die steigende Bedeutung sozialer Aspekte in der Innenpolitik manifestierten sich schließlich in Lloyd Georges Sieg bei den Parlamentswahlen im Dezember 1918. Im Vorfeld dieser Wahlen hatte er bereits Anfang des Jahres mit einer in enger Fühlung mit der Arbeiterbewegung entstandenen Kriegszielrede die soziale Konfliktlage zu entschärfen versucht und war mit dem Versprechen umfassender Maßnahmen zur Reform des Gesundheitswesens sowie des Arbeits- und Wohnungsmarktes angetreten ${ }^{108}$. Der Wahlerfolg der liberal-konservativen Koalition stellte den vorläufigen Schlußpunkt einer Entwicklung dar, die vor dem Krieg mit den noch unter überwiegend sozial-administrativen Gesichtspunkten formulierten Sozialreformen begonnen hatte ${ }^{109}$. Gleichzeitig spiegelte er die Herausforderung von Großbritanniens innerer Reformfähigkeit wider: Hatten ein steigender Wettbewerbsdruck und die Herausbildung eines nationalwirtschaftlich geprägten Mächtesystems schon vor 1914 die soziale Lage der Bevölkerung notgedrungen zu einem wichtigen Anliegen der Regierung gemacht, so rückte sie nach dem Großen Krieg, dessen materielle Entbehrungen die Erwartung förderten, daß die Beseitigung sozialer Mißstände nicht mehr länger ausschließlich der Selbstregulierung des freien Marktes anvertraut werden könne, vollends ins Zentrum regierungsamtlicher Aufmerksamkeit.

In der Folge des Ersten Weltkrieges setzte sich der Vorkriegstrend zu einer stärker introspektiv orientierten Sozial- und Wirtschaftsordnung schließlich auch im industriellen Bereich fort. Der Umfang des Welthandels lag in den ersten Friedensjahren erheblich unter dem Vorkriegsniveau. Die kriegsbedingte Unterbrechung des Handelsverkehrs der europäischen Länder mit ihren überseeischen Handelspartnern führte zu einer Schwerpunktverlagerung der Austauschbeziehungen zugunsten der aufstrebenden Mächte USA und Japan. Die erzwungene Abstinenz der europäischen Staaten auf dem Weltmarkt wirkte zugleich als Impetus für verstärkte Industrialisierungsbemühungen ihrer Handelspartner, die dadurch ihre wirtschaftliche Unabhängigkeit weiter ausbauen konnten. Der zur Kriegsfinanzierung notwendig gewordene Abbau von Kapitalinvestitionen in den Überseegebieten verminderte zusätzlich eine Einflußnahme auf die internationale Handelsstruktur. Am Ende war ein Rückgang des europäischen Anteils am

\footnotetext{
106 Pollard, S. 47; Milward, S. 37f.; Wendt, War Socialism, S. 130-133.

${ }_{107}$ Beveridge, S. $136 \mathrm{f}$.

108 Vgl. Mommsen, Entstehung; Abrams.

109 Vgl. den Überblick bei Peter, Britische Kriegsziele.
} 
Welthandel unabwendbar ${ }^{110}$. Ließ diese Entwicklung an sich schon Anpassungsprobleme für die britische Wirtschaft befürchten, so wurde sie weiter negativ beeinflußt durch die Veränderungen in der Nachfragestruktur der Weltwirtschaft. Der enorme Technologieschub zugunsten der neuen Industrien, den der Weltkrieg verursachte, beschleunigte den Verfall traditioneller britischer Exportmärkte. Die Gefahr einer rasch um sich greifenden Inflation und die Knappheit an lang- und kurzfristigen Krediten für den Wiederaufbau schmälerten überdies die Chancen für eine erfolgreiche Rückgewinnung der alten handelspolitischen Stellung Europas; auch Londons Potential als internationales Bankhaus war aufgrund substantieller US-Kredite während des Krieges empfindlich geschwächt worden und hatte Großbritannien in das allgemeine Schuldennetz eng verstrickt ${ }^{111}$. Diese Faktoren förderten die Tendenz zu einer stärkeren Fixierung der britischen Wirtschaft nach dem Ersten Weltkrieg auf den Binnenmarkt.

Die Versailler Friedenskonferenz fand also in einer Periode wirtschaftlichen und sozialen Wandels statt, der durch den Weltkrieg keinesfalls ausgelöst worden war, auch wenn es den meisten Zeitgenossen so erscheinen mochte, durch ihn jedoch eine neue Qualität erhalten hatte und für Großbritannien als dem Garanten der alten Ordnung mehr als für jedes andere Land besondere Konsequenzen haben mußte. Der Prozeß der Aufgabe des Freihandelsprinzips, des Goldstandards sowie des Prinzips der wirtschaftspolitischen Enthaltsamkeit der Regierung fiel zusammen mit der Krise der britischen Exportwirtschaft, einem hohen Grad an Arbeitslosigkeit sowie wachsender Instabilität des internationalen ökonomischen Systems. Hinzu kam, daß durch die wachsende internationale Konkurrenz und den Verlust traditioneller britischer Exportmärkte der Binnenmarkt als Feld wirtschaftlicher Aktivität an Bedeutung zunahm. Während daher vor 1914 die zyklischen Bewegungen der britischen Wirtschaft vor allem durch die Entwicklung der internationalen Märkte bestimmt waren und zu einer Konzentration der Investitionen auf die exportintensiven traditionellen Sektoren der Industrie führten, sollten in den Zwischenkriegsjahren vor allem interne Bewegungen den Wirtschaftskreislauf dominieren 112. Der Große Krieg wirkte aus dieser Perspektive betrachtet als Veränderungsbeschleuniger, der die ökonomischen und sozialen Triebkräfte im Inneren unwiderruflich in den Bereich des Politischen katapultierte. Der daraus resultierende Anpassungsdruck zwang die zuständigen Regierungsstellen zur aktiveren Übernahme von Verantwortung in allen sozialen und wirtschaftlichen Belangen und stellte das traditionelle Verhältnis von außen- und innenpolitischen Interessen in Frage.

So offensichtlich der Zwang zu umfassenden Reformmaßnahmen aus der Rückschau freilich erscheinen mag, ihre Realisierung traf auf ein weitverbreitetes Bedürfnis nach einer Rückkehr zur vermeintlichen Stabilität der Vorkriegszeit ${ }^{113}$. Obwohl London das Pfund Sterling im März 1919 frei konvertibel machte, war doch von Beginn an klar, daß

\footnotetext{
${ }^{110} \mathrm{Vgl}$. Svennilson, S. 20-24, $169 \mathrm{f}$.

111 Großbritannien hatte rund $£ 350$ Millionen mehr an Krediten an seine Alliierten vergeben, als es selbst an Anleihen während des Krieges aufnahm. Die amerikanischen Dollars flossen also indirekt über London an die Kriegsgegner des Deutschen Reichs, während Großbritannien im wesentlichen auf seine eigenen Ressourcen zurückgriff. Zwar hatte London damit seine Stellung als Clearing-Stelle behauptet, die dahinterstehende Führungsrolle als Finanzmacht aber de facto an die USA abgegeben. Vgl. Pollard, S. 37 f.; Burk, Britain, S. 265.

112 Vgl. dazu die Beiträge bei Buxton/Aldcroft (Hrsg.).

${ }^{113}$ Vgl. Robinson, What Has Become of the Keynesian Revolution?, S. 123.
} 
das langfristige Ziel nur die Wiederherstellung des Wirtschaftssystems des 19. Jahrhunderts sein würde. Sichtbarster Ausdruck dieser Haltung war der Report des Cunliffe Committee, das, unter den Auspizien des Schatzamtes und des neugegründeten Wiederaufbauministeriums arbeitend, 1918 die unverzügliche Rückkehr zur Goldparität empfahl114. Dabei spielte jedoch nicht nur die Überzeugung von der für Großbritannien vorteilhaften Wirkung des Goldstandards eine Rolle, welche die Wirtschaftspolitiker und Bankleute jener Generation aufgrund ihrer Erfahrungen vor dem Krieg beherrschte. Eine Rückkehr zur Sicherheit der Vorkriegszeit entsprach auch dem psychologischen Bedürfnis jener Zeit nach Überwindung eines allgemeinen Gefühls der Entwurzelung und Unsicherheit: "The prewar gold standard, symbol of a liberal capitalist order which had just hurled back the challenge of Prussian imperialism and was menaced by the specter of working-class revolution, provided that stability. The old bankers' internationalism now comingled with the transatlantic current of Wilsonian idealism, as embodied in the League of Nations." 115 Hinzu kam, daß die Weigerung der USA, das Konzept der kaum noch lebensfähigen Pax Britannica Oeconomica zu unterstützen, den Anpassungskonflikt Großbritanniens noch verschärfte, dessen Traditionen und intakter institutioneller Rahmen trotz der Erschütterungen des Krieges den Fortbestand Londons als finanzpolitisches Zentrum zu gewährleisten schienen. Daß diesem institutionellen Rahmen längst die wirtschaftliche Grundlage entzogen war, fiel dabei nicht ins Gewicht, da das Funktionieren der internationalen monetären Ordnung der Vorkriegszeit bezeichnenderweise zu keinem Zeitpunkt auf Großbritanniens wirtschaftlicher Überlegenheit beruhte, sondern vielmehr auf der Bereitschaft anderer Goldstandardländer, das Pfund Sterling als Leitwährung zu benutzen ${ }^{116}$. Demgegenüber basierte umgekehrt der steigende Einfluß der USA auf die Entwicklung des weltwirtschaftlichen Fundaments nach dem Ersten Weltkrieg nicht auf der weiten Verbreitung des Dollars, sondern vielmehr auf der herausragenden wirtschaftlichen Vormachtstellung des Landes sowie auf dem Umfang seiner Goldvorräte. Diese Umkehrung der monetären Grundlagen ließ, wie der Cunliffe-Report zeigte, in Whitehall-Kreisen eine Politik der Rückkehr zur Goldparität als alternativlos erscheinen, machte aber die USA zu einem finanzpolitischen Elefanten im Porzellanladen der Weltwirtschaft ${ }^{117}$.

Der Konflikt zwischen Aufbruchstimmung und Nostalgiegefühl beherrschte aus Keynes' Blickwinkel auch die britischen Politiker bei der Versailler Konferenz. Der Innenbezogenheit, die sich für ihn in einer "harten“ Reparationsregelung sowie generell in der von nationalegoistischen Zielen geprägten Verhandlungstaktik ausdrückte, entsprach dabei die Lösungssuche entlang der Mechanismen der alten Ordnung. Dieses Vorgehen äußerte sich für ihn am sichtbarsten in der Unfähigkeit, eine Friedensordnung

\footnotetext{
114 Vgl. First Interim Report, S. 11. Vgl. auch Final Report.

115 Skidelsky, Retreat From Leadership, S. 169.

116 Im Gegenteil, man hat zu Recht auf die merkwürdige Diskrepanz hingewiesen, die zwischen Großbritanniens Führungsrolle als Bankier des Welthandels und seiner relativen industriellen Schwäche bestand: So machte der britische Anteil am Welthandel im Jahre 1913 lediglich noch $13 \%$ aus. Trotzdem war London zunächst noch in der Lage, nicht nur die eigene Währung zu dominieren, sondern gleichzeitig die internationalen Kreditbeziehungen unangefochten zu steuern. Vgl. Cleveland, S. 16f., 18-22; Ashworth, S. 343. Auch Keynes scheint diesen Zusammenhang gesehen zu haben; vgl. JMK VI, S. 274 ff.

117 Cleveland, S. 40-44.
} 
auf der Grundlage einer den Verfall des hegemonialen Weltwirtschaftssystems berücksichtigenden internationalen Kooperation unter Einschluß Deutschlands, der Schaffung neuer Kreditquellen und der Schuldentilgung anzustreben. Es wird auch verständlich, warum Keynes nach der Ablehnung seines "Grand Scheme“ durch die Amerikaner Präsident Wilson zu einer besonderen Zielscheibe seiner Attacken machte und ihn als „a fallen hero" betrachtete ${ }^{118}$. Die Haltung Washingtons mußte nicht nur den europäischen wirtschaftlichen Wiederaufbau erheblich erschweren, sondern zugleich den Handlungsspielraum der britischen Regierung zur Durchführung von Anpassungsmaßnahmen beträchtlich einengen. Das Versailler Friedenssystem erschien Keynes nicht einfach als Versuch zu ökonomischer Restauration, sondern stand vielmehr für eine Tendenz zur Modernisierungsverweigerung bei den wirtschaftlichen und politischen Entscheidungseliten Großbritanniens. Schlagendes Beispiel hierfür war für Keynes Lord Cunliffe, der nicht nur die Rückkehr zur Goldparität vorbereitete, sondern als Mitglied des Reparationskomitees des Kabinetts und britischer Delegierter in der Reparationskommission in Versailles für die Durchsetzung harter Reparationsbedingungen eintrat. Er betrachtete den Hardliner als Zugeständnis Lloyd Georges, der damit seine Wiederwahl im Dezember 1918 habe sichern wollen ${ }^{119}$. Anstatt eine Grundlage für die Reorganisation der durch wirtschaftspluralistische Zentrifugalkräfte bedrohten internationalen monetären Ordnung sowie für dringend erforderliche Reformmaßnahmen der britischen Wirtschaft zu schaffen, zementierten orthodoxe Ministerialbeamte vom Schlage Cunliffes die durch den Weltkrieg verschärften Krisentendenzen der spätviktorianischen Epoche. Für Keynes stellten die Versailler Verträge also nicht einfach eine verpaßte Chance dar; sie schrieben die strukturellen Defizite des Weltwirtschaftssystems, die Großbritanniens ökonomische und machtpolitische Stellung gefährdeten, in die Nachkriegszeit fort und würden daher mit großer Wahrscheinlichkeit aus außenwirtschaftlicher Perspektive zur Erhöhung der inneren und äußeren Bedrohung des Landes beitragen. Versailles steigerte die Krise der internationalen Wirtschaftsordnung zur Dauerkrise.

Der Unfähigkeit, zur Entschärfung der äußeren Krisenpotentiale eine strukturadäquate Friedensordnung zu schaffen, entsprachen die Versäumnisse hinsichtlich der inneren Entwicklung Großbritanniens, der sich Keynes' Aufmerksamkeit nach seiner Rückkehr aus Paris verstärkt zuwandte. Hatte er in den „Economic Consequences“ das außenwirtschaftspolitische Bezugsfeld einer eingehenden kritischen Analyse unterzogen, so attackierte er in der Folgezeit vor allem die orthodoxe wirtschaftspolitische Einstellung seiner Umgebung. Dabei blieb seine damals entwickelte Doppelkritik am Prinzip nationalwirtschaftlicher Interessenpolitik und am naiven Glauben an eine Rückkehr zur vermeintlichen Sicherheit einer Pax Britannica Oeconomica maßgebend und bildete daher zugleich den Ausgangspunkt für seine eigene Theoriebildung. Beide Sichtweisen sah er durch die Ereignisse des Ersten Weltkrieges diskreditiert. Der Fokus Keynesscher Kritik in den zwanziger Jahren war dabei, wie zu erwarten, die Finanzpolitik der britischen Regierung.

Durch die Empfehlungen des Cunliffe-Reports bestätigt und durch die heftige zyklische Aufwärtsbewegung der britischen Wirtschaft 1919 ermutigt, verfolgte das Schatz-

${ }^{118}$ KCKP, EC/2/4/27-30, Keynes an Davis, 18.4.1920; EC/2/4/69-72, Minute Keynes, 22.5.1919;

JMK II, S. 23-34.

119 KCKP, EC/2/1/12-15, Keynes an Chamberlain, 28.12.1919. 
amt, flankiert von einer konsequenten Deflationspolitik der Bank von England, nach Kriegsende kontinuierlich eine Politik mit dem Ziel der Wiederherstellung der Goldparität auf Vorkriegsniveau ${ }^{120}$. Es entsprach allgemeiner Überzeugung, dies werde die Liberalisierung des Handels fördern und die Beschäftigungsrate vor allem in Großbritanniens Exportindustrien anheben. Auch wenn es de facto kaum möglich war, die im Verlaufe des Ersten Weltkrieges in Gang gekommenen sozialen, wirtschaftlichen und administrativen Modernisierungstendenzen vollständig rückgängig zu machen ${ }^{121}$, war man bestrebt, Preisregulierungen, Rationierungen und andere Kontrollmaßnahmen, die der Krieg notwendig gemacht hatte, wieder abzubauen. Ausgeglichene Haushalte und die Verpflichtung der Regierung auf eine nichtexpansionistische Wirtschaftspolitik gewannen erneut den Wert unangefochtener Axiome in den Wirtschaftsabteilungen der Ministerien $^{122}$. Alle diese Schritte zielten zugleich aber auch auf die Erneuerung des Vertrauens in den Finanzplatz London. Insofern erschien es notwendig, das Pfund genau an den Vorkriegsgoldwert anzubinden, auch wenn dies den inzwischen eingetretenen Kursverschiebungen der Währungen nicht gerecht wurde. Angesichts der fortdauernden Weigerung Washingtons, den US-Dollar zur Leitwährung aufzubauen, war diese Maßnahme als eine Art letzter Rettungsversuch zunächst verständlich. Eine Abwertung von Sterling auf einen realistischen Stand hätte mit großer Wahrscheinlichkeit das Vertrauen der Investoren in die Themsestadt als den sicheren Platz für ihr Kapital erschüttert oder doch wenigstens den Wiederaufbau des Geldmarktes zur Schaffung dringend benötigter Kreditmöglichkeiten erheblich verzögert. Darüber hinaus wäre eine Rückkehr zu Gold auf der Grundlage einer reduzierten Parität einem massiven währungspolitischen Eingriff durch Regierungsstellen gleichgekommen, den die damalige wirtschaftspolitische Orthodoxie als Sakrileg verstanden hätte. Die Ankündigung des Schatzkanzlers Winston Churchill am 25. April 1925 über die Wiederherstellung der Vorkriegsparität des Pfunds gegenüber dem US-Dollar von \$ 4,86 entsprach daher der allgemeinen Erwartung. Churchill selbst meinte, diese Entscheidung "has always been as a matter of course“. Im Kontext seiner Haushaltsrede, in der er weitere Steuersenkungen versprach und die Einführung einer Rentenversicherung ankündigte, verstand Churchill diesen Schritt ausdrücklich als Kern einer Politik des „appeasement of class bitterness“123.

Noch 1916/1917 hatte Keynes selbst es trotz des Kursverfalls gegenüber dem Dollar abgelehnt, die Goldparität aufzugeben, und die Mehrheitsmeinung unterstützt, die vor allem den psychologischen Wert des Goldstandards hervorhob. Eine Aufkündigung würde sowohl von Deutschland als auch von den Verbündeten als Schwäche ausgelegt, brächte das Vertrauen in Großbritannien als kriegführender Nation in Gefahr und damit letztlich die Stellung Londons als Bankhaus der Welt. Allerdings hatte Keynes diese Empfehlung auf die Situation des Kriegsjahres 1917 bezogen, was eine spätere Modifizierung unter den Vorzeichen einer Friedenswirtschaft keineswegs ausschloß. Darüber

${ }^{120}$ Vgl. Gilbert, Churchill, Bd. V, S. 92.

121 Wendt, War Socialism, S. 140-142.

122 Vgl. ausführlich Tawney; Lloyd, S. 387-398; Wendt, War Socialism, S. 142-146. Vgl. auch die Darstellungen von Keynes' Mentor und Nachfolger Alfred Marshalls auf dem Lehrstuhl für politische Ökonomie in Cambridge, Pigou, Government Control, sowie ders., Aspects, S. 107144. Zur Hoffnung des Schatzamts, das Arbeitslosenproblem durch Ausbau der Exportindustrie zu lösen, vgl. Booth/Glynn, S. $624 \mathrm{f}$.

${ }^{123}$ Haushaltsrede Churchills, 28.4.1925, zitiert nach: Gilbert, Churchill, Bd. V, S. 113, 120. 
hinaus hatte er deutlich gemacht, daß zu diesem Zeitpunkt die Beibehaltung der Goldparität weniger eine freie Entscheidung der britischen Regierung als hinsichtlich ihrer psychologischen Wirkung eine finanzpolitische Notwendigkeit war, völlig unabhängig von der tatsächlichen Währungssituation. Aus diesem Grund hatte Keynes betont, daß dieser Schritt keinesfalls Ausdruck währungspolitischer Stärke war, sondern eine wichtige Maßnahme im Propagandakrieg gegen Deutschland. Die Abkehr von Gold „is not so much a possible policy for deliberate adoption, as the symptom, if it occurs, of a grave desease" 124 .

Tatsächlich hatte sich nach dem Krieg die Situation gewandelt. Jetzt hielten Kritiker wie Keynes und der ehemalige Schatzkanzler Reginald McKenna die Entscheidung zugunsten einer erneuten Goldanbindung entweder grundsätzlich für falsch oder zumindest die Höhe des Kurses für unvernünftig und nostalgischen Gefühlen entsprungen ${ }^{125}$. Keynes erkannte, daß die neuerliche Anbindung von Sterling an Gold nur Ausdruck der Illusion vergangener Finanzkraft war. Sie mußte im Kontext der ungeklärten Schuldenfrage und der Reparationslast, die beide den Kreditfluß aus den USA und damit deren Interesse an einem dauerhaften finanziellen Engagement in Europa etablierten, die Abhängigkeit von Washington verstärken ${ }^{126}$. Keynes gab zu bedenken, daß eine Anbindung an die amerikanische Wirtschaft über die Goldparität nicht der tatsächlichen wirtschaftlichen Schwäche Großbritanniens entspreche und zu wenig Spielraum für notwendige Korrekturen auf dem Arbeitsmarkt und in der Industrie lasse ${ }^{127}$. Auch wenn das Festhalten an der Idee stabiler Wechselkurse zur Ankurbelung von internationalem Handel und Investment für ein Land, das traditionell so stark von einem erfolgreichen Außenhandelssystem abhing wie Großbritannien, eine aus der Zeit heraus verständliche Entscheidung war ${ }^{128}$, so spiegelte sich darin doch das Bemühen, die neuen, innengeleiteten Probleme mit dem wirtschaftspolitischen Instrumentarium einer Zeit zu lösen, als die Zyklusbewegungen noch im wesentlichen außengesteuert waren. Nach Keynes wurde hier der verfehlte Versuch unternommen, eine im Grunde veraltete Ordnung zu retten und überdies alten Wein in alten Schläuchen zu verkaufen, d. h. eine den Bedingungen der Nachkriegsordnung nicht gerecht werdende Wirtschaftspolitik fortzuschreiben. An die Stelle notwendiger Reformmaßnahmen traten Bemühungen zur Restauration auf der Grundlage einer unrealistischen Überbewertung des Pfunds Sterling, sozusagen eines "monetären Potemkinschen Dorfes“. Hinter dessen Fassade würden durch die Auswirkungen einer rigorosen Deflationspolitik auf die Preis- und Nachfragestruktur über kurz oder lang die sozialen Folgen unvermeidlicher Arbeitslosigkeit sichtbar werden und nach ihrer Demaskierung eine Periode äußerer Krisen einleiten.

124 Public Record Office, Treasury Files (im folgenden T), 172/643, Memorandum Keynes, „Memorandum on the Probable Consequences of Abandoning the Gold Standard“, 17.1.1917. Vgl. Moggridge, Maynard Keynes, S. $250 \mathrm{f}$.

125 Moggridge, British Monetary Policy; Skidelsky, Retreat From Leadership, S. 170; Drummond, The Gold Standard, S. 33; Youngson, S. 139; Gilbert, Churchill, Bd. V, S. 92-100.

126 Vgl. Skidelsky, Keynes, Bd. II, S. XXVI, 20, der die anti-amerikanische Stoßrichtung dieser Haltung von Keynes betont.

${ }^{127}$ "The Return to Gold" [The Nation, 21.2.1925], in: JMK XXX; vgl. Gilbert, Churchill, Bd. V, S. $96 \mathrm{f}$.

128 So etwa die Verständnis aufbringende Wertung Youngsons, S. $138 \mathrm{f}$. 
Diese „monetäre Überdehnung“ unterzog Keynes einer ausführlichen Kritik, die er zunächst 1923 in seinem „Tract on Monetary Reform "129 entwickelte, ein Jahr später im Rahmen der Anhörung vor dem Chamberlain Committee, die der Entscheidung vorausging, präzisierte ${ }^{130}$ und nach der Verkündung durch den Schatzkanzler im April 1925 noch einmal in polemischer Form in „The Economic Consequences of Mr. Churchill" "131 zusammenfaßte. In diesen Schriften entwickelte er in deutlicher Abgrenzung zu den in der Nationalökonomie bislang dominierenden Krisenmodellen den Grundgedanken, $\mathrm{da} ß$ soziale Probleme, namentlich die Arbeitslosigkeit, in direktem Zusammenhang mit der Währung eines Landes standen und folglich mit geld- und kreditpolitischen Mitteln entschärft werden konnten ${ }^{132}$. Der Goldstandard nahm daher dem Staat ein wichtiges konjunkturpolitisches Instrumentarium. Keynes warnte darüber hinaus vor einer Überbewertung des Pfunds, die nicht der Position der britischen Industrie im internationalen Wettbewerb entspreche und folglich den Abwärtstrend der Exporte noch verstärken werde; der entstehende Druck zur Anhebung der Zinsen mit dem Ziel, London als Kapitalmarkt attraktiver zu machen und die Handelsverluste auszugleichen, werde die Kredite für die britische Industrie zu teuer machen und mit seinen deflationären Auswirkungen schließlich die Lohn-Preis-Struktur in einer Weise verändern, die, so prophezeite Keynes, in soziale Unruhen münden mußte. Zum ersten Mal erklärte er offen, daß er stabile Preise, Kredite und Beschäftigungsraten für wichtiger hielt als eine fixierte Währung mit der Folge permanenter Anpassungsprobleme des Lohn-Preis-Gefüges sowie des Arbeitsmarktes, deren Lösung dem längst nicht mehr funktionierenden „freien Markt" überlassen blieben. Er befürwortete eine aktivere Rolle des Staates und zeichnete als Alternative zu einem einheitlichen, hegemonial organisierten monetären System das Gespenst eines Doppelsystems mit dem britischen Empire und Kontinentaleuropa als Sterlingblock und Nord-sowie Südamerika als Dollarblock - eine Vorwegnahme der Entwicklung in den dreißiger Jahren ${ }^{133}$.

Doch Keynes' scharfsichtige Kritik traf nur eine Seite der Medaille. Mit der künstlichen Überbewertung des Pfunds ging in den zwanziger Jahren eine kontinuierliche Verschlechterung der britischen Außenhandelsposition einher, deren Ursachen als industrielles Spiegelbild der von Keynes herausgestellten finanzwirtschaftlichen Strukturdefizite angesehen werden können. Nach dem kurzen zyklischen Aufwärtstrend 1919 sank die britische Exportrate bis 1924 auf $80 \%$ des Vorkriegsvolumens, um nach einem langsamen Anstieg auf 86,6\% bis zum Jahr 1929 im Verlauf der Großen Depression auf 54,4\% (1932) abzufallen. Obwohl sich der Außenhandel in der Aufschwungphase der dreißiger Jahre erholen konnte, wurde der Vorkriegsstand erst wieder in den Jahren 1950/51 erreicht. Der britische Anteil am Welthandel sank von 13\% im Jahre 1913 auf durchschnittlich etwa $10 \%$ im Jahrzehnt vor Ausbruch des Zweiten Weltkrieges. Gleichzeitig stiegen die Importe in den Zwischenkriegsjahren um ein Drittel gegenüber

${ }^{129}$ JMK IV. Zum Hintergrund vgl. Harrod, Keynes, S. 339-345; Skidelsky, Keynes, Bd. II, S. 153164; Clarke, Keynesian Revolution, S. 22-24.

${ }^{130}$ Skidelsky, Keynes, Bd. II, S. 191-195; Moggridge, Maynard Keynes, S. 417-419.

${ }^{131}$ JMK IX, S. 207-230. Vgl. auch JMK XIX, S. 357-453; Skidelsky, Keynes, Bd. II, S. 200-206; Moggridge, Maynard Keynes, S. 431-433.

${ }^{132}$ Vgl. beispielhaft JMK IV, S. 1-36 (gekürzt als Social Consequences in the Value of Money, in: JMK IX, S. 59-75).

133 JMK IV, S. 116-140, 160; James, S. 312-328, besonders S. 317. 
dem Vorkriegsniveau und trugen so entscheidend zur Verschlechterung der Zahlungsbilanz bei ${ }^{134}$. Die Erwartung, die vorläufige Abwesenheit Deutschlands vom internationalen Markt käme der Erweiterung der britischen Exportindustrie zugute, erfüllte sich also nicht. Im Gegenteil, während die deutsche Wirtschaft in Kontinentaleuropa und Lateinamerika schneller als erwartet Fuß fassen konnte, erhöhte die aufstrebende japanische Konkurrenz im Fernen Osten den Wettbewerbsdruck; auch der nordamerikanische Markt erwies sich als kaum noch ausbaufähig für britische Waren ${ }^{135}$.

Dieser Marktverlust ist auf vier eng miteinander verzahnte Ursachen zurückzuführen. Erstens wurden Veränderungen in der internationalen Nachfragestruktur zugunsten der neuen Industrien in Großbritannien ignoriert bzw. unterschätzt. Obwohl die steigenden Importe selbst ein steter Beleg für das wachsende Bedürfnis nach Gütern der chemischen und elektrotechnischen Industrie waren und damit nur der Vorkriegstrend fortgesetzt wurde, erfolgten Investitionen weiterhin in den wenig zukunftsträchtigen Wirtschaftssektoren. Durch die Wachstumsraten in den alten Stapelindustrien während des kurzfristigen Nachkriegsbooms entstand zusätzlich die Illusion, auf eine industrielle Modernisierung verzichten zu können. Zweitens schuf die Beibehaltung des Schwerpunkts auf den „Paläoindustrien“136, die kaum noch Wachstumsraten erwarten ließen und deren Exportfähigkeit durch höher werdende Zollbarrieren in den Importländern weiter eingeschränkt wurde, rasch Überkapazitäten; dadurch wurde zusätzlich zu dem aus einem ungünstigen Verhältnis von alten und neuen Industrien resultierenden Strukturproblem die Wettbewerbsfähigkeit der britischen Wirtschaft reduziert. Auch der Abstand in der Innovationsfähigkeit mußte gegenüber den Marktkonkurrenten größer werden ${ }^{137}$. Drittens förderte die wachsende Bedeutung des binnenwirtschaftlichen Sektors nach dem Ersten Weltkrieg verstärkt Organisations- und Führungsmängel in der britischen Industrie zutage, so daß man nicht ohne Berechtigung von einer „industriellen Managementkrise" gesprochen hat ${ }^{138}$. Obwohl das Einkommen aus den unsichtbaren Exporten weiterhin beträchtlich blieb, konnte es schließlich viertens nicht mehr in gleichem Maße wie vor dem Krieg die langsameren Wachstumsraten der Exportindustrien kompensieren. Wie bereits festgestellt, engten z. B. die Kriegsschulden an die USA und der Druck auf das internationale Währungssystem durch die Schulden- und Reparationslasten die Fähigkeit der Londoner City zur Vergabe von umfangreichen Krediten empfindlich ein. Der Anteil der britischen Handelsflotte am gesamten Frachtaufkommen des Welthandels fiel von 44\% im Jahre 1915 auf $28 \%$ im Jahre 1935139.

Eine Steigerung der Beschäftigungsrate und der Ausbau der britischen Exportwirtschaft, die sich die Wirtschaftskreise inner- und außerhalb der Regierung durch die Reliberalisierung des Handels und die Restauration der Goldparität versprachen, konnte also aus einem doppelten Grund nicht eintreten: Zunächst erzielten die finanzpolitischen Maßnahmen das Gegenteil dessen, wozu sie ergriffen wurden, und übten so

${ }^{134}$ Kahn, Great Britain, S. 132 (Tab. 17 und 18); Ashworth, S. 342 f.; Feinstein, Statistical Tables, T 82 (Tab. 37).

${ }^{135}$ Drummond, Britain and the World Economy, S. 296; Skidelsky, Retreat From Leadership, S. 175.

${ }^{136}$ Kahn, Great Britain, S. 72.

${ }^{137}$ Vgl. auch den Überblick bei Pollard, S. 66-76; Ashworth, S. $309 \mathrm{ff}$.

${ }^{138}$ Meyers, Die vierte Teilstreitkraft, S. 200.

${ }^{139}$ Kahn, Great Britain, S. 137-144; Ashworth, S. 346. 
Druck auf die industrielle Wettbewerbsfähigkeit Großbritanniens aus; des weiteren verschlechterte sich die außenwirtschaftliche Stellung des Landes relativ zu seinen Marktkonkurrenten und untergrub ihrerseits die Fähigkeit Londons, Laissez-faire-Prinzipien und Goldstandard aufrechtzuerhalten und die internationale Währungsordnung vor dem Zerfall zu bewahren ${ }^{140}$. Der Zusammenbruch des internationalen Finanzssystems und die Wirtschaftskrise zwischen 1929 und 1932 markierten das endgültige Ende des Goldstandards; Großbritannien selbst kehrte nach 6 Jahren und 5 Monaten im September 1931 wieder zum flexiblen Wechselkurs des Pfunds zurück. Die Große Depression ließ die Strukturdefizite in Großbritanniens Wirtschaft nun vollends aufbrechen. Sie erweiterte die Krise des internationalen Systems nach Versailles zu einer politisch-ökonomischen Doppelkrise ${ }^{141}$ und verschärfte dadurch den machtpolitischen und ökonomischen Außendruck. Wie Keynes vorhergesehen hatte, entstand jetzt eine Reihe unabhängiger Währungsblöcke um Dollar, Pfund, Franc und Reichsmark, die allerdings nicht, wie Keynes vorgeschwebt haben mochte, durch die Schaffung einer Doppelleitwährung (Dollar und Pfund) die monetäre Ordnung wiederherstellten. Vielmehr verstärkten die Wirtschafts- und Finanzministerien im Einklang mit den Zentralbanken ihre Neigung, die Währungspolitik zur Verfolgung nationalistischer Ziele zu instrumentalisieren und durch restriktive Handels- und Währungskontrollen ihre Interessen zu schützen. Hatte London in den zwanziger Jahren die Erosion der Pax Britannica Oeconomica mit restaurativen Maßnahmen aufzuhalten versucht, so stellte sich nunmehr die Frage, durch welches Kriseninstrumentarium das entstehende wirtschaftspolitische Vakuum aufgefüllt werden konnte.

\section{Die Wirtschaftstbeorie von Keynes als Blaupause für die innere und äußere Krisenbewältigung?}

Keynes hatte inzwischen seine Thesen weiterentwickelt. In seiner 1930 vorgelegten Schrift „A Treatise on Money“, mit der „die eigentliche Revision der herkömmlichen nationalökonomischen Theorie erfolgt ${ }^{* 142}$ und die im Kontext der Weltwirtschaftskrise eine entscheidende geistesgeschichtliche Zäsur darstellt, griff er erneut die Themen seines "Tract on Monetary Reform“ auf und sezierte in großem Stil das monetäre Nachkriegssystem. Dabei führte er die Krise des Goldstandards auf die Verschärfung nationaler Zielsetzungen in der Wirtschafts- und insbesondere der Währungspolitik der beteiligten Staaten zurück, die den „Automatismus" des Systems als Illusion erwies. Dieses System ließ seinen Mitgliedern zu wenig Handlungsspielraum, individuelle Auswege aus der Konjunkturkrise zu finden. Die Wirtschafts- und Währungspolitik konnte so leicht zu einem Spielball des politischen Nationalismus werden ${ }^{143}$. Die theoretische Aussage der Arbeit attackierte aber gezielt den Grundgedanken des Sayschen Gesetzes. Keynes versuchte aufzuzeigen, daß entgegen der orthodoxen Auffassung die durch die

${ }^{140}$ Die Wechselbeziehung zwischen Finanzpolitik und wirtschaftsindustriellen Faktoren wird etwa auch daran deutlich, daß Keynes in den ${ }_{n}$ Economic Consequences of Mr. Churchill" die negativen Auswirkungen des Goldstandards am Beispiel eines „alten“ Industriezweigs - Kohle - erläuterte. Vgl. JMK IX, S. 220-224.

${ }^{141}$ Schmidt, Politisches System, S. 38.

142 So das Urteil Dietmar Petzinas in: Schäfer (Hrsg.), S. 138.

${ }^{143}$ Vgl. z. B. JMK VI, S. 272-274. 
Angebotsseite erwirtschafteten Gewinne nicht automatisch auch alle wieder in Form von Investitionskapital in den Wirtschaftskreislauf zurückflossen. Entgegen der Lehrmeinung der alten Textbücher überforderte das Arbeitslosenproblem aus diesem Grunde und unter den veränderten Bedingungen der Nachkriegszeit den freien Markt nicht nur; es mußte sich ohne Eingreifen staatlicher Stellen in einer Periode stagnierender Wirtschaftsaktivitäten sogar noch verschärfen. Solange allerdings Großbritannien an der Goldparität festhielt und die darin verborgene Überbewertung des Pfunds zudem die Wirtschaft erheblich belastete, bestand kaum eine Möglichkeit geldpolitischer Einflußnahme seitens des Schatzamtes. Als Lloyd George den Wahlkampf 1929 für die Liberalen mit einem Programm umfangreicher, anleihefinanzierter Staatsausgaben zur Schaffung zusätzlicher Arbeitsplätze führte, unterstützte ihn Keynes daher mit dem Argument, daß Staatsinvestitionen in gleichem Maße wie Privatinvestitionen den Arbeitsmarkt beleben könnten. Wenn Unternehmer in ihrer Investitionstätigkeit nachließen sei es aus Gründen unzureichender Gewinnaussichten, sei es wegen zu hoher Zinsen -, den zuständigen Regierungsstellen aber finanzpolitisch die Hände gebunden waren, so mußte der Staat eben vorübergehend die Rolle eines Investors übernehmen und eine antizyklische Beschäftigungspolitik einleiten ${ }^{144}$.

Einen gewissen Erfolg konnte Keynes zunächst als Gutachter des Macmillan-Komitees und als Mitglied des Economic Advisory Council erzielen. Obwohl er keinesfalls mit ausgereiften Lösungsvorschlägen zur Überwindung der Krise aufwartete, ließ er das Komitee unter Vorsitz Lord Macmillans doch in keinem Zweifel über seine Kritik an der Finanzpolitik des Landes seit Kriegsende und bekräftigte seine Forderung nach staatlicher Konjunkturpolitik. Tatsächlich hob das Komitee in seinem Abschlußbericht, den es drei Monate vor Aufhebung der Goldparität im Juni 1931 vorlegte, die Diskrepanz zwischen Großbritanniens industriellen Strukturproblemen und der bislang von Regierungsseite vertretenen konservativen Finanzpolitik hervor. Es unterstrich die Priorität von industrieller Produktion und Vollbeschäftigung als Hauptziele der britischen Wirtschaftspolitik. Dazu wurde die Übernahme des Prinzips der Währungslenkung empfohlen. Einige Mitglieder, darunter der Generalsekretär der Transportarbeitergewerkschaft und spätere Vorsitzende des Trades Union Congress, Ernest Bevin, traten für eine sofortige Abkehr vom Goldstandard und ein staatliches Beschäftigungsprogramm entlang der von Keynes gezeichneten Linien ein ${ }^{145}$. Der im Januar 1930 ins Leben gerufene Econo-

144 Vgl. die zusammen mit dem Ökonomen Hubert Henderson verfaßte Schrift "Can Lloyd George Do It ${ }^{c}$, in: JMK IX, S. 86-125; vgl. auch JMK XIX, S. 761-838. Zum Hintergrund vgl. Harrod, Keynes, S. 371-431, besonders S. 392-396; sowie Clarke, Keynesian Revolution, S. 9197; aus der Sicht eines Beteiligten Kahn, The Making of Keynes' General Theory, S. 77-90. Den Kern von Keynes' Überlegungen findet man bloßgelegt in einem Brief an den Gouverneur der Bank von England, Montagu Norman, in: JMK XX, S. 350-356.

${ }^{145}$ Report of the Committee on Finance and Industry, S. 108-132, 190-210. Keynes' Aussagen als Gutachter in: JMK XX, S. 38-311. Vgl. insgesamt Clarke, Keynesian Revolution, S. 103-225, besonders S. 120-124; Peden, Keynes, the Treasury and British Economic Policy, S. 34-37; Kahn, The Making of Keynes' General Theory, S. 82-88; Taylor, S. 360-362. Zu Bevin vgl. Bullock, Bevin, Bd. II, S. 418, 425-434; sowie Durbin, S. 64, 77-79. 
mic Advisory Council146 schien ebenfalls eine Konsequenz des Drucks nach stärkerer staatlicher Wirtschaftslenkung zu sein und damit in Keynes' Richtung zu arbeiten. Er wurde bewußt als wirtschaftspolitisches Pendant zum Committee of Imperial Defence geschaffen, und die Mitgliedschaft von Premierminister, Schatzkanzler und anderen wichtigen Ministerien sowie Fachberatern wie Keynes signalisierte auch nach außen seinen hohen Stellenwert. Zum ersten Mal wurde hier der Versuch unternommen, dem unzureichenden Stand der ökonomischen Voraussagemöglichkeiten abzuhelfen und dem wirtschaftspolitischen Entscheidungsprozeß analytische und prognostische Hilfestellung zu leisten ${ }^{147}$.

Auch wenn mit den Empfehlungen des Macmillan-Komitees und der Einsetzung eines wirtschaftspolitischen Beraterkreises bereits wesentliche Vorentscheidungen zur Durchsetzung der Keynesschen Theorien auf der politisch-administrativen Ebene gefallen waren, so blieb in den dreißiger Jahren doch der orthodoxe "Treasury View" vorherrschend ${ }^{148}$. Dies zeigte sich besonders deutlich, als die neue "nationale“ Regierung unter Ramsay MacDonald im Laufe des Jahres 1931 die sorgfältigen Analysen des Komitees in den Wind schrieb und statt dessen den Schlußfolgerungen des „May Reports" 149 folgte, der vor umfangreichen Staatsausgaben warnte und erneut die Doktrin des ausgeglichenen Haushalts propagierte. Kürzungen, nicht Anleihen hieß die Devise, und der Report traf damit exakt die Stimmung in der Beamtenschaft, die vor einer Staatsverschuldung zurückschreckte. Auch die Arbeit des Economic Advisory Council stieß rasch an ihre Grenzen, als das Kabinett im November 1930 einen Keynes' Handschrift tragenden Bericht des Committee of Economists über Ursachen und Abhilfemaßnahmen der Wirtschaftskrise zurückgab ${ }^{150}$. Obwohl nach Aufhebung des Goldstandards die britischen Regierungen in der Folgezeit teilweise ihre Politik der Nichteinmischung in den Wirtschaftsprozeß aufgaben und auf eine Politik des Teilprotektionismus einschwenkten ${ }^{151}$, blieben die Beamten des Schatzamts doch dem Grundsatz der Risikovermeidung bei der Formulierung ihrer Finanzpolitik treu und lehnten eine Politik des „deficit spending“ als konjunkturpolitische Stabilisierungsmaßnahme unter Hinweis auf den grundsätzlich unproduktiven Charakter von Staatsausgaben weiterhin ab ${ }^{152}$.

Ungeachtet der Widerstände in der Beamtenschaft war aber deutlich geworden, daß die Erosion der traditionellen Wirtschaftsordnung unaufhaltsam fortschritt. Der er-

146 Vgl. Copy of Treasury Minute, dated 27th January, 1930, Appointing an Economic Advisory Council. Dem EAC gehörten auch Ernest Bevin und in seiner Eigenschaft als Chancellor of the Duchy of Lancaster der spätere Premierminister Clement Attlee an. Vgl, Bullock, Bevin, Bd. II, S. 436-439; Harris, Attlee, S. 87.

${ }^{147}$ Vgl. Bridges, S. 14; Howson/Winch, S. 17-29.

148 Middleton, passim.

$149 \mathrm{Vgl}$. Report of the Committee on National Expenditure.

${ }^{150}$ Howson/Winch, S. 73-81. Der "The Causes of the Present Depression“ betitelte umfangreiche Bericht - eine herausragende zeitgenössische Analyse der Weltwirtschaftskrise und ihrer Implikationen für die britische Wirtschaft - ist abgedruckt in: ebenda, S. 180-243. Der EAC wurde im folgenden Jahr denn auch in seiner bestehenden Form aufgelöst und in das „Committee on Economic Information" umgewandelt. Vgl. Moggridge, Maynard Keynes, S. 536.

151 Der "Import Duties Act“" vom Februar 1932 belegte Waren außerhalb des Empire mit Zöllen zwischen 10\% und 33\% ihres Wertes und markierte den Beginn des Aufbaus eines imperialen Handelsblocks. Vgl. den Überblick bei Pollard, S. 119-125.

152 Vgl. insgesamt Peden, Keynes, the Treasury and British Economic Policy, S. 27-39; Middleton, S. 48, 50f., 62-65; Skidelsky, Reception, S. 98 ff. 
zwungene Abschied von der Goldparität verlagerte nolens volens den Schwerpunkt des wirtschaftspolitischen Entscheidungsprozesses in einem Maße auf das Schatzamt, daß eine vollständige Rückkehr zur Orthodoxie nicht nur unmöglich wurde, sondern zugleich ökonomische Aspekte bei der Formulierung der Innen- wie Außenpolitik einen zentralen Stellenwert gewannen. Machte die Depression der Jahre 1929-1931 eine Überprüfung der Wirtschaftspolitik vor allem mit dem Ziel der Krisenbewältigung im Inneren notwendig, so sah sich London im Laufe der dreißiger Jahre aufgrund einer massiven wirtschafts- und rüstungspolitischen Herausforderung durch das nationalsozialistische Deutschland zu einer weiteren Überprüfung des traditionellen Instrumentariums mit Blick auf die Vermeidung einer Krise im Äußeren veranlaßst. Wie sollte unter Beibehaltung des für die innere soziale Sicherheit unumgänglichen außenpolitischen Primärziels der Friedenswahrung auf die faschistische Bedrohung reagiert werden?

Unter dem Eindruck der nationalsozialistischen Versuche nach der Machtergreifung, die Krise sowohl wirtschaftlich als auch ordnungspolitisch zu überwinden, und der parallel dazu in den USA eingeleiteten „New Deal“-Maßnahmen sahen sich die Briten mit einer doppelten Herausforderung konfrontiert. Erstens verdiente auf dem europäischen Kontinent die nationalsozialistische Wirtschaftspolitik als ein möglicher Ausweg aus der Doppelkrise von Versailles und Großer Depression besondere Aufmerksamkeit. Insbesondere Hjalmar Schachts Politik der Bilateralisierung des deutschen Außenhandels, dem Kern seines „Neuen Plans“, aber auch die öffentliche Ausgabenpolitik im Inneren erschienen als eine Antwort auf die Krise des Laissez-faire und deutsches Gegenstück zu Keynes' Bemühungen um eine Reformierung des wirtschaftspolitischen Kriseninstrumentariums in Whitehall. Auf der anderen Seite des Atlantiks war es Roosevelt mit seinem „New Deal“ gelungen, das Land vor einen programmatischen Neuanfang zu stellen. Angesichts dieser ideologischen Zangensituation sahen sich die Entscheidungsträger Londons in ihrer Suche nach Lösungen für die Bewältigung der sozio-ökonomischen Probleme des Landes auch einem konzeptionellen Druck ausgesetzt. Gerade die Parallelität der Entwicklungen in den USA und Deutschland führte ihnen zunehmend das Dilemma einer liberalen Demokratie vor Augen, die auf eine konzeptionelle Defizitsituation kaum vorbereitet war ${ }^{153}$.

Diese Problematik läßt sich zweitens besonders am Beispiel der Rüstungsfrage veranschaulichen. Ab Mitte der dreißiger Jahre zeichnete es sich immer deutlicher ab, daß die Herausforderung, die von der Aufrüstung des Dritten Reiches ausging, die Pax Britannica Oeconomica weiter aushöhlte und die Bedingungen, unter denen britische Regierungsstellen glaubten, die innere Stabilisierung im Aufwind der konjunkturellen Aufschwungphase 1932-1937 sicherstellen zu können, veränderte: Würde man dem Druck zur Aufrüstung nachgeben, so war dies nur auf Kosten der dringend erforderlichen Modernisierung der Wirtschaft möglich. Darüber hinaus konnte auch die eng mit der deut-

${ }^{153}$ Insofern muß man den bisher in der Forschung hervorgehobenen deutsch-amerikanischen Gegensatz im Ringen um eine neue Wirtschaftsordnung zum Dreieck USA ( ${ }^{N} N e w$ Deal ${ }^{*}$ ) Deutschland ("Neuer Plan") - Großbritannien (Keynesianismus) erweitern, auch wenn letzterer keine vergleichbare Basis in Regierungskreisen und schon gar nicht den messianischen Charakter des "Neuen Plans“ oder auch nur des „New Deal" aufweisen konnte. Zum „Neuen Plan“ im Kontext des deutsch-amerikanischen Antagonismus vgl. Schröder, Deutschland und die Vereinigten Staaten, besonders S. 127-135; vgl. auch Berghahn, Deutschland, sowie ders., Unternehmer und Politik, S. 20-39. 
schen Aufrüstung verflochtene handelspolitische Penetration des kontinentaleuropäischen, namentlich südosteuropäischen Binnenmarktes und dessen Umwandlung in einen autarken Großwirtschaftsraum nicht ohne Auswirkungen für die britische Exportwirtschaft bleiben, von denen in letzter Konsequenz auch der Empire-Block nicht verschont bleiben würde. Schließlich war die Tatsache, daß Schacht als Vertreter des Nationalsozialismus galt, auch unter ideologischen Prämissen ein Beleg für die Diskreditierung jedes interventionistischen Ansatzes in der Wirtschaftspolitik.

Zwar legte die Regierung MacDonald auf der Konferenz von Ottawa im Sommer 1932 den Grundstein für die währungs- und handelspolitische Einheit des EmpireBlocks; eine aktive Ausgabenpolitik wurde in der Beamtenschaft jedoch überwiegend abgelehnt. Diese wirtschaftspolitische "Zwischenposition", die ihrerseits die bestehende Spannung zwischen Tradition und Neubeginn widerspiegelte, mußte von der Aufrüstungsdebatte ab 1935 genauso in Frage gestellt werden wie die Grundlagen des bisherigen Krisenmanagements in London insgesamt. Das Doppelproblem, dem sich London in der Auseinandersetzung mit dem Nationalsozialismus mithin ausgesetzt sah, bestand in der Frage, ob die britische Wirtschaft auf die Erfordernisse umfangreicher Aufrüstungsprogramme neu ausgerichtet werden sollte, mit anderen Worten: ob der Prozeß des wirtschaftlichen Wiederaufbaus durch umfangreiche Aufrüstungslasten in Gefahr gebracht werden durfte. Zugleich mußte sich zeigen, ob diese Form öffentlicher Ausgabenpolitik im Verbund mit notwendigen sozialpolitischen Maßnahmen die Bereitschaft innerhalb der Regierung zur Wirtschaftslenkung förderte.

Bereits die ersten Erörterungen dieser Themen auf Kabinettsebene und in den verschiedenen Unterabteilungen des Committee of Imperial Defence Ende 1935 unterstrichen die Auffassung der meisten Minister, daß eine adäquate Aufrüstung die zumindest partielle Umstellung weiter Teile der Industrie auf die Erfordernisse einer Kriegswirtschaft erforderte. Die mit solchen "semi-war conditions“ verbundenen Konsequenzen für die britische Industrie und den labilen sozialen Konsens in Großbritannien wollte man allerdings nicht ziehen, so daß das Kabinett im Februar 1936 beschloß, den Aufrüstungsbedarf der Streitkräfte auf der Basis einer Prioritätenliste zu decken; die Rüstungsproduktion sollte dabei jedoch keinesfalls zu Lasten der zivilen Produktion gehen ${ }^{154}$. Wie der Industrielle Lord Weir, der als Berater des Defence Requirements SubCommittee wesentlich am Zustandekommen des Kabinettsbeschlusses beteiligt war, hierzu mitteilte, erfordere das Aufrüstungsprogramm vor allem die Freistellung von Facharbeitern. Angesichts des Mangels an gelernten Arbeitskräften könne das aber nur auf Kosten der facharbeiterintensiven neuen Zweige wie der technischen Industrie gehen. Diese das „Dilution“-Problem des Ersten Weltkrieges noch verschärfende Entwicklung mußte seiner Meinung nach angesichts der anhaltend hohen regionalen und strukturellen Arbeitslosigkeit zu einer gravierenden Verzerrung des Arbeitsmarktes führen und zwangsläufig die Wettbewerbsfähigkeit der britischen Industrie beeinträchtigen. Der Prozeß ihrer Restrukturierung würde in gefährlicher Weise verlangsamt ${ }^{155}$. Verschiebungen auf dem Arbeitsmarkt zugunsten der Rüstungsindustrie erschienen der Regierung zudem angesichts des relativen Rückgangs der britischen Exportindustrie ge-

$154 \mathrm{Vgl}$. Parker, Chamberlain, S. $273 \mathrm{f}$.

155 Parker, British Rearmament, S. 307, 318-343; Peden, Keynes, the Treasury and Unemployment, S. 14-16; ders., British Rearmament, S. 82. 
fährlich ${ }^{156}$. Das Aufrüstungsprogramm, so wurde weiter eingewandt, führe zu einem Rückgang der zivilen Produktion und damit entweder zu einer Verringerung des Lebensstandards oder aber, sollte der Verlust durch die vermehrte Einfuhr von Lebensmitteln und Industriegütern kompensiert werden, zu einer gefährlichen Belastung der Zahlungsbilanz. Damit nicht genug, werde die Verringerung der Exportproduktion die Außenhandelsposition Großbritanniens verschlechtern. Sowohl das Handelsministerium als auch das Schatzamt befürchteten den Verlust von Exportmärkten. In den Augen eines Beamten bedeutete Aufrüstung, „to lose a large part of our world market not merely temporarily but probably forever" 157 . Wie Ralph Hawtrey, der Leiter der Financial Enquiries Branch des Schatzamts und Gegner von Keynes ${ }^{158}$, zusammenfassend kommentierte: "The diversion of productive power from foreign trade products involves an increase in imports and a fall in exports, and the continued suspension of external investment, along with some realization of our existing foreign investment, would have to be relied on to fill the gap. Heavy taxation would help to keep down the adverse balance by diminishing consumption generally and incidentally consumption of imported goods." 159 Steuererhöhungen zur Finanzierung des Programms und zur Senkung der Kaufkraft kamen zwar als flankierende Maßnahmen in Betracht, trafen allerdings den empfindlichen Nerv des sozialen Konsenses in Großbritannien. Die Regierung fürchtete neben Verzerrungen im industriellen und finanzpolitischen Sektor aber vor allem, daß Unternehmer wie Arbeiter gleichermaßen in Friedenszeiten zu materiellen Opfern nicht bereit sein würden. Diese Einschätzung war um so begründeter, als sich der bereits im Macmillan-Report postulierte Primat der sozialen Sicherheit als Ziel britischer Wirtschaftspolitik immer stärker durchsetzen konnte. Gewerkschaftler wie Bevin erklärten ihr Unverständnis über das Versagen der Regierung, Abhilfemaßnahmen für das weiterhin drängende Arbeitslosenproblem und für die weitgehend regionalisierte industrielle Strukturkrise zu schaffen, während gleichzeitig ein Aufrüstungsprogramm in Höhe von $£ 10$ Milliarden verabschiedet werde. Die Labour Party, in die langsam Keynessches Gedankengut einzusickern begann ${ }^{160}$, warf ihrerseits der Regierung Untätigkeit angesichts der drängenden sozialen Probleme vor und kritisierte das Klassenverhalten auf den Fluren Whitehalls, das weder eine koordinierte und konsequente Politik zur Beseitigung sozialer Härten im Inneren noch energische Maßnahmen gegenüber dem deutschen $\mathrm{Fa}$ -

156 Vgl. Parker, Chamberlain, S. $274 \mathrm{f}$.

157 Zitiert nach: Parker, British Rearmament, S. 310; vgl. auch Peden, Keynes, the Treasury and Unemployment, S. 16.

${ }^{158}$ Vgl. Hawtrey, Public Expenditure; Howson, Tabled Paper (mit weiterführender Literatur); Clarke, Keynesian Revolution, S. 146-148, 236-244; Peden, British Rearmament, S. 22 f.; ders., Keynes, the Treasury and British Economic Policy, S. 13; sowie ders., Keynes, the Treasury and Unemployment, S. 4-9.

159 Memorandum Hawtrey, 23.10.1936, zitiert nach: Parker, British Rearmament, S. 309.

${ }^{160} \mathrm{Vgl}$. dazu beispielhaft die für das New Fabian Research Bureau verfaßte Schrift des Ökonomen und späteren Leiters der Economic Section of the Cabinet Secretariat, James Meade, Public Works and their International Aspect [1933], in: Howson (Hrsg.), Collected Papers, Bd. I, S. 6-25. Vgl. auch British Library of Political and Economic Science (im folgenden BLPES), Meade Papers 2/7, „The Exchange Policy of a Socialist Government", Juni 1934; das Referat ist auch abgedruckt in: Howson (Hrsg.), Collected Papers, Bd. III, S. 11-26. Vgl. auch BLPES, Dalton Papers II, 2/1, Labour Party Finance and Trade Committee Papers 1932/33, und II, 2/3, Labour Party Finance Policy Papers 1938. Vgl. insgesamt den Überblick bei Brooke, zu den dreißiger Jahren besonders S. 159-161; sowie Durbin, Part II, passim. 
schismus zulasse ${ }^{161}$. Gegen eine massive Aufrüstung wurde ferner geltend gemacht, daß eine gezielte Konfrontationspolitik gegenüber Berlin das deutsch-britische Handelsverhältnis empfindlich stören würde. Sowohl Stanley Baldwin, Premierminister der Jahre 1935 bis 1937, als auch der Gouverneur der Bank von England, Sir Montagu Norman, der bereits in den zwanziger Jahren für eine gemäßigte Haltung gegenüber Deutschland in der Reparationsfrage eingetreten war ${ }^{162}$, glaubten, daß ein wirtschaftlich wiederaufgebautes Deutschland als Handelspartner für die britische Wirtschaft vorteilhaft sei. Sie griffen dabei Gedanken auf, die Keynes bereits in den „Economic Consequences“ zu einem Hauptargument gegen die Versailler Friedensordnung gemacht hatte und die in der Öffentlichkeit weit verbreitet waren: So hatte die Londoner "Times“ bereits 1922 kommentiert, der wirtschaftliche Wiederaufbau Deutschlands sei gleichbedeutend mit der Wiederherstellung des britischen Handels, der Beseitigung der Arbeitslosigkeit und der Schaffung von Einnahmequellen zur Begleichung der britischen Schuldenlast gegenüber den USA ${ }^{163}$. Schließlich erwies sich nicht zuletzt die eigene wirtschaftspolitische Tradition als unüberwindliches Hindernis für eine adäquate Aufrüstung. Wie ein Spitzenbeamter bemerkte, war auch in der zweiten Hälfte der dreißiger Jahre eine antizyklische staatliche Ausgabenpolitik „still heresy in Whitehall“, und Chamberlain wies als Schatzkanzler noch Mitte 1936 darauf hin, daß ein umfangreiches Rüstungsprogramm eine Kontrolle der Industrie und des Arbeitsmarktes impliziere, für deren Rechtfertigung der Zeitpunkt noch nicht gekommen sei164.

Alle diese Argumente der Jahre 1935-1938 reflektieren die in Regierungskreisen dominierende Überzeugung, daß, wenn auch nicht die völlige Wiederherstellung der Pax Britannica Oeconomica, so doch wenigstens die Sicherung der Stellung Großbritanniens als Weltmacht von der Beibehaltung wirtschaftlicher Prosperität, d. h. genauer: von einem stabilen Wirtschaftswachstum, sowie von der Vermeidung industrieller und fiskalischer Verzerrungen abhing. Dieses Ziel konnte freilich eher durch eine Politik der Abrüstung, der Kriegs- und Konfliktvermeidung, denn durch ein Wettrüsten mit dem nationalsozialistischen Deutschland erreicht werden. Eine Politik des wirtschafts-, rüstungsund machtpolitischen Appeasement gegenüber dem faschistischen Deutschland war die Klammer, die die Kluft zwischen den außen- und sicherheitspolitischen Verpflichtungen des Landes als Mutterland des Empire und den hierzu notwendigen Ressourcen schmälern und den Übergang der Krise der Pax Britannica in einen weltweiten militärischen Konflikt verhindern sollte. Ein Weltkrieg mußte eine an den Bedürfnissen der Bevölkerung orientierte Modernisierung erneut auf unabsehbare Zeit unterbrechen und den sozio-ökonomischen Konsens im Inneren sowie den weiteren Weg zu allgemeiner Prosperität, auf die allein Großbritannien seiner Tradition entsprechend seine machtpolitische Stellung zu gründen glaubte, in Gefahr bringen. Diese nur im Zusammenhang mit der historischen Entwicklung des Inselreichs zu verstehende Auffassung wurde namentlich von Thomas Inskip, dem Minister für Verteidigungskoordination zwischen März 1936 und Januar 1939, prägnant auf den Begriff gebracht, der die ökonomische Stabilität des

161 Vgl. Coghlan, S. 208 f.; Wendt, Demokratie, S. $13 \mathrm{f}$.

162 Jones, Bd. I, S. 240 (8.6.1923).

163 Coghlan, S. 208; Wendt, „Economic Appeasement", S. 160.

${ }^{164}$ Sir Arthur Salter, Memoirs of a Public Servant, London 1961, S. 253, zitiert nach: Howson/ Winch, S. 145. Chamberlain in: Parliamentary Debates, Official Report, House of Commons. Fifth Series (im folgenden H.C. Deb. 5s), Bd. 311, Sp. 434 f. (23.4.1936). 
Landes unter sicherheitspolitischen Gesichtspunkten als zentrales Element der britischen Verteidigungsfähigkeit bezeichnete, als neben den drei Teilstreitkräften gleichberechtigter "fourth arm in defence ${ }^{\text {" } 165}$.

Der von Inskip so eindringlich umrissene Kern der britischen Appeasementpolitik beinhaltete mit seinem impliziten Primat der Innenpolitik, der Beseitigung von Arbeitslosigkeit und industrieller Strukturkrise unmißverständlich Keynessche Ideen. Die traditionell internationalistische Ausrichtung des Schatzamtes, die eine minimalistische Wirtschaftspolitik nach innen bedingte, ging in den dreißiger Jahren langsam dazu über, ein Mitspracherecht und damit aktivere Eingriffsmöglichkeiten gegenüber den mit der Außen- und Verteidigungspolitik betrauten Ministerien mit dem Ziel durchzusetzen, eine angemessene Ziel-Mittel-Relation gerade für Maßnahmen gegenüber dem Nationalsozialismus zu gewährleisten, die die innere Stabilisierung nicht gefährdete. Der Vorwurf, das Schatzamt habe eine rechtzeitig eingeleitete Aufrüstung behindert, trifft daher nicht zu. Vielmehr versuchte es, die in sich zerstrittenen und ihrerseits veraltetem Strategiedenken anhängenden Teilstreitkräfte zu effizienteren Vorschlägen anzuleiten und eine koordinierte Aufrüstung voranzutreiben ${ }^{166}$. Lautete das Rezept in den zwanziger Jahren noch Rekonstruktion durch Restauration, so verlangte die Entwicklung in den Dreißigern eine allgemeine Neuorientierung. Es wird aber auch deutlich, daß es der Regierung nicht gelang, in diesem Jahrzehnt eine Wirtschaftskonzeption zu entwickeln, die als Antwort auf die Herausforderung durch das nationalsozialistische Autarkie- und Blockdenken hätte betrachtet werden können, zugleich jedoch in Relation zum amerikanischen „New Deal“ der immer größeren Bedeutung der USA als Machtfaktor in der Weltwirtschaft Rechnung getragen hätte ${ }^{167}$. Appeasement war daher nicht nur das Resultat wirtschaftlicher Strukturdefizite und militärischer Fehlentwicklungen; es spiegelt darüber hinaus den Verlust der wirtschaftspolitischen Initiative im Transformationsprozeß der Pax Britannica Oeconomica seit dem Ende des Ersten Weltkrieges wider.

\section{Keynes' "General Theory“ und das Problem der militärischen Aufrüstung}

Auch Keynes selbst blieb in diesem Zwiespalt zunächst gefangen. Zwar hatte er 1936 mit der Publikation seiner "General Theory“ seinen Lehren einen autoritativen Abschluß verliehen; gerade die Aufrüstungsdiskussionen sollten jedoch zeigen, daß sein Theorie-

165 Meyers, Die vierte Teilstreitkraft, S. 191; Peden, A Matter of Timing, S. 16. Vgl. ausführlicher Meyers, Britische Sicherheitspolitik, S. 398-424.

166 Vgl. Meyers, Britische Sicherheitspolitik; ders., Die vierte Teilstreitkraft; Peden, British Rearmament; ders., Keynes, the Economics of Rearmament and Appeasement.

${ }^{167}$ Eine zumindest währungspolitisch wirksame Teilanerkennung dieses Entwicklungsprozesses stellte jedoch das trilaterale Finanzabkommen zwischen Großbritannien, Frankreich und den USA vom September 1936 dar. Der ihm zugrundeliegende britisch-amerikanisch-französische monetäre Konsens wurde in Berlin tatsächlich als bedrohliches Zusammenrücken der „Goldblockländer" empfunden. Freilich wurde der Effekt des Abkommens durch die konjunkturelle Lage der Weltwirtschaft konterkariert: Hitler antwortete auf die Verschlechterung des Außenhandels und die kritische Devisenlage Deutschlands im Krisenjahr 1936 im gleichen Monat auf dem Nürnberger Parteitag mit der Verkündung des Vierjahresplans. Doch unabhängig von ihrer unmittelbaren Wirkung signalisierten die untereinander flexiblen Währungskurse von Pfund, Dollar und Franc, auf denen das Abkommen beruhte, doch den Beginn einer Entwicklung, die schließlich in der Entstehung eines "Dollar-Standards" nach dem Zweiten Weltkrieg gipfeln sollte. Vgl. dazu Cleveland, S. 6 f.; sowie aus französischer Sicht Girault. 
gebäude weitere Denkanstrengungen erforderte und auch der Durchsetzungsprozeß in Whitehall noch keinesfalls ein ihn befriedigendes Stadium erreicht hatte. Die nur vordergründige Stabilisierungsphase der mittleren dreißiger Jahre sowie die ungebremste Aufrüstung in Deutschland stellten den Anspruch keynesianischer Wirtschaftspolitik erneut vor eine Bewährungsprobe und verstärkten den Druck, sie angesichts der Ausgabenpolitik der Reichsregierung und namentlich des Vierjahresplans von 1936 zu legitimieren. Die Perspektive eines heraufziehenden Krieges bestimmte deshalb ungeachtet ihres theoretischen Kerns auch seine „Allgemeine Theorie der Beschäftigung, des Zinses und des Geldes“. Daß es Keynes letztendlich um die Durchsetzung des Primats der binnenwirtschaftlichen Konsolidierung ging, daran ließ er auch in seiner Hauptschrift keinen Zweifel. Seine Kritik am System der internationalen Wirtschaftsbeziehungen vor dem Ersten Weltkrieg und dessen Laissez-faire-Prinzipien erneut aufgreifend, bemerkte er, daß Vollbeschäftigung und allgemeine Wohlfahrt in einer Zeit, die durch den Aufstieg von Nationalwirtschaften gekennzeichnet sei, nicht mehr durch ein Festhalten an einer internationalistischen, eine minimalistische Rolle der öffentlichen Hand verlangenden Wirtschaftspolitik garantiert werden könnten, sondern gezielte Eingriffe des Staates erforderten. Dies dürfe jedoch - und hier setzte seine Kritik an den totalitären Staaten ein nicht zur Verfolgung nationalegoistischer und das Gleichgewicht destabilisierender Ziele geschehen, sondern diene vielmehr der Schaffung einer neuen Friedensgrundlage. Keynes hoffte, "that the new system might be more favourable to peace than the old has been" 168 .

Damit unterstrich Keynes erneut sein Anliegen, das traditionelle Ziel der Friedenswahrung in der britischen Außenpolitik aus dem zusammenstürzenden Gebäude der Pax Britannica Oeconomica durch eine Transformation der wirtschaftspolitischen Grundsätze seiner Zeit und eine Reorganisation des Weltwirtschaftssystems zu retten. Krieg, so bemerkte er in seiner „General Theory“, habe mehrere Ursachen. Neben der allgemeinen Kriegsbereitschaft von Diktatoren diagnostizierte der Nationalökonom vor allem die bereits verschiedentlich von ihm als treibende Kräfte des Wirtschaftslebens identifizierten Faktoren des Bevölkerungswachstums und des Ringens um Märkte, die seiner Meinung nach die Neigung, Krisensituationen durch Mittel der Aggression zu lösen, förderten. Diese Verzahnung von Ökonomie und Außenpolitik habe vermutlich im 19. Jahrhundert gerade deshalb eine wichtige Rolle gespielt, weil Laissez-faire und Goldstandard einer Regierung zur Lösung wirtschaftlicher Krisen im Inneren keine andere Möglichkeit ließen als die Verbesserung der Handelsbilanz durch die Eroberung neuer Absatzmärkte ${ }^{169}$. „Thus,“ so bemerkte Keynes, „whilst economists were accustomed to applaud the prevailing international system as furnishing the fruits of the international division of labour and harmonising at the same time the interests of different nations, there lay concealed a less benign influence; and those statesmen were moved by common sense and a correct apprehension of the true course of events, who believed that if a rich, old country were to neglect the struggle for markets its prosperity would droop and fail." Demgegenüber entzog für Keynes der Zustand der Vollbeschäftigung als Ergebnis gezielter staatlicher Wirtschaftspolitik dem aggressiven und potentiell friedensbedrohenden Konfliktverhalten von Staaten den Boden: „There would still be room for

${ }^{168}$ JMK VII, S. 381.

${ }^{169}$ Dieser Gedanke ist ausführlich erläutert in: ebenda, S. 333-371. 
the international division of labour and for international lending in appropriate conditions. But there would no longer be a pressing motive why one country need force its wares on another or repulse the offerings of its neighbour, not because this was necessary to enable it to pay for what it wished to purchase, but with the express object of upsetting the equilibrium of payments so as to develop a balance of trade in its own favour. International trade would cease to be what it is, namely, a desperate expedient to maintain employment at home by forcing sales on foreign markets and restricting purchases, which, if successful, will merely shift the problem of unemployment to the neighbour which is worsted in the struggle, but a willing and unimpeded exchange of goods and services in conditions of mutual advantage." 170

Der in der "General Theory“ deutlich erkennbare Schwerpunkt, den die Wirtschaftspolitik im Inneren einnahm, vernachlässigte jedoch die gerade durch die skizzierte Rüstungsdebatte aufgeworfene Frage nach der internationalen Dimension jeder Stabilisierungspolitik. Dabei hielt Keynes an seiner Forderung nach Schaffung wirtschaftspolitischer Planungsinstanzen fest. In einem Interview im Januar 1939 betonte Keynes, daß gerade in der Auseinandersetzung mit Diktatoren zentrale Planungsstellen mehr denn je ein Gebot der Zeit seien. „In contemporary conditions“, so bemerkte er, „we need, if we are to enjoy prosperity and profits, so much more central planning than we have at present that the reform of the economic system needs as much urgent attention if we have war as if we avoid it. The intensification of the trade cycle and the increasingly chronic character of unemployment have shown that private capitalism was already in its decline as a means of solving the economic problem. But the breakdown of international good faith and the constant threat to peace are making it still more obvious that, quite apart from war, we have to move a long distance along that very road which actual war would make it imperative for us to take. "171 $\mathrm{Da}$ eine staatliche Konjunkturpolitik und begrenzte Lenkungsmaßnahmen in dem von Keynes beschriebenen Rahmen eine wichtige Funktion in der Auseinandersetzung mit den Diktatoren ausübten, erklärte er im März 1938 auch dem amerikanischen Präsidenten: „The tragedy is that the right-minded show no inclination of supporting one another. You will be reluctant to support us; we are reluctant to support France, France is reluctant to support Spain. At long last we shall get together. But how much harm will have been done by then?" Vor diesem Hintergrund erschien ihm Roosevelts wirtschaftspolitischer Kurs keineswegs ausreichend, um den innenpolitischen Reformkurs angesichts der außenpolitischen Bedrohung zu sichern. Keynes ließ den US-Präsidenten wissen, „that you are treading a very dangerous middle path. You must either give more encouragement to business or take over more of their functions yourself. If public opinion is not ready for the latter, then it is necessary to wait until public opinion is educated. Your present policies seem to presume that you possess more power than you actually have." 172

Keynes sah, daß sich seine Theorien zwar im Laufe der dreißiger Jahre auf der administrativen Ebene durchzusetzen begonnen hatten; die wirtschaftspolitische Konversion der Beamten war jedoch keinesfalls soweit fortgeschritten, daß sie eine geschlossene und kohärente Antwort auf das Ausgreifen des Faschismus ermöglicht hätte. Der National-

\footnotetext{
170 Ebenda, S. $382 \mathrm{f}$.

171 "Democracy and Efficiency" (New Statesman, 28.1.1939), in: JMK XXI, S. 491-500, hier S. 492.

172 KCKP, L/38/11-12, Keynes an Roosevelt, 25.3.1938.
} 
ökonom betrachtete daher die bürokratische Struktur als retardierendes Moment bei dem Versuch der Krisenbewältigung. Der "Civil Service“, so bemerkte er bissig, werde von der Schule des Schatzamts beherrscht - „trained by tradition and experience and native skill to every form of intelligent obstruction". Er sei voller Bewunderung für die Leistung der Beamtenschaft, aber "I am afraid that they are becoming a heavy handicap in our struggle with the totalitarian states and in making ourselves safe from them. They cramp our energy, and spoil or discard our ideas. " ${ }^{173}$ Das Argument, man könne der Herausforderung eines Staates mit einer totalitären Wirtschaftsverfassung nicht dadurch begegnen, daß man dessen illiberale Politik adoptiere, ging deshalb nach Keynes' Auffassung am eigentlichen Problem vorbei. Vielmehr war die Frage zu lösen, wie das außenpolitische Primärziel der Friedenssicherung unter veränderten außenwirtschaftlichen Bedingungen so beibehalten werden konnte, daß weder die eigenen Wiederaufbaubemühungen gestört bzw. „verzerrt“ wurden, noch das Festhalten am inadäquaten traditionellen Kriseninstrumentarium in eine Appeasementpolitik mündete, an deren Ende die völlige Zerstörung liberaler Ideen stand. Denn "the obstacle lies not here, but in our rulers - first of all in the personnel of the Cabinet, and secondly in the personnel of the heads of the Civil Service. [...] The totalitarian states have shown us clearly enough that the central mobilisation of resources and the regimentation of the individual can be carried to a point which threatens the elements of personal liberty. I do not deny that. I say that we are so far from such a situation that the risk does not now exist. Nor is the real controversy about this. The question is whether we are prepared to move out of the nineteenth century laissez-faire state into an era of liberal socialism, by which I mean a system where we can act as an organised community for common purposes and to promote social and economic justice, whilst respecting and protecting the individual - his freedom of choice, his faith, his mind and his expression, his enterprise and his property. " 174

Trotz aller Kritik an den Beamten verband ihn doch bei der Beurteilung des Rüstungsprogramms eine Grundauffassung mit dem Schatzamt: Der Umfang des Verteidigungshaushalts mußte sich innerhalb der wirtschaftlichen Leistungsgrenzen des Landes bewegen. Neben einer umfangreichen Staatsanleihe empfahl Keynes zu seiner Finanzierung Steuererhöhungen, ergänzt um Kürzungen bei den Sozialausgaben; zusätzlich warnte er vor der Einführung von Marktkontrollen zur Sicherstellung der für die Aufrüstung benötigten Rohstoffe ${ }^{175}$. Auch wenn auf den ersten Blick eine gezielte Aufrüstungspolitik als ein Äquivalent zu dem von ihm und Lloyd George Ende der zwanziger Jahre geforderten staatlichen Investitionsprogramm erscheinen mochte ${ }^{176}$, so zeigte sich nun, daß die damit verbundenen Probleme vielfältiger und komplexer als bisher angenommen waren. Keynes hoffte tatsächlich, die Aufrüstung werde zur Entspannung des Arbeitsmarktes beitragen und seinen Theorien zum endgültigen Durchbruch verhelfen. In einem Beitrag für die BBC zwei Monate vor Kriegsausbruch erklärte er, „if expenditure on armaments really does cure unemployment, I predict that we shall never go back all the way to the old state of affairs. If we can cure unemployment for the wasted purposes

${ }_{173}$ „Democracy and Efficiency“ (New Statesman, 28.1.1939), in: JMK XXI, S. 497.

174 Ebenda, S. 497, 500.

175 Peden, Keynes, the Economics of Rearmament and Appeasement, S. 143-145, 150.

176 Zum Einfluß des Aufrüstungsprogramms auf den Arbeitsmarkt vgl. Thomas. 
of armaments, we can cure it for the productive purposes of peace. Good may come out of evil. We may learn a trick or two which will come in useful when the day of peace comes, as in the fullness of time it must. "177 Dennoch teilte er die Besorgnis in Finanzkreisen, die Aufrüstung könne sich zu einem nur schwer kontrollierbaren, in seiner Tendenz inflationären Boom entwickeln. Der Rückgang der Arbeitslosigkeit und ein rüstungswirtschaftlich bedingter Konjunkturaufschwung konnten dazu führen, daß vor allem die Nachfrage nach Importen stieg und bei der ungelösten Exportkrise des Landes Druck auf die Zahlungsbilanz ausübte. Wie er in einer Artikelserie für die "Times“ im Januar 1937 eingestand, liege überdies das Stabilisierungsproblem einer Wirtschaft im fortgeschrittenen Stadium des Wiederaufbauprozesses im Unterschied zum Frühstadium, in dem eine Ankurbelung der generellen Investitionstätigkeit der Industrie ausschlaggebend sei, vor allem in der richtigen strukturellen Verteilung von Investitionskapital - eine Schwierigkeit, deren Behebung, so hob er hervor, auch durch Wirtschaftsplanung nicht garantiert werden könne ${ }^{178}$.

Es ist unübersehbar, daß diese Ratschläge in einem scheinbaren Widerspruch zu seinen bislang entwickelten Überlegungen standen. An diesem Punkt gelangte Keynes zu der Erkenntnis, daß die ökonomische Stabilisierung Großbritanniens stärker von außenwirtschaftlichen Faktoren abhing; dieser Befund ging über den enger gesteckten Rahmen seiner „General Theory“ hinaus. Würden in einer zyklischen Aufwärtsbewegung eingesetzte Staatsinvestitionen und die sich zwangsläufig ergebende Nachfragesteigerung nicht drastische Exporterhöhungen oder damit korrespondierende Einschränkungen der Importe notwendig machen, um einer Verschlechterung der Außenhandelsbilanz und einem möglichen Abzug ausländischen Kapitals vorzubeugen? Würden staatliche Eingriffe in den Verteilungsprozeß der Ressourcen zugunsten der rüstungsintensiven Industrien den Exportsektor und damit Großbritanniens Wettbewerbsstellung auf den internationalen Märkten nicht noch weiter schwächen? Konnte unter solchen Bedingungen sichergestellt werden, daß ausreichendes Investitionskapital in jene Industriezweige floß, die den Stabilisierungsprozeß in Friedenszeiten trugen? Und barg etwa auch eine antizyklische Investitionspolitik der öffentlichen Hand die Gefahr, daß eine bereits rezessiv bedingte negative Zahlungsbilanz durch Verzerrungen im Verhältnis von Im- und Exporten weiter in die roten Zahlen gedrückt würde? Auf solche Fragen ging die "General Theory“ nur am Rande ein.

Es kann daher nicht verwundern, daß Keynes im Frühjahr 1937 das Zahlungsbilanzproblem als Angelpunkt der Aufrüstungsbemühungen Großbritanniens, ja letztlich des gesamten Wiederaufbau- und industriellen Anpassungsprozesses herauszustellen begann. Dabei sprach er sich zur Inflationsprophylaxe gegen Importkürzungen aus, wies dagegen darauf hin, daß es mehr denn je darauf ankomme, die Exportindustrie, vor allem in den Regionen, in denen die strukturelle Arbeitslosigkeit trotz der Boomjahre besonders gravierend war, zu unterstützen und die Produktion auszuweiten. Dies werde inflationären Tendenzen entgegenwirken und den unvermeidlichen Zustrom der Importe ausgleichen ${ }^{179}$. Auch die allgemeine Rezession von 1938, die jede Furcht vor einer Infla-

\footnotetext{
177 "Will Rearmament Cure Unemployment?", in: JMK XXI, S. 528-532, hier S. 532.

178 "How to Avoid a Slump", in: JMK XXI, S. 384-395.

${ }^{179}$ Ebenda; „Borrowing for Defence: Is It Inflation? A Plea for Organised Policy“, in: ebenda, S. 404-409; sowie „Crisis Finance: An Outline of Policy“, in: ebenda, S. 509-518, hier S. 512.
} 
tion als unbegründet erwies, konnte nicht von der besonderen Gefahr ablenken, die von den sich gegenseitig beeinflussenden Kraftfeldern von Aufrüstung und Handelsbilanz ausging. In einem Memorandum, das im Dezember 1938 dem Kabinett vorlag, warnten Keynes und seine Kollegen vom Committee on Economic Information vor einem Kapitalabzug aus Großbritannien als Folge einer sich verschlechternden Zahlungsbilanz. Die Situation sei nicht weniger kritisch als 1931, als das Land zur Aufgabe des Goldstandards gezwungen worden sei. Das Komitee riet, zur Stabilisierung der zwischen Rüstungsproduktion und Außenhandelsentwicklung eingeklemmten britischen Wirtschaft rüstungswirtschaftlich wichtige Waren einzuführen, etwa Werkzeugmaschinen und Stahl, um industrielle Engpässe zu überwinden ${ }^{180}$.

Damit schließt sich der Kreis mit den zuvor angestellten Überlegungen zu Keynes' Kritik der Versailler Friedensordnung. Die mangelnde Rückbindung seiner Theorien an die internationale Dimension der wirtschaftspolitischen Praxis, auf die ihn die Finanzierungsfrage der Rüstungsprogramme aufmerksam gemacht hatte, deutete bereits in die Richtung seiner Beratertätigkeit während des Zweiten Weltkrieges; dabei sollte das Deutschlandproblem erneut in den Mittelpunkt rücken.

\section{Kontinuitätsaspekte der Appeasementpolitik Londons}

Im Hinblick auf die im folgenden zu analysierenden Kriegszielplanungen und die britische Deutschlandpolitik der unmittelbaren Nachkriegszeit sollte der Rekurs auf die Zwischenkriegszeit und die thematische Anbindung an die Zeit vor 1914 auf wichtige Kontinuitätsmomente der britischen Außenpolitik aufmerksam machen; zugleich wurde auf die damit eng verflochtene Appeasementproblematik der dreißiger Jahre hingewiesen, in der sich diese Entwicklungslinien zu einer außenpolitischen Krise verdichteten. Es sollte ebenfalls deutlich werden, wie Keynes in seiner Kritik an der wirtschaftspolitischen Tradition des Landes zu Einsichten gelangte, die das außenpolitische Primärziel der Friedenssicherung als notwendige Voraussetzung für die sozio-ökonomische Stabilität im Inneren nicht durch ein Festhalten an einem inadäquaten wirtschaftspolitischen Instrumentarium und einer volkswirtschaftlichen Orthodoxie zu retten versuchte, sondern durch deren Überwindung. In dieser progressiven Diagnose griff er weit über die zeitgenössischen Ansichten der jeweiligen Regierungen hinaus. Seine Überlegungen waren zugleich der Versuch, eine Antwort auf die wirtschaftskonzeptionelle wie machtpolitische Herausforderung durch den friedensbedrohenden Nationalsozialismus zu finden. Aus der Perspektive der Zeit nach dem Zweiten Weltkrieg kommt daher dem „Keynesianismus“ eine Brückenfunktion zu, die den Schlüssel zur Kontinuitätsfrage in der britischen Außenpolitik darstellt.

Die Appeasementpolitik und die Erosion der Pax Britannica Oeconomica gingen Hand in Hand. Eine Politik der Konfliktvermeidung gegenüber seinen außenpolitischen Herausforderern gewann für Großbritannien in dem Maße an Gewicht, wie seine Stellung als wirtschaftliche Führungsmacht schwand. Zwar trifft Sir Eyre Crowes Feststel-

180 Public Record Office, Cabinet Office Papers (im folgenden CAB) 24/281, C.P. 296 (38), Memorandum by the Committee on Economic Information, „Problems of Rearmament". Vgl. das Material in T 175/104. Das Memorandum wurde vom Kabinett jedoch nicht erörtert; vgl. zum Hintergrund Howson/Winch, S. 148 f.; Peden, Keynes, the Economics of Rearmament and Appeasement, S. 147. 
lung zu, daß Friedenswahrung durch die Aufrechterhaltung bzw. Wiederherstellung des Mächtegleichgewichts das Grundanliegen der britischen Außenpolitik darstellen mußte, wollte das Land seine Vormachtstellung - im Interesse aller Beteiligten - wie auch seinen Besitzstand wahren ${ }^{181}$; eine Politik des Ausgleichs und der Konfliktvermeidung war daher ein traditionelles Anliegen Londons. Zu Appeasement konnte sie allerdings erst dann werden, als eine Kluft entstand zwischen der wirtschaftlichen Stellung des Landes in Relation zu den aufstrebenden Mächten USA, Deutsches Reich und Japan einerseits und dem Besitzstand bzw. den außenpolitischen Verpflichtungen andererseits. Das Festhalten an einem Vormachtkonzept in der Außenpolitik mußte schließlich zwangsläufig dazu führen, daß bei einer relativen Schmälerung der Ressourcenbasis die Schere zwischen behauptetem Führungsanspruch und real vorhandenem Handlungsspielraum immer weiter auseinanderging.

Dabei muß betont werden, daß der relative wirtschaftliche Machtverlust ein wesentlicher Grund für jenes Maß an territorialer Expansion war, das schließlich in eine „Überdehnung" mündete. Mithin begründete nicht allein ein bloßes Auseinanderklaffen zwischen Ressourcen und geographischer Ausdehnung, sondern die Erschütterung der Pax Britannica Oeconomica als Ursache zusätzlicher kolonialer Expansion den außenpolitischen Wechsel von einer „splendid isolation“ zu Appeasement. Hier knüpft die Forschung an einen in der „General Theory“ ausgeführten Keynesschen Grundgedanken an, der die Expansionsbewegung als wirtschaftspolitische Notlösung einer Nation begriff, deren Regierung in einer Periode sozio-ökonomischer Spannungen im Inneren keine Möglichkeiten zu aktiverem Handeln zur Verfügung standen, da sie zu keinem Konsens hinsichtlich einer aktiveren Wirtschaftspolitik fand ${ }^{182}$. Vollends bloßgelegt wurde dieser Entwicklungsprozeß schließlich, als sich nach dem Ersten Weltkrieg auch der institutionelle weltwirtschaftliche Rahmen und insbesondere Londons Rolle als Clearing-Stelle des internationalen Zahlungsverkehrs aufzulösen begann - ein Umstand, der die Formation einzelner Wirtschaftsblöcke als einzig sinnvollen Ausweg aus den Krisen erscheinen ließ und den machtpolitischen und militärischen Aufstieg des Dritten Reichs und letztlich die Intensivierung britischer Appeasementpolitik entscheidend förderte.

Keynes hatte diese Entwicklung antizipiert und nach Lösungsmöglichkeiten gesucht, vor dem Hintergrund wachsender sozialer Unruhen und drohender kommunistischer Infiltration den wirtschaftlichen Kollaps zu vermeiden und die liberalen Prinzipien des 19. Jahrhunderts zu bewahren. Seine Hinweise auf die Wirtschaftskraft der USA lassen vermuten, daß er hoffte, Washington werde das Vakuum nach und nach füllen, das der Machtverlust Londons hinterlassen würde. Gleichzeitig mußte es gelingen, in einem

${ }^{181}$ Vgl. sein "Memorandum on the Present State of British Relations With France and Germany“, 1.1.1907: Die Entstehung einer den Status Großbritanniens bedrohenden Mächtekonstellation könne nur dadurch verhindert werden, "that the national policy of the insular and naval State is so directed as to harmonize with the general desires and ideals common to all mankind, and more particularly that it is closely identified with the primary and vital interests of a majority, or as many as possible, of the other nations“. Für Crowe blieb das Prinzip des Freihandels eine unverzichtbare Voraussetzung für die Wahrung nationaler Grundinteressen, und das Einstehen Großbritanniens für dieses Prinzip ließ seiner Meinung nach die britische Vorherrschaft den beteiligten Staaten eher akzeptabel erscheinen als die Aussicht auf die Hegemonie einer protektionistischen Macht. British Documents on the Origins of the War, Bd. III, S. 397-420, hier S. $402 \mathrm{f}$.

$182 \mathrm{Vgl}$, oben Anm. 169. 
pluralistischen internationalen Wirtschaftssystem den Aufstieg Deutschlands zur wirtschaftlich dominierenden kontinentaleuropäischen Macht zum Vorteil für alle zu kanalisieren. Dieses Integrationsproblem mußte freilich in dem Moment zu einem nur schwer lösbaren Problem werden, in dem das Wirtschaftssystem keine „imperiale“ Führungsmacht hatte, die mit der Rolle Großbritanniens als Gleichgewichtshalter vor 1914 vergleichbar gewesen wäre. Es stand also zu vermuten, daß sich erst mit der Herausbildung einer neuen hegemonialen Wirtschaftsstruktur - und dies konnte nur bedeuten: unter Führung der USA - neue Lösungswege ergeben würden. Für Großbritannien selbst hieß dies, angesichts der Doppelherausforderung von amerikanischem Führungsanspruch und nationalsozialistischer Bedrohung, hinter der letztlich zwei sich gegenseitig ausschließende Wirtschaftskonzepte standen, die alten Anpassungs- und Modernisierungsprobleme zu lösen und die Rolle des Landes innerhalb eines neuen, hegemonial orientierten Weltwirtschafts- und Mächtesystems neu zu definieren. Gleichzeitig war eine Neubewertung des Faktors Deutschland vorzunehmen und dessen Gefahrenpotential für die internationalen Beziehungen vor allem durch wirtschaftspolitische Maßnahmen zu entschärfen, ein Befund, dessen Tragweite sich mit dem Verlauf der alliierten Besatzungspolitik, insbesondere der Reparationspolitik, vor allem aber in den das integrative Element betonenden Maßnahmen im Rahmen von Marshallplan und Schumanplan bis hin zur Debatte um einen deutschen Verteidigungsbeitrag nach 1945 in vollem Umfang zeigen sollte. Dieser letzte Aspekt, den Keynes in den „Economic Consequences" in seiner Bedeutung zu Recht herausgestellt hatte, der aber zunächst noch recht blaß geblieben war, sollte während des Zweiten Weltkrieges neben der Suche nach einer neuen monetären Ordnung auf der Basis einer anglo-amerikanischen Partnerschaft zum zweiten wichtigen Schwerpunkt seiner Überlegungen werden. 